DOE/AL/ $58181--T 1$

DE92 018563

\title{
ASSESSMENT OF RESEARCH NEEDS FOR WIND TURBINE ROTOR MATERIALS TECHNOLOGY
}

\author{
DISCLAIMER
}

\begin{abstract}
This report was prepared as an account of work sponsored by an agency of the United States Government. Neither the United States Government nor any agency thereof, nor any of their employees, makes any warranty, express or implied, or assumes any legal liability or responsibility for the accuracy, completeness, or usefulness of any information, apparatus, product, or process disclosed, or represents that its use would not infringe privately owned rights. Reference herein to any specific commercial product, process, or service by trade name, trademark, manufacturer, or otherwise does not necessarily constitute or imply its endorsement, recommendation, or favoring by the United States Government or any agency thereof. The views and opinions of authors expressed herein do not necessarily state or reflect those of the United States Government or any agency thereof.
\end{abstract}

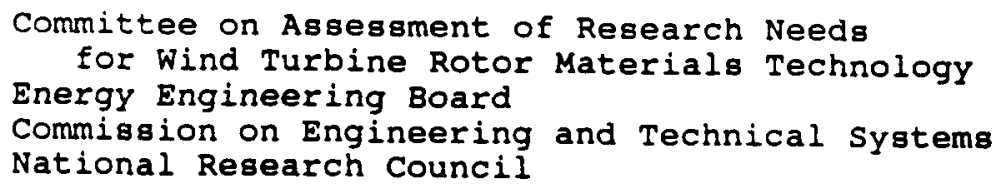

NATIONAL ACADEMY PRESS

Washington, D.C. 1991 


\section{DISCLAIMER}

This report was prepared as an account of work sponsored by an agency of the United States Government. Neither the United States Government nor any agency Thereof, nor any of their employees, makes any warranty, express or implied, or assumes any legal liability or responsibility for the accuracy, completeness, or usefulness of any information, apparatus, product, or process disclosed, or represents that its use would not infringe privately owned rights. Reference herein to any specific commercial product, process, or service by trade name, trademark, manufacturer, or otherwise does not necessarily constitute or imply its endorsement, recommendation, or favoring by the United States Government or any agency thereof. The views and opinions of authors expressed herein do not necessarily state or reflect those of the United States Government or any agency thereof. 


\section{DISCLAIMER}

Portions of this document may be illegible in electronic image products. Images are produced from the best available original document. 
NOTICE: The project that is the subject of this report was approved by the Governing Board of the National Research Council, whose members are drawn from the councils of the National Academy of Sciences, the National Academy of Engineering, and the Institute of Medicine. The members of the committee responsible for the report were chosen for their epecial competences and with regard for appropriate balance.

This report has been reviewed by a group other than the authors according to procedures approved by a Report Review Committee consisting of members of the National Academy of Sciences, the National Azademy of Engineering, and the Institute of Medicine.

The National Academy of Sciences iz a private, nonprofit, self-perpetuating society of distinguished scholars engager in jcientific and engineering research, dedicated to the furtherance of science and technology and to their use for the general welfare. Upon the authority of the charter granted to it by the Congress in 1863, the Academy has a mandate that requires it to advise the federal government on scientific and technical matters. Dr. Frank Press is president of the National Academy of sciencer.

The National Academy of Engineering was established in 1964, under the charter of the National Academy of Sciences, as a parallel organization of outstanding engineers. It is autonomous in its administration and in the selection of its members, sharing with the National Academy of Sciences the responsibility for advising the federal government. The National Academy of Engineering also sponsors engineering programs aimed at meeting national needs, encourages education and research, and recognizes the superior achievements of engineers. Dr. Robert $M$. White is president of the National Academy of

Engineering.

The Institute of Medicine was established in 1970 by the National Academy of sciences to secure the services of eminent members of appropriate professions in the examination of policy matters pertaining co the health of the public. The

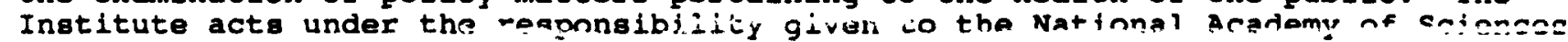
by Its congressional charter to be an udviser to the federal government and, upon its own initiative, to identify issues of medical care, research, and education. Dr. Samuel 0 . Thier is the president of the Institute of Medicine.

The National Research Council was organized by the National Academy of Sciences in 1916 to associate the broad community of science and technology with the Academy's purposes of furthering knowledge and advising the federal government. Functioning in accordance with general policies determined by the Academy, the council has become the principal operating agency of both the National Academy of Sciences and the National Academy of Engineering in providing services to the government, the public, and the scientific and engineering communities. The council is administered jointly by both Academies and the Institute of Medicine. Dr. Frank Press and Dr. Robert $M$. White are chairman and vice chairman, respectively, of the National Research Council.

This one study on which it is based were supported by contract No. Academy of Sciences-National Research Council.

Library of Congress Catalog Card No. 91-60990

International Standard Book Number 0-309-04479-0

NAT $s-324$

Additional Copies of this report are available from:

National Academy Press

2101 Constitution Avenue, N.W.

Washington, D.C. 20418

Printed in the United States of America 
COMITIEE ON ASSESSMENT OF RESEARCE NEEDS

FOR WIXD TURBINE ROTOR MATERIALS TECEMOLOGY

GEORGE E. DIETER (Chaiman), Dean, College of Engineering, Unireidity of Maryland, College Park, Maryland

JAMIE CHAPMAN, Power Systems Consultant, Boston, Massachusetta

H. THOMAS HAHN, Department of Engineering Science and Mechanics, Fenn State

University, University Park, Pennsylvania

DEWEY H. HODGES, School of Aerospace Engineering, Georgia Institute of Technology, Atlanta, Georgia

CHARLES $w$. ROGERS, Bell Helicopter Textron, Inc., Fort Worth, Texas

LENA VALAVANI, Department of Aeronautics and Astronautics, Massachusetts Institute of Technology, Cambridge, Massachusetts

MICHAEL D. zUTECK, Consultant, Kemah, Texas

\section{National Research Council Staff}

KAMAL J. ARAJ, Study Director, Energy Engineering Board THERESA A. FISHER, Study Assistant (to April 1990)

JAN C. KRONENBURG, study Assistant (to February 1991)

\section{ENERGY ENGINEERINO BOARD}

JOHN A. TILLINGHAST (Chaiman), Tiltec, Portsmouth, New Hampshire

DONALD B. ANTHONY, Bechtel Corporation, Houston, Texas

RICHARD E. BALZHISER, Electric Power Research Institute, Palo Alto, California

BARBARA R. BARKOVICH, Barkovich and Yap, Consultants, san Rafael, California JOHN A. CASAZzA, CSA Energy Consultants, Arlington, Virginia

RALPH C. CAVANAGH, Natural Resources Defense Council, San Francisco, California

DAVID E. COLE, University of Michigan, Ann Arbor, Michigan

H. M. (HUB) HUBBARD, Midwest Research Institute (retired), Golden, Colorado

ARTHUR E. HUMPHREY, Lehigh University, Bethlehem, Pennsylvania (to February 1991)

CHARLES IMBRECHT, California Energy Commission, Sacramento, California

CHARLES D. KOLSTAD, University of Illinois, Urbana, Illinois

HENRY R. LINDEN, Gas Research Institute, Chicago, Illinois

JAMES J. MARKOWSKY, American Electric Power Service corporation, columbus, ohio

(to February 1991)

SEYMOUR L. MEISEL, MObile R\&D Corporation (retired), Princeton, New Jersey

DAVID L. MORRISON, The MITRE Corporation, McLean, Virginia

MARC H. ROSS, University of Michigan, Ann Arbor, Michigan

MAXINE L. SAVITZ, Garrett Ceramic Component Division, Torrance, California

HAROLD H. SCHOBERT, The Pennsylvania State University, University Park,

Pennsylvania

GLENN A. SCHURMAN, Chevron Corporation, San Francisco, California

JON M. VEIGEL, Oak Ridge Associated Universities, Oak Ridge, Tennessee

BERTRAM WOLFE, GE Nuclear Energy, San Jose, California 
ARCHIE L. WOOD, Executive Director, Commission on Engineering and Technical Systems, and Director, Energy Engineering Board (to January 1991) MAHADEVAN (DEV) MANI, Director, Energy Engineering Board

KAMAL J. ARAJ, Senior Program officer

ROBERT COHEN, Senior Program officer (retired)

GEORGE LALOS, Senior Program officer

JAMES J. 2UCCHETTO, Senior Program officer

JUDITH A. AMRI, Administrative/Financial Assistant

THERESA M. FISHER, Administrative Secretary

JAN C. KRONENBURG, Administrative Secretary

PHILOMINA MAMMEN, Administrat 1ve Secretary

NANCY WHITNEY, Administrative Secretary 


\section{PREFACE}

Wind-driven power gygtems res=esent a renewable energy technology that is still in the early stages $=r$ development. These wind power plants installed in the early 1980 s suffered atructural failures chiefly because of incomplete understanding of the wind forces (especially the turbulence component) acting on these large structures and in some cases because of poor quality in manufacture. Failure of the rotor blades was one of the principal and most serious structural failures. Failures from these causes are now somewhat better understood. Another limitation to economical achievement of the potential of wind energy is uncertainty about the long-term response of wind turbine rotor materials to the turbulent stochastic loadings to which they are subjected. These structures can be subjected to as many as a billion stress cycles.

In accordance with its assessment of its long-term research responsibilities, the Department of Energy requested the National Research Council to assess the research needs for wind turbine rotor technology. Such a study would assist in organizing the information about the current status of wind turbine rotor materials, their manufacture into blades, and their operation and life performance in service. Of special importance was an assessment of current materiala tonhnology and design methodologies to provide perspective ror iuture investigations.

The Committee on Assessment of Research Needs for Wind Turbine Rotor Materials Technology was formed by the Energy Engineering Board to specifically evaluate the following issues (see Appendix A for statement of Taвk): failure:

- the adequacy of existirig models to predict dynamic stress patterns;

- the properties of wind turbine materials in dynamic and fatigue

- understanding of the performance of joints, fastenerg, and critical sections in relation to failure modes and fracture;

- the tools needed to study these phenomena, such as computer design tools, and materials databases;

- the need for special laboratory facilities, models, and prototypes to

improve the design and operation of wind energy systems;

- the opportunities for new materials to improve wind turbine life;

- the potential for improved design methods, advanced control

techniques, and better manufacturing processes and advanced materials for better performance and longevity.

In addition, the committee took as its responsibility the development, in broad outline, of a research and development program that would place U.S. wind power technology in a preeminent world position.

In carrying out its assignment the committee examined an extensive literature on wind machines and wind turbine rotor materials. The emphasis of the study was on wind machines suitable for utility applications. Many U.S. experts on these subjects briefed the Committee in two meetings of two-day duration (see Aopendix B). The committee wishes to acknowledge with gratituro the assistance of the following individuals for th:ir tint and knowledge: 
Holt Ashley, Standford University; Charles Carleon and Marilyn W. Wardle, E.I. Dupont de Nemours \& Co.; John C. Doyle, California Institute of Technology; Brant Goldsworthy, ALCOA/Goldsworthy Engineering; Richard H. Hilt, Gas Research Institute; William Holley, U.S. Windpower; Donald Hunston, National Institute for standards and Technology; Edwin T.C. Ing; John Mandell, Montana State University; Robert C. Monroe, Hudson Products; Robert H. Monroe, Gougeon Brothers; Peter Ogle, Dow United Technologies Composite Products; Donald Pederson and Fred J. Policelli, Hercules, Inc.; Lawrence Rehfield, University of California-Davis; Forrest S. Stoddard, Alternative Energy Institute; Robin Whitehead, Northrop; Daniel F. Ancona, III, Leonard J. Rogers, and Jeffrey H. R'-mbaugh, U.S. Department of Energy; James Tangler and Robert Thresher. Solar Energy Research Institute; and Herbert Sutherland, Sandia Nationa) Labr ratories.

George E. Dieter, Chairman

Committee on Assessment of Research Needs for Wind Turbine Rotor Materials Technology 


\section{CONTENTS}

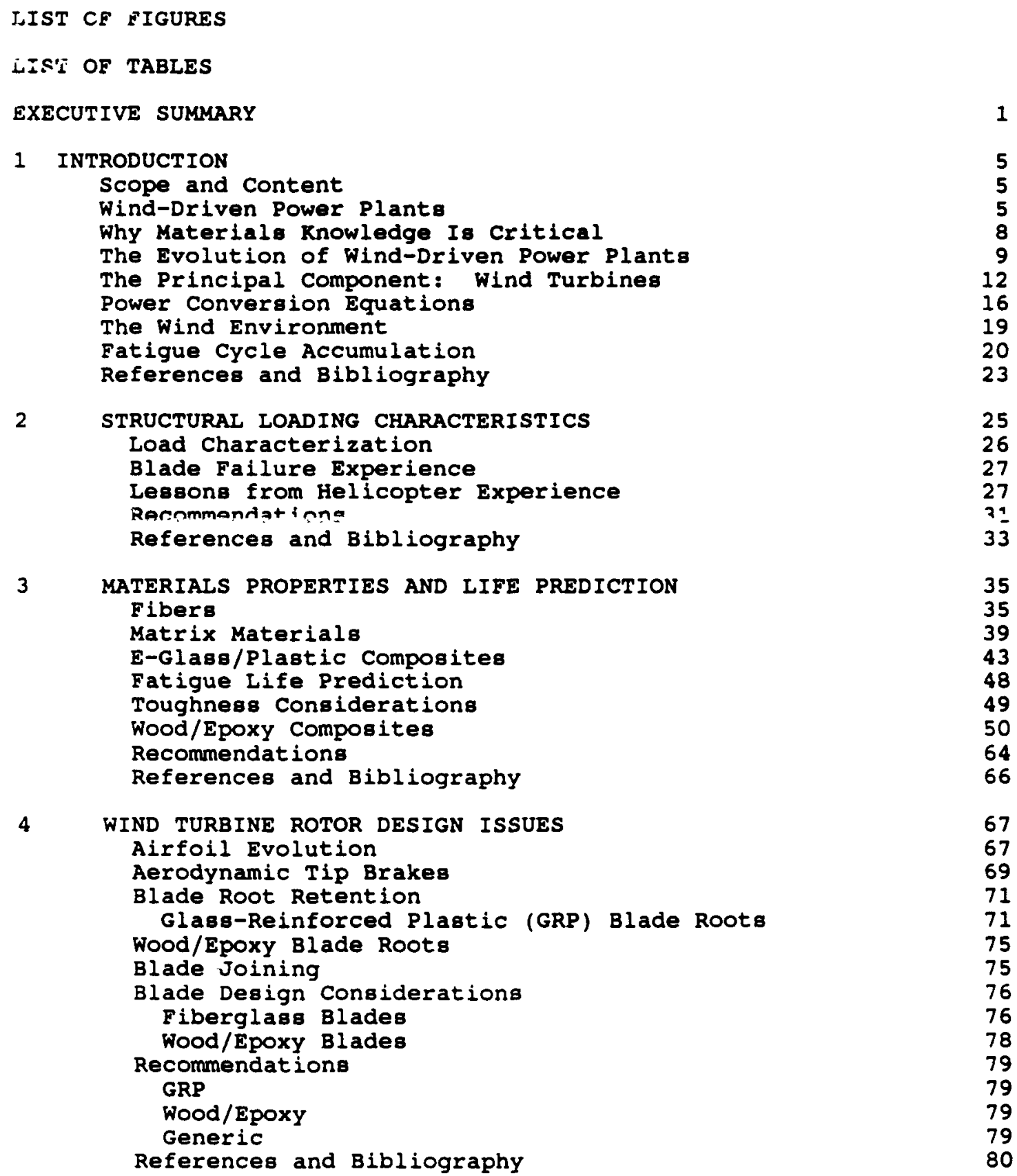


MANUFACTURING PROCESSES FOR ROTOR BLADES

Current Manufacturing Processes

Blade Root End Concepts $\quad 82$

Manufacturing MethodB Influence Blade Life

Matrix Stress Versus Fatigue $\quad 83$

Helicopter Rotor Blade Design and Processing 84

Manufacturing Processes Applicable to Wind Turbine Blader 84

Resin Transfer Molding (RTM) $\quad 84$

Pultrusion

Fiber Placement

Root End Design for Ps nducibility

$\begin{array}{ll}\text { Manufacturing Recor:nendations } & 87\end{array}$

$\begin{array}{lr}\text { References and Bibi lography } & 89\end{array}$

6 ACTIVE CONTROL IN NIIND TURBINES 91

The control problem for wind Turbines 91

Recent Trends in Control System Theory 93

Existing Control Technology for Wind Turbines 94

Role of Control Technology in the Wind Power Induatry 95

$\begin{array}{ll}\text { References and Bibliography } & 98\end{array}$

7 CONCLUSIONS AND RECOMMENDATIONS 101

Conclusions $r \begin{array}{ll}101 \\ \text { Research }\end{array}$

$\begin{array}{ll}\text { Research Recommendations } & 102\end{array}$

APPENDIX A: STATEMENT OF TASK 105

APPENDIX B: COMMITTEE MEETINGS AND ACTIVITIES 107 


\section{LIST OF FIGURES}

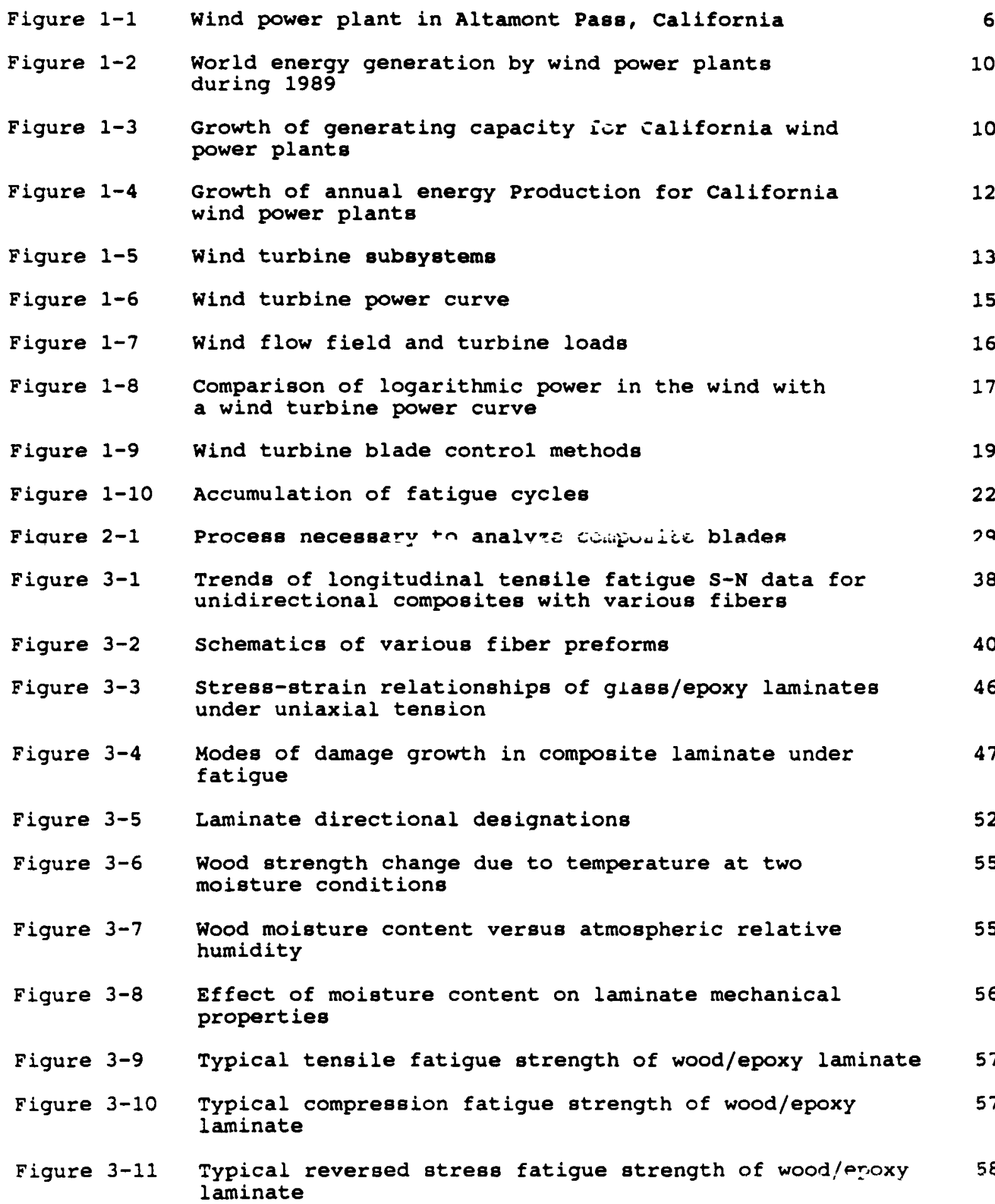

6

10

10

12

15

16

17

19

22 


$\begin{array}{lll}\text { Figure 4-1 } & \text { Commonly used early HAWT airfoils } & 68 \\ \text { Figure 4-2 } & \text { SERI advanced wind turbine airfoils } & 68 \\ \text { Figure 4-3 } & \text { Nine-meter GRP wind turbine blade } & 70 \\ \text { Figure 4-4 } & \begin{array}{l}\text { Eleven-Meter wood/epoxy blade airfoil thickness } \\ \text { distribution and planform }\end{array} & 70 \\ \text { Figure 4-5 } & \text { Flanged GRP blade root design } & 71 \\ \text { Figure 4-6 } & \begin{array}{l}\text { Flanged root design limitation due to steel/GRP Strain } \\ \text { incompatibility }\end{array} & 73 \\ \text { Figure 4-7a } & \text { Bonded steel root tube GRP hub design } & 74 \\ \text { Figure 4-7b } & \text { Wood/epoxy blade root } & 74 \\ \text { Figure 4-8 } & \text { All-wood/opoxy composite hub } & 76 \\ \text { Figure 5-1 } & \text { UH-1H composite main rotor blade } & 85 \\ \text { Figure 5-2 } & \text { RTM cooling tower blade } & 86 \\ \text { Figure 5-3 } & \text { 4BW hingeless bearingless rotor } & 88 \\ \text { Figure 6-1 } & \text { Wind turbine drive train } & 92\end{array}$

\section{UST OF TABLES}

Table 2-1 Blade Sectional Analysis Codes:-

Table 3-1 Typical Properties of Fibers 36

Table 3-2 Typical Properties of Unidirectional Composites 37

Table 3-3 Properties of Case Resins 42

Table 3-4 High-Performance Thermoplastics Used as Matrix Resins 44

Table 3-5 Trade-offs Between Thermosets and Thermosets as 45 Matrices

Table 3-6 Typical static Strength, Type 110 Laminate 542

Table 6-1 Control Effectors and sensors for a pitch-Controlled 92 Wind Turbine 


\section{Executive Summary}

The commícee's charge was to define a research and development agenda for the Department of Energy's wind energy program focusing on materials aspects of the wind turbine rotor technology. In particular, the committee interpreted its mandate to include an assessment of the potential for new design methods, better manufacturing processes, and advanced control methods in addition to advanced materials for improvement in turbine rotor performance and lifetime.

In addition, the committee took as its responsibility the development, in broad outline, of a research and development program that would place U.S. technology in rotors for wind power in a preeminent world position.

In carrying out its charge the committee examined an extensive

literature on wind machines and wind turbine rotor materials and was briefed by many experts on these subjects, both in the wind industry and in related industries.

Wind-driven power systems represent a renewable energy technology that is still in the early stages of development. Arrays of interconnected wind turbines convert the lower carried by the wind into electricity for users of the utility power arid Major concentrations of this technology exist in Cd+lifinla, Denmark, and Hawall. At the end ot 1989, the wind power plants in California comprised a power-generating capacity of $1335 \mathrm{MW}$, equivalent to a medium-sized utility power plant. Not only do these wind power plants produce no gaseous emissions, particulates, or radioactive by-products, but they can be installed rather quickly as modular units, each providing capacity from a few tens of kilowatts to hundreds of megawatts. They can be readily integrated into existing utility generation-transmission-distribution systems. While economic utilization of wind energy depends critically on location and siting, many available sites exist in the United States. While land intensive, wind power plants can coexist with other uses of the land on which they are situated.

Wind power plants installed in the early 1980 s guffered structural failures chiefly because of incomplete understanding of the wind forces (especially the turbulence component) acting on these large structures and in some cases because of poor quality in manufacture. Failure of the rotor blades was one of the principal and most serious structural failures. Failures from these causes are now somewhat better understood. An associated additional limitation to achievement of the full economic potential of wind energy is uncertainty about the long-term response of wind turbine rotor materials to the turbulent stochastic loadings to which they are subjected. Over their projected operational lifetimes (typically 20 to 30 yearg), these structures are subjected to as many as a bilition stress cycles.

Since a number of U.S. electric power utilities are continuing to add capacity, there will be an opportunity to introduce new, longer-lasting designs. Moreover, renewed public interest in environmental issues associated with power generation gives a renewed impetus to wind power. A new wind turbine system will probably take advantage of advances in semiconductor power electronics to produce changes in the system configuration that. will make wind-generated electric power more stenable for use by eiectric utilities. New speed control schemes wish oe introduced, but a major advance must come 
through the design of 1 ess expensive, longer-lived, and higher-efficiency rotor blades. A guiding principle in creating this design should be that knowledge of aerodynamic forces must be carefully integrated with the structural response of the material, all balanced by the practicalities of field experience and tempered by the need to manufacture a consistently highquality product at reasonable cost.

This committee has examined the experionce base accumulated by wind turbines, and the accompanying R\&D prograr.s sponsored by the Department of Energy. We have concluded that a wind energy system such as described above is within the capability of engineering proctice. But certain gaps in knowledge exist, so achieving the goa 1 without costly and inefficient trial and error requires certain critical research and development. Because of the fragile nature of the wind power equipment producers in the United States this will require an R\&D investment from the Department of Energy.

The committee cannot conclude without commenting on the status of the wind power equipment industry. Because of the decrease in the rate of installation of machines in the last 5 years (since the tax incentives expired), there currently is only one major integrated manufacturer in the United States; only a few companies are actively producing blades. In recent years a major Japanese manufacturex has entered the world market, foining the European manufacturers who have been participants for some time. As a result, the U.S. industry is not in a financial position to engage in the R\&D necessary to gain worldwide technological leadership for what the committee sees as a future growing worldwide market for wind power. The committee believes that the United States is facing a future reduction in most fossil fuel sources of energy. When this is coupled with a resurgence of public concern over environmental issues in energy production, the need to develop wind power energy to the fullest extent possible seems compelling.

\section{RESEARCH RECOMOMNATIONS}

The committee has identified four goals to guide the research needs in wind turbine rotor technology:

Goal 1: To improve the material properties and design capability so that the structure will either withstand higher stresses or the same level of stress for a much longer period of time.

Goal 2: To lower the operating stress levels by altering the structural/configuration design.

Goal 3: To improve the blade manufacturing process so that quality variations and cost are minimized.

Goal 4: To reduce the cost of blades enough so that periodic replacement becomes cost-effective.

The details of specific research recommendations are given in Chapter 7 (Conclusions and Recommendations) and, in greater depth, at the ends of Chapters 2, 3, 4, 5, and 6. The main research tasks are summarized below.

\section{MATERIALS}

Initiate a program to generate long-term (10-year-equivalent), highcycle fatigue $\left(10^{8}-10^{3}\right)$ data for candidate structural materials: glassreinforced plastic, wood/epoxy, and advanced high-modulus composite materials under appropriate environmental conditions. The program would contribute an element in a needed databank for wind turbine blade materials.

\section{DESIGN}

The wind turbine industry needs design tools that are beyond the capability for development by the private sector. For example, it is necessary to be able to compute laminate stresses in three dimensions and to 
relate these stresses by means of a suitable failure theory. It is also necessary to rigorously relate blade material and geometry to beam-like stiffnesses. In turn, the stiffness and mass must be combined with suitable aerodynamic models to determine structural dynamic response in the rotating field of the rotor. This type of analysis will help to assess the benefits of active control as well as passive (such as by elastic tailoring) load relief systems. Most of these tools either exist or are being developed in the aerospace industry. They are largely developed under government. systems procurements and should be extracted and adapted to the special needs of the wind turbine rotor.

Emerging technologies in active and passive control of both the rotor and the generator need to be studied on an overall system basis considering the probable gains in structural efficiency and reduction in blade life-cycle cost.

\section{MANUTACIURINO}

Two emerging manufacturing processes, resin transfer molding, and pultrusion, offer significant opportunities for cost reduction but with attendant limitations on blade design freedom. A feasibility study should be conducted to evaluate each of these processes in a real application and at a reasonable scale, allowing realistic design and cost trade studies to be accomplished. For example, the cost of a geometrically simple pultruded blade can be little more than the cost of the materials, thus making it appreciably less costly than the curved and shaped wind turbine blades currently employed. However, while less costly, such blades are also less efficient

aerodynamically. Thus, from a life-cycle economics perspective, $2 .=$ is not clear that the attendant reduction in the initial cost of the wina turbine can

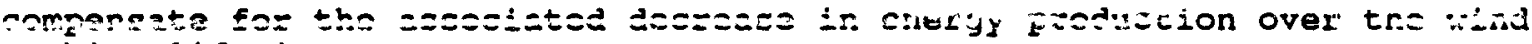
turbine lifetime. 
$$
\text { . }
$$ 
INTRODUCTION

\author{
SCOPE AND CONHENT
}

Wind-driven power systems represent a renewable technology that is still in the early stages of its development and maturation. It is a renewable power technology that, during the course of its rapid evolution over the last decade, hag accumulated significant, large-scale, utility-connected experience. This experience not only revealed the early design problems, which for the most part have been resolved, but also presented opportunities for further significant improvements in the technology and economics of the wind turbine, the principal component of these renewable power systems. The principal improvements will be associated with increases in wind turbine size, improved knowledge of atructural materials, incorporation of improved control hardware and algorithms, utilization of power conversion electronics, and development and integration of short-term energy storage systems. A major area of potential improvement, and the focus of this report, is the need for improved knowledge of materials properties and advanced, economical, high-volume manufacturing processea.

This chapter traces the evolution of wind power systems in this country,

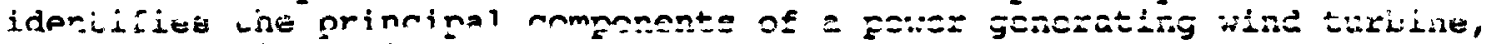
presents a simplified description of the relationship between the power in the wind and the power flow through the turbine drive train, and describes the characteristics of the wind environment that impact both the ohort-and the long-term structural integrity of wind turbines.

The remaining chapters of this report explore and further define the need for improved materials properties, manufacturing processes, and control systems. The report closes with major conclusions and recommendations.

\title{
WIND-DRIVEN POWER PLANTS
}

Large-scale, wind-driven power stations have emerged as one of the most attractive of the recently developed renewable power technologies. These arrays of interconnected wind turbines convert the power carried by the wind into standardized electricity. This electricity is delivered into a conventional grid system for use by utility customers. Shown in the photograph of Figure 1-1 are some of the wind turbines of a grid-connected wind power plant in California.

These renewable power systems have evolved rapidly over the last decade. The first sizeable, grid-connected installations began operation in 1981 in California. Their development was facilitated initially by federal and state tax incentives, high energy prices, and a favorable regulatory environment. These factors supported the attraction of the private sector risk capital required for the development and early commercialization of a new, untried, and capital-intensive power generation technology. As the reliability and economics improved, these power systems were able to attract conventional financing similar to that available for other industrial capital equipment. These factors and improvements have regulted in a renewable power technology with major inst=llations in California, Denmark, and Hawaii. For a technology that can be described as being in its infancy, these power systems have achieved a remarkable record of performance. At the close of 1989, the 


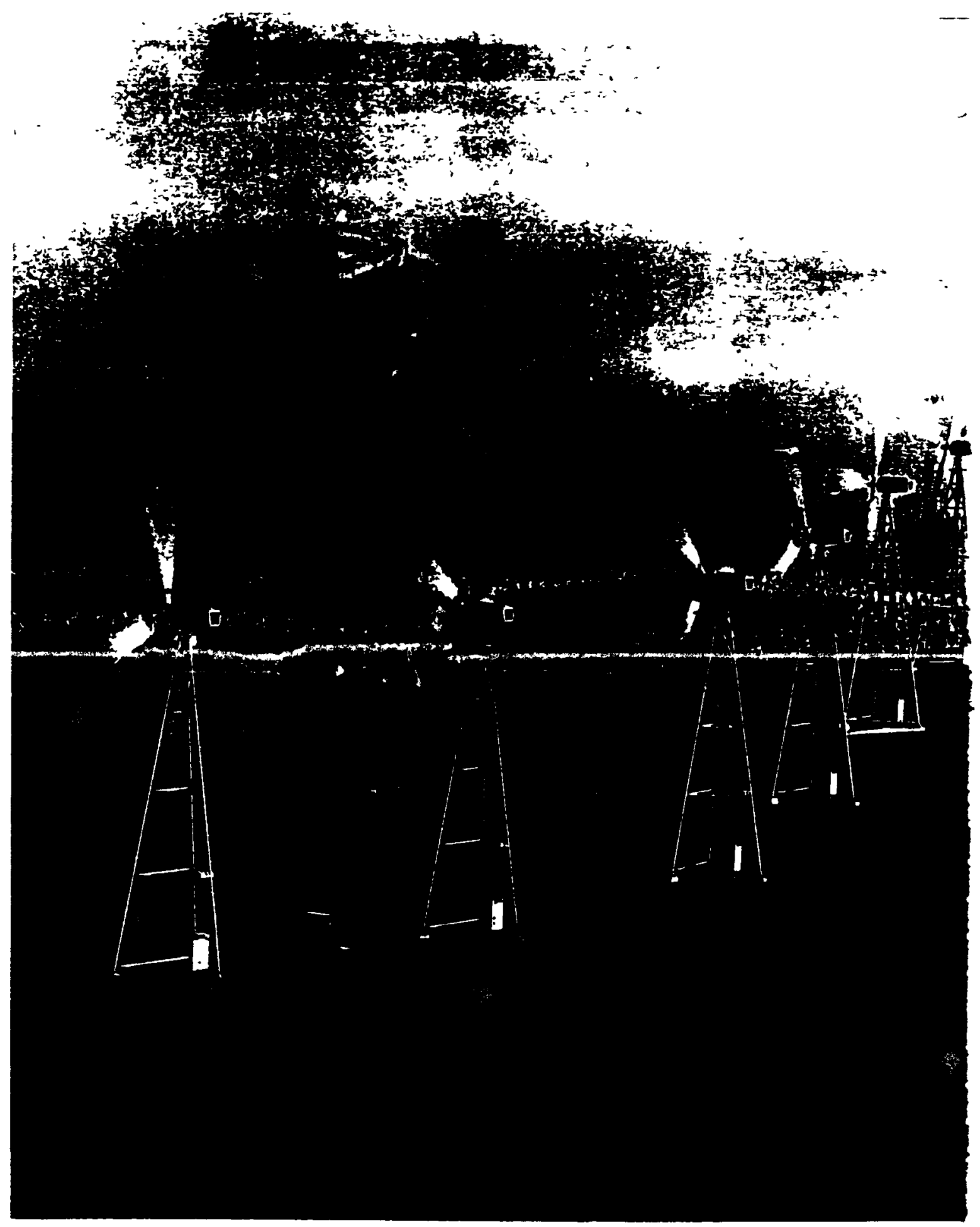

FIGURE 1-1 wind power plant in Altamont Pase, California. (Courtesy, U.S. Windpower, Inc.) 
wind power plants in California represented a power-generating capacity of $1335 \mathrm{Mw}$, equivalent to a medium-size nuclear or coal-fired power plant. During 1989 the wind power systems of California delivered slightly more than 2 bilition kwh of electricity. This amount of electrical energy is equal to the annual residential needs of a city the gize of san Francisco or Washington, D.C. In Europe, Denmark has been a pioneer in the use of modern wind turbines for electricity generation. The approximately 2500 wind turbines installed throughout Denmark currently aupply aboit 1 percent of the country'g annual electrical needs. We note here that appioximately half of the wind turbines installed in California during th.e $\$ 9808$ were of Danish manufacture. This is relevant to the longer-term impact of this study as it relates to the future viability of U.S. manufacturer:,

The progress of the last decade was not achieved without difficulty and, at times, controversy. Early structural fallures, together with undercapitalization of some wind power plant operators, led to the perception, from some quarters, that the California installations were "tax farms." However, as the systems improved in performance and began to produce large amounts of energy, these accusations were replaced by a growing appreclation of the environmental benefits and advantages offered by this renewable power generation technology. The advantages: and benefits include the following:

Environmentally Benign: Wind power systems are environmentally benign. There are no gaseous emissions, no particulates, and no radioactive byproducts.

Rapid Modular Addition of Capacity: Wind power systems can be installed quickly, thus reducing financing costs and providing flexibility in meeting demand growth.

Wide Range of Capacities: Wind power systems can range in size from very small systems to power plants of utility scale (1.0., from a few kilowatts to hundreds of meaawatte in parver-aenesecing capacity)

Ease of Integration: Wind power systems are readily integrated into existing utility generation-transmission-distribution systems, using standard utility components and practices. The wind turbine is the only new component. Couse of Land: While landintensive, wind-driven power plants coexist with other uses of the land on which they are situated. The wind turbine and towers, service roads, and electrical equipment typically occupy only 10 percent of the land on which the wind power plant is ingtalled. Previous uses, typically agricultural, can continue with little useful area removed. Use of Indigenous Resources: Wind-driven power plants use indigenous resources for their fuel. Since the fuel is without cost, the user country achieves a degree of energy independence and preserves hard currency assets. This is important not only for developed countries with adequate wind resources but perhaps more so for developing countries.

Economically Competitive: The cost of energy (CoE) from wind power plants is competitive now with some conventional energy generation sources. Large-scale systems now being installed deliver energy at costs in the range 7 to $9 \mathrm{k} / \mathrm{kwh}$. Under comparable wind resource conditions, third-generation wind turbines (under design now) are expected to deliver energy at costs in the range of 4 to $6 \% / \mathrm{kwh}$.

These advantages are applicable not only to this country but global as well. While not a complete solution to environmental concerns, wind power gystems do represent an attractive part of the total generation mix.

As with most technologies, the advantages of wind power systems must be weighed against the disadvantages and limitations. The disadvantages include their visual impact, noise, potential interference with the reception of television signals, and potential hazard to birds. Visual impact is inescapable, particularly $= \pm$ close jistances.

Ihe principal sources of noise in wind turbines have been the blaces and gearboxes. Early machines were relatively noisy compared with more recent designs. Advances in blade airfoll shape and manufacture have significantly reduced the noise from wind turbine blades. Similarly, attention to the sources of noise in wind turbine gearboxes has resulted in significant reductions. However, with both sources a certain amount of noise is 
inevitable. At reasonable distancea (several rotor diameters), wind turbine noise can be difficult to discern from ambient background and cultural noise Bources (e.g., wind nolse, automobile traffic).

Television interference has not been a problem with recent large

ingtallations. This may be due in part to the use of composite materials in the blades and the fact that people typically do not reside in close proximity to wind turbines.

There also are limitations to the broader application of the technology. The relarive newness of the technology has justifiably required the ascumulation of significant operating experience. This limitation is belny cemo.ed by the favorable technical and economic performance accumulated over the pait half decade or more by many existing installations.

A fundamental limitation is that the economic generation of electricity is governed by the quality of the wind resource--no wind, no energy; poor wind, some energy but unattractive economics. Wind systems thus have a geographical limitation based on availability of the required resource--wind. Finally, a limitation of current systems is that the electricity generated is time variable, reflecting the variability of the wind. This variability occurs on several time scales. Seasonal and diurnal variations are statistically predictable, such that the generated energy can be factored into the planning of the overall utility generation mix. However, time variations on the order of minutes and tens of minutes (faster than the ramp rates of conventional generation sources) can pose system voltage and frequency stability problems. The utility rule of thumb is that wind systems of current design are 1 imited to the ranges of 5 to 15 percent of the total generating capacity. For a given utility system, the specific wind penetration limit depends on such technical details as transmission line characteristics, the ratio of real and reactive power, and allowable excursions of voltage and frequency. Thus far, with the large installations

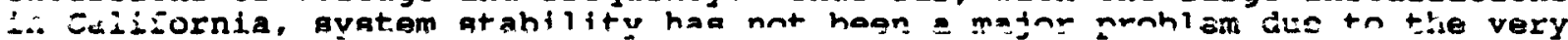
large utility gystems to which the energy is gupplied. The fraction of wind generation capacity is less than 10 percent of the total generation on-line. Depending on the time of day and the load profile, the wind systems on the island of Hawaii do approach limitations imposed by system stability arguments. At night, when the load is minimal, the installed wind systems can exceed the range cited above.

The system stability limitation represents an upper bound on the amount of current design wind capacity that can be integrated with the balance of the utility generation mix. As such, this limitation is a market limitation having technical origins. There are three approaches, now undergoing research and development, that will mitigate and eventually remove this limitation. New wind turbine system designs form the first of these approaches, one example of which is the variable-speed architecture with power electronic control and interface to the grid. Other less complex examples are provided by innovative, passive, load-relieving rotor designs and by advances in selfregulating airfoils. A second approach that will provide relief from this limitation is improved control of the wind system and integration of control with the conventional generation sources. Finally, the third technique for removing the penetration limitation is the incorporation of energy storage, which will compensate for the time variability of the wind.

We are beginning to see all of these techniques employed in smaller integrated power systems. These are systems uged in regions where no large regional grid system is available, where the wind power capacity is comparable to the conventional power generation capacity (often provided by diesels), and where the conventional power sources can be turned off, with the load being supplied by the wind system.

\section{WHY MATERIALS ROWLEDGE IS CRITICAL}

From an engineering perspective, the early structural failures and continuing risks had their genesis in an early lack of understanding of the wind forces acting on these large structures. This included not only the effects of the steady-state component of the incident wind flow field, but 
more particularly the turbulence component. Research, field measurements, and improved modeling, augmented by operational experience, have greatly increased our understanding of these stochastic forcing functions and the response of the wind turbine. Nevertheless, it is still true that the turbulence structure of the wind contributes the most uncertainty in the design and sizing of the major etructural components of a wind turbine.

From the perspective of a designer, this uncertainty continues to be due in part to incomplete knowledge of the turbulence and its description and in part to the difficulty of moleiing the structural vibrational responses. However, a major contribilur is uncertainty about the long-term responses of the wind turbine mater $i=16$ to the turbulent stochastic loadings. The specific long-term responses of intislist here are fatigue fallures that is, failures due to the cumulative effects of many millions of flexural cycles of a structural component. Fatigue failures represent the greatest uncertainty with regard to the long-term service lifetime (typicaliy projected to be 20 to 30 years) of the major structural components of a wind turbine. Thus, fatigue failures represent a major uncertainty in the life-cycle COE.

Uncertainty about the properties of materials causes the wind turbine designer either to add more weight (and cost) than is required or to misjudge and inadequately size a component so that failure occurs (usually more costly). To further improve the economics of wind turbine systems and increase their range of use, improved materials properties are required. This is particularly true with regard to the long-term fatigue properties of composite materials. As used thus far in wind turbines, composite materials are combinations of glass, other gynthetic fibers, or wood in a resin matrix. with the anticipated increasing use of these and other composite materials, improved knowledge about both their static strength and their fatigue properties becomes critical in order to assure both short-term performance and the long-term life required of these power aystems. This knowledge base is

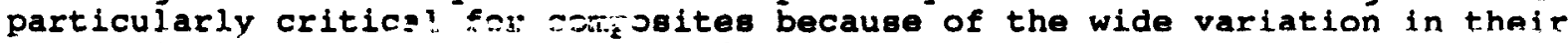
geometries, constituerts, and manufacture.

In addition to the need for improved materials knowledge, there is also a need for increased awareness in the wind turbine community (within both the federal and the private sectors) of advanced manufacturing processes. These processes, which may be used in other industries, are required to support not only the more extensive use of composites but also their large-volume, economical manufacture.

\section{THE EVOLUTION OF WIND-DRIVEN POWER PLANTS}

Wind-driven power plants are arrays of interconnected wind turbines used for generating and delivering large amounts of electricity. The electricity typically is delivered to a larger utility generation-transmissiondistribution system or grid. These large-scale power plants are often referred to as wind farms or wind parks. The term wind power plant or wind power system will be used here. These renewable energy generation systems have evolved rapidly over the past 10 years. There are now substantial installations in three regions of California, in Hawaii, and in Denmark. Currently there are about 14,000 wind turbines in California-all installed since 1980. The California installations are situated principally in the Altamont Pass region, about $60 \mathrm{miles}$ east of san Francisco near Livermore; the Tehachapi region, about $100 \mathrm{miles}$ northwest of Los Angeles near Mojave; and the San Gorgonio Pass region, about $100 \mathrm{miles}$ southeast of Los Angeles near Palm Springs. The wind power plants in northern California (about half of the total) deliver their energy to the grid system of the Pacific Gas and Electric Company, while the installations in southern Califarnia feed their energy into the southern California Edison grid system. As illustrated in Figure 1-2, during 1989 t.ne wiru power plants in California delivered about 2 billion kwh of electricity.

The two graphs of Figure 1-3 illustrate the growth in the rated powergenerating capacity of the California wind power plants. The graph units are megawatts. The bar graph shows the capacity added during each year from 1981 


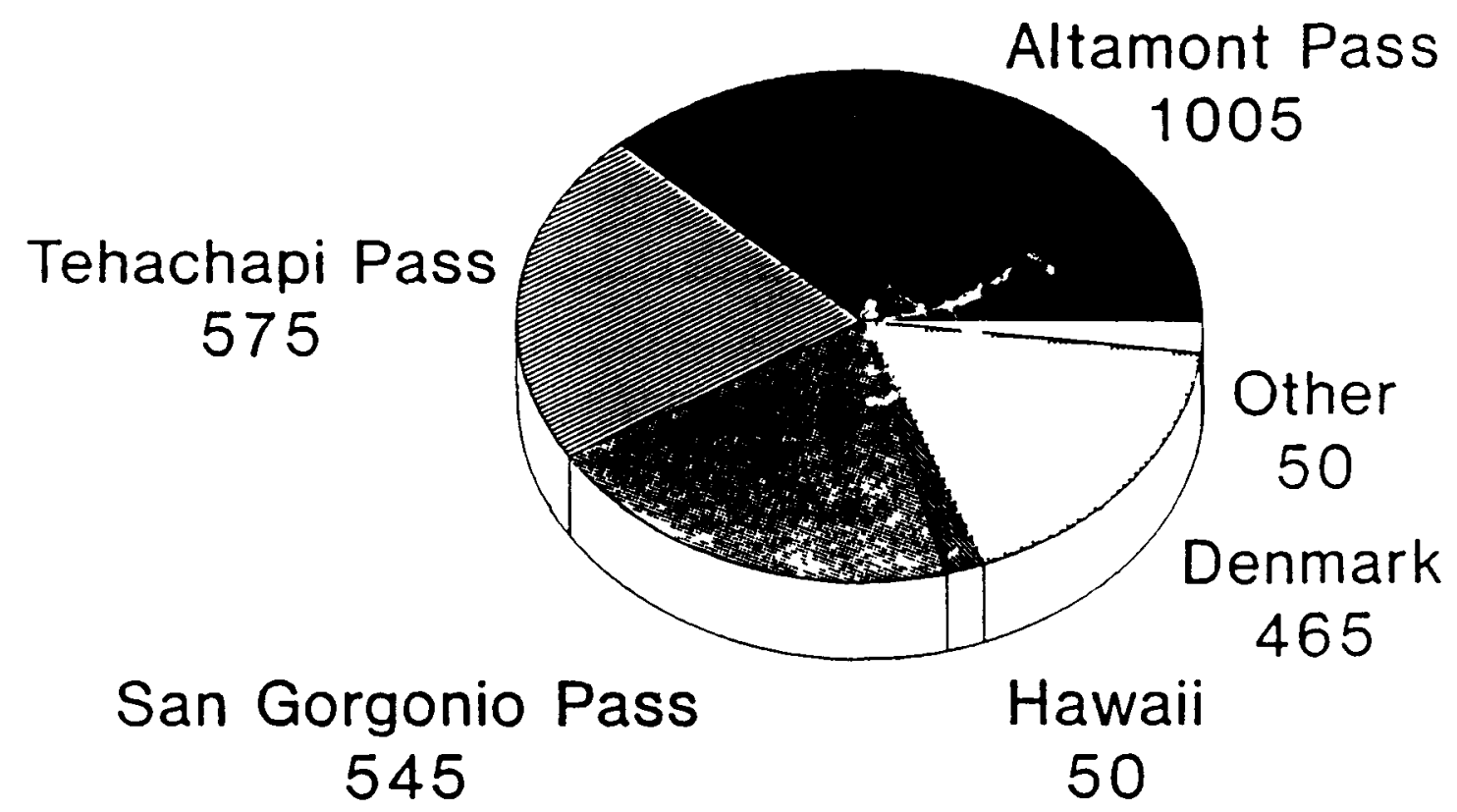

FIGURE 1-2 World energy generation by wind power pl=nts during 1989 (units of millions of $\mathrm{kwh}$ ). (Courtesy, Paul Gipe Associates.)

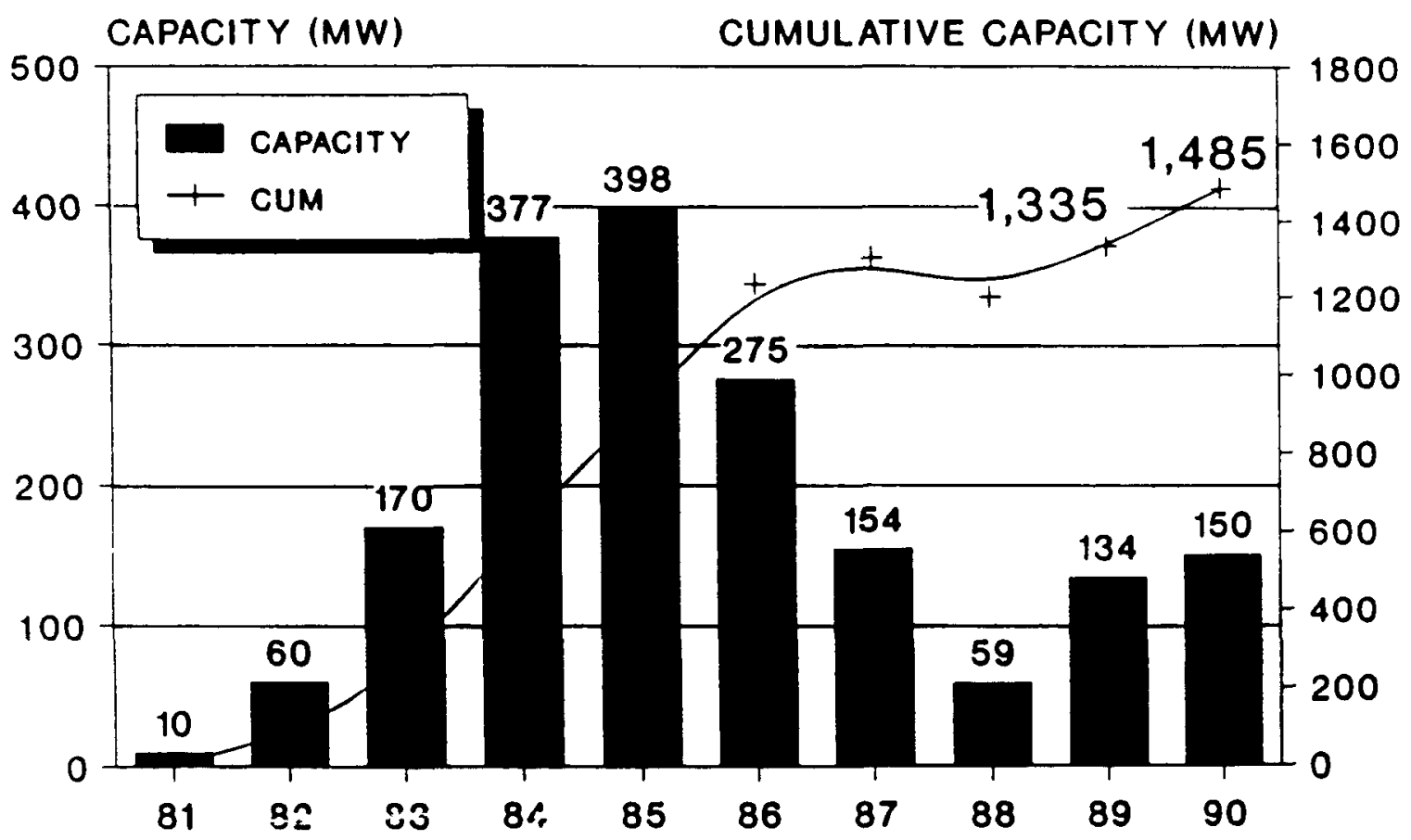

FIGURE 1-3 Growth of generating capacity for the California wind power plants. Sources: California Energy Commission (CEC); CEC Performance Reporting Systems (PRS). (Courtesy: Paul Gipe and Associates) 
through the projection for 1990. The line graph of Figure 1-3 deplcts almost the eame information but in a cumulative format. This graph shows the cumulative total of the net installed capacity at the end of each year during this 10-year period.

There are four features in the data of Figure 1-3 that merit attention: (1) the current total rated capacity, (2) the shape of the year-to-year growth in capacity, (3) a comparibon of the capacity ingtalled before and after the end of 1985, and (4) the 1988 decrease in the cumulative total capacity. Eiscussion of these features will illuminate the reasons behind the rapid evolution and growth of these large-scale renewable power systems. The first thing to notice about the information in Figure 1-3 is the current rated capacity of the wind power plants. For a power generation technolngy tist has evolved over the recent decade, the nearly $1500 \mathrm{Mw}$ of installed canjcity is substantial. The second aspect of Figure 1-3 that merits comment is the rapid growth of the year-to-year added capacity from 1981 through 1985 and the generally reduced rate of new installations in the oucceeding years. This is a manifestation of the mechanisms used to initiate the early, large-scale commercialization of a relatively new and untried power generation technology. These mechanisms included tax incentives at the federal level and at some state levels (including California) and federal legislation requiring regulated utilities to purchase the energy produced by nonregulated or independent power producers (IPPB).

The development occurred first in California not only because of the three excellent wind regions, but also because of a favorable legislative and regulatory climate at the state level. The legislative climate resulted in tax credits to California residents who invested in renewable energy generation facilities. The favorable regulatory climate, as represented through the actions of the California Public Utilities Commission and the -alifornia Energy Commission, influenced the terms of power purchase contxacts negotiated between the regulated utilities and the IPPB.

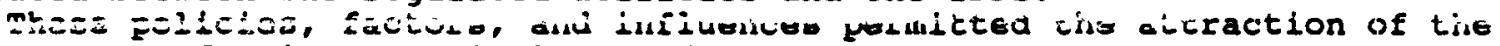
large amounts of private capital needed to launch a new, capital-intersive industry. The wind power systems of California represent a private capital investment of about $\$ 2.5$ bilition. The incentives and the attendant attractive returns compensated the investors for participation in a risky and relatively untried power generation technology.

The tax incentives at the federal level expired at the end of 1985 . The California tax incentives were phased out over the 2-year period of 1986 and 1987. While there were some carryovers and grandfathering, for all practical purposes the tax credit era that fostered the early development of wind power technology expired at the end of 1985. The effects can be seen in the post1985 decrease in the yearly installation rate of new capacity, depicted in the bar graph of Figure 1-3.

At this point, we are equipped to appreciate the third feature in the data of Figure 1-3. If one sums in Figure 1-3 the yearly capacity added from 1986 through the projections for 1990, this post-tax-incentive added capacity is about equal to that installed from 1981 through 1985. Aside from any carryovers or phaseouts of special tax incentives, two factors supported continued installations in the years following 1985: (1) the continualiy improving energy production and overall economic performance of the wind systems and (2) the carry-forward provisions of some of the pre-1985 power purchase contracts.

Finally, in Figure 1-3, the 1988 dip in the cumulative capacity on-line (the line graph) reflects the fact that a number of older, first-generation wind turbines were retired. They were replaced to some extent but not entirely, by the new capacity ( $59 \mathrm{Mw}$ ) installed during 1988.

The growth in annual energy production of the California wind power systems is depicted in Figure 1-4. The data in this figure show that energy production has ateadily improved from 1981 through the present. Nevertheless, averased ove. the fleat, the current average capacity factor is still not up to the realistically achievable potential in the wind regimes of the three California regions. For good sites in any of these regions, a capacity factor of 0.25 is a reasonable performance value. The best of the current machines do achieve this value or higher. 


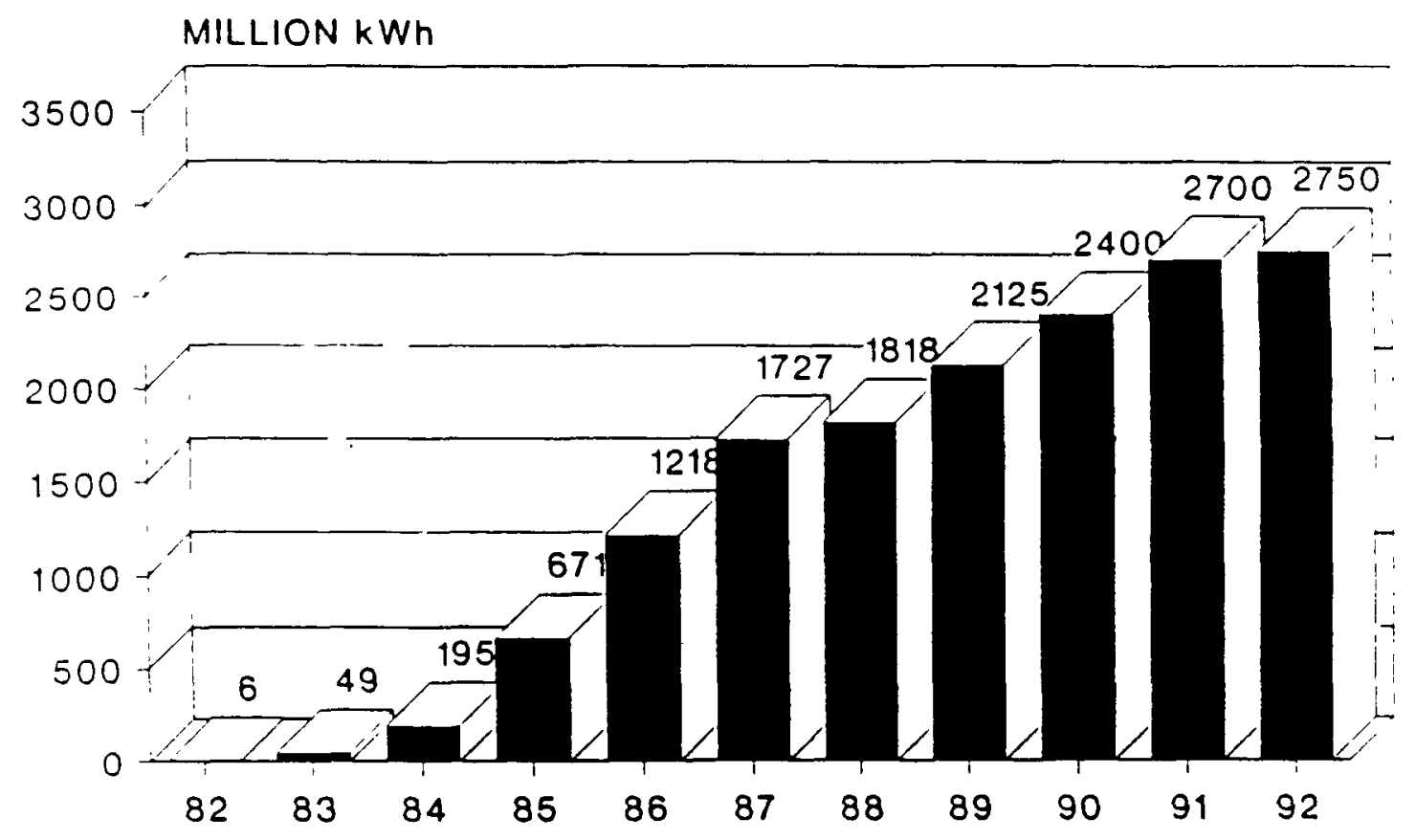

FIGURE 1-4 Growth of annual energy production for Callfornia wind power plants. Sources: CEC, CEC PRS. (Courtesy, Paul Gipe Associates.)

The high energy prices in the early part of the 1980 were accompanied by the expectation of still higher prices. This led to the development and approval of negotiated power purchase contracts wherein the energy prices paid were consistent with the prevailing expectations of high, and higher, energy prices. By means of a long-term fixed-price payment provision in certain contracts, the operator of wind power syateme surrendered the poseiblilty of receiving near-future higher energy sales prices in return for defined energy prices that were fixed for a long-term period (typically 10 years).

This benefited the utility rate payers by putting a cap on energy prices :rom these sources; it benefited the IPPB by providing revenue certainty over the period of fixed prices. This period of revenue certainty loften coincident with the term of third-party financing) supported the continued (post-1985) attraction of investment capital from the private sector. Now, however, these investments, made in the absence of special tax incentives, took on a different complexion.

These factors allowed wind gystems to be financed on the basis of their economic performance. Thus, beginning in 1986, large-scale wind power plants began to be financed in the same ways that other industrial capital equipment is financed. These included sale-lease transactions and straight debt, secured by the equipment, with repayment supported by the revenue streams generated by the equipment.

\section{THE PRINCIPAI CONPONEATS WIND TURBINES}

Wind turbines are the principal component of wind farms. They are the only component that is not a standard piece of utility equipment. They represent the major fraction, in the range of 60 to 75 percent, of a wind farm's total installed cost. The cue associated with currently installed, second-generation wind turbines is in the range of 7 to $94 / k w h$. While this is economically competitive in the context of the most attractive power purchase contracts currently in place, and is competitive with some conventional means of energy generation, the full potential of wind power as a large-scale 
renewable energy source will not be realized until coete can be reduced Eurther.

Both the installed capital cost and the continuing maintenance costa need to be reduced. Two paths by which this might occur are improved knowledge of the behavior of materials and the use of advanced manufacturing techniques. Through utilization of these and other improvementa, it is believed that the CoI from wind syeteme can be brought to the range of 4 to $6 \mathrm{c} / \mathrm{kwh}$. This range will make wind power syeteme competitive not only with nuclear but also with new coal-fired installitions. At the same time, the performance characterietica will be impro"ed to the extent that wind turbine installatione can be economically prociuctive over a broader clase of wind regimes and geographical reglons.

There are two generic types of bind turbines: (1) the horizontal axis wind turbine (HAWT) and (2) the vertical axis wind turbine (VAWT). Although many of the findinge and recommendations of this study are applicable to both architectures, the focus here is on the HANT. This is the type predominantly uged in the approximately 20,000 wind turbines now in eervice throughout the world.

Illuetrated in Figure 1-5 are the princlpal elements of a wind turbine. These include (1) the rotor, consisting of the blades and the supporting hub; (2) the drive train, consisting of the low-speed shaft (LSS), the gearbox or transmission, the high-speed shaft (HSS), and the generator; (3) the machine bedplate or supporting frame; (4) the yaw bearing and yaw orientation syatem; and (5) the tower. In the interest of clarity, the bedplate or frame has been omitted from the drawing of Figure 1-5, as have the tower foundation and most of the tower.

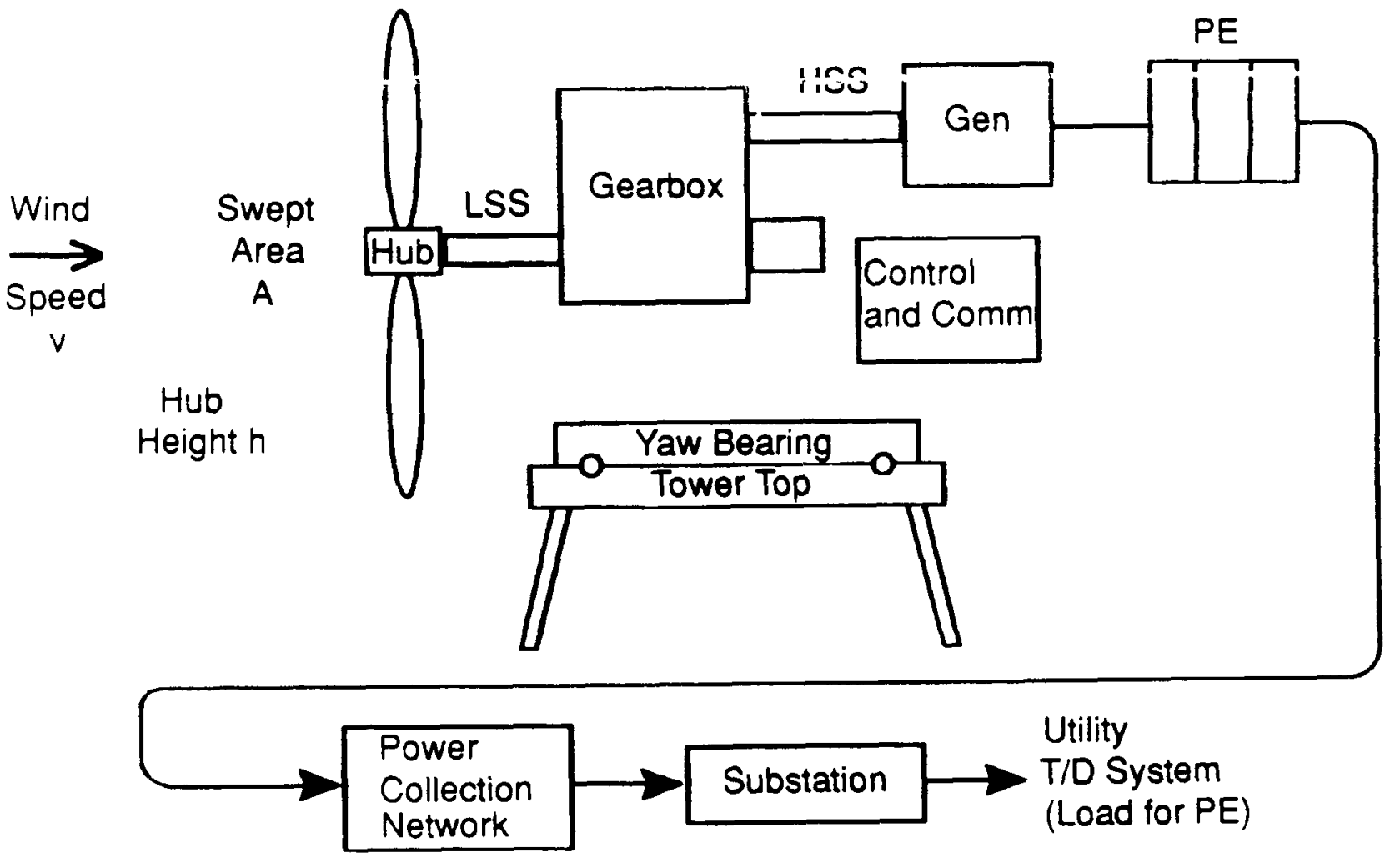

FIGURE 1-5 wind turbine subsystems. 
The wind turbine blades are rotating airfoil surfaces that transform power in the wind to mechanical shaft power. As will be discussed later, the blades also provide one means for the control of power flow through the drive train.

The wind turbine gearbox is a step-up type, used to convert the lowspeed power and torque produced by the rotor to their high-speed equivalents required for operation of the generator. The gearbox matches the different operating speeds of the generator and the rotor.

The electrical machine typically used as a generator in wind turbines is the four-pole, squirrel cage induction machine or, more b ief: $y$, an induction machine. An induction machine operates within a narrow range sif speeds centered about the gynchronous speed of the machine. For a fos- pole induction machine designed for use on a $60-\mathrm{Hz}$ electrical system, the synchronous speed is $1800 \mathrm{rpm}$. At speeds below synchronous, the induction machine functions as a motor. At speeds above synchronous, it operates as a generator.

The range of operating speeds is defined by the glip range. Typically, the slip range for the four-pole induction machines used in wind turbines is 2 percent of synchronous speed, or about $35 \mathrm{rpm}$. Used as a generator, this machine begins to develop power at about $1800 \mathrm{rpm}$ and reaches full rated power at about $1835 \mathrm{rpm}$.

The aerodynamic characteristics of the blade airfoils, the rotor diameter, and the range of operating wind speeds determine the optimum rotor speed. For wind turbines having power ratings in the range of 100 to $600 \mathrm{kw}$, the range of current interest and emphasis, the corresponding rotor speed range would be approximately 35 to $70 \mathrm{rpm}$. Thus, for an $1800-\mathrm{rpm}$ generator and this range of rotor speeds, the corresponding gearbox ratiog would be in the range of 26:1 to 51:1. Typically, such ratios would be implemented by two- or three-stage gearboxes.

The wind speeds over which turbines can generate pows typirallv lie in the range of 10 to $50 \mathrm{mph}$. For the California wind regions, the number of hours per year that the wind speeds lie within this operating range varies from 3000 to 4500 . The actual number of operating hours accumulated in any given year depends not only interannual wind statistics and local siting effects but also the characteristics of a given wind turbine. For use in a later illustration, we choose the intermediate value of 4000 hours per year. This means that the wind turbine operates often enough to generate power 4000 hours out of the 8760 hours per year, or about 46 percent of the time. Typically, there is a pronounced seasonal variation. In California, for example, about 70 percent of the annual energy is produced during the five summer months, May through September.

In most regions there are many hours per year when the wind speeds are $1 e s 8$ than $10 \mathrm{mph}$. For these speeds the wind does not carry enough power, with current technology, to overcome the effects of conversion inefficiencies and 108ses. At the other end of this range, the number of hours during which the wind speeds are greater than $50 \mathrm{mph}$ usually is quite small. Thus, for wind speeds greater than $50 \mathrm{mph}$, the added revenues generated do not compensate for the costs of the necessary increased structural strength. Finally, it is important to note that the wind turbine structure is required to survive very high (nonoperating) wind speeds. A typical design survival wind speed is 125 $\mathrm{mph}(56 \mathrm{~m} / \mathrm{s})$.

As a function of wind speed, the power output of wind turbines may be characterized by four numbers. In this simplified but useful description, three of the numbers specify characteristic wind speeds and one defines the power rating of the wind turbine:

$v_{c 1}$ the cut-in wind speed, defined as the wind speed at which the wind turbine begins to generate useahte amounte $=f$ electrical power. Typical valuer, are $v_{c t}=10 \mathrm{mph}=6.5 \mathrm{~m} / \mathrm{s}$.

$v_{r}$ the rated wind speed, defined as the lowest wind speed at which the wind turbine reaches the maximum value of its electrical power output. Typical values are $v_{r}=27 \mathrm{mph}=12 \mathrm{~m} / \mathrm{s}$. 
power output.

Pr the rated power, defined as the maximum value of the electrical

$v_{c o}$ the cut-out wind gpeed, defined as the wind speed at which the wind turbine reduces its electrical output from the maximum rated power level to zero. Although this usually occurs over a narrow range of wind apeeds, for simplicity it is often assumed to occur at the single value $v_{c o}$. Typical values are $v_{c o}=50 \mathrm{mph}=22 \mathrm{~m} / \mathrm{s}$.

These valies define the wind turbine power curye, a graph of the electrical $x$ wer output as a function of wind speed. The general features of a wind turbine power curve are depicted in Figure 1-6. The wind turbine produces no prine? from zero wind speed through the cut-in value $v_{e 1}$. As the wind speed increases further, the power output rises, reaching the rated value $P_{r}$ at the wind epeed $v_{r}$. As the wind speed increases beyond the value $v_{r}$ the wind turbine control syetem (which may be active or paseive) endeavore to hold the output power constant at the rated value $P_{r}$. This output value is maintained until reaching the cut-out wind apeed $v_{c o}$, at which speed the power output is reduced to zero.

The power curve of Figure $1-6$ is an idealization. It neglects differences in wind turbine control etrategiee. It accounte for rapid variations in wind speed only in an average sense. However, this representation does indicate the average performance characteristics of a

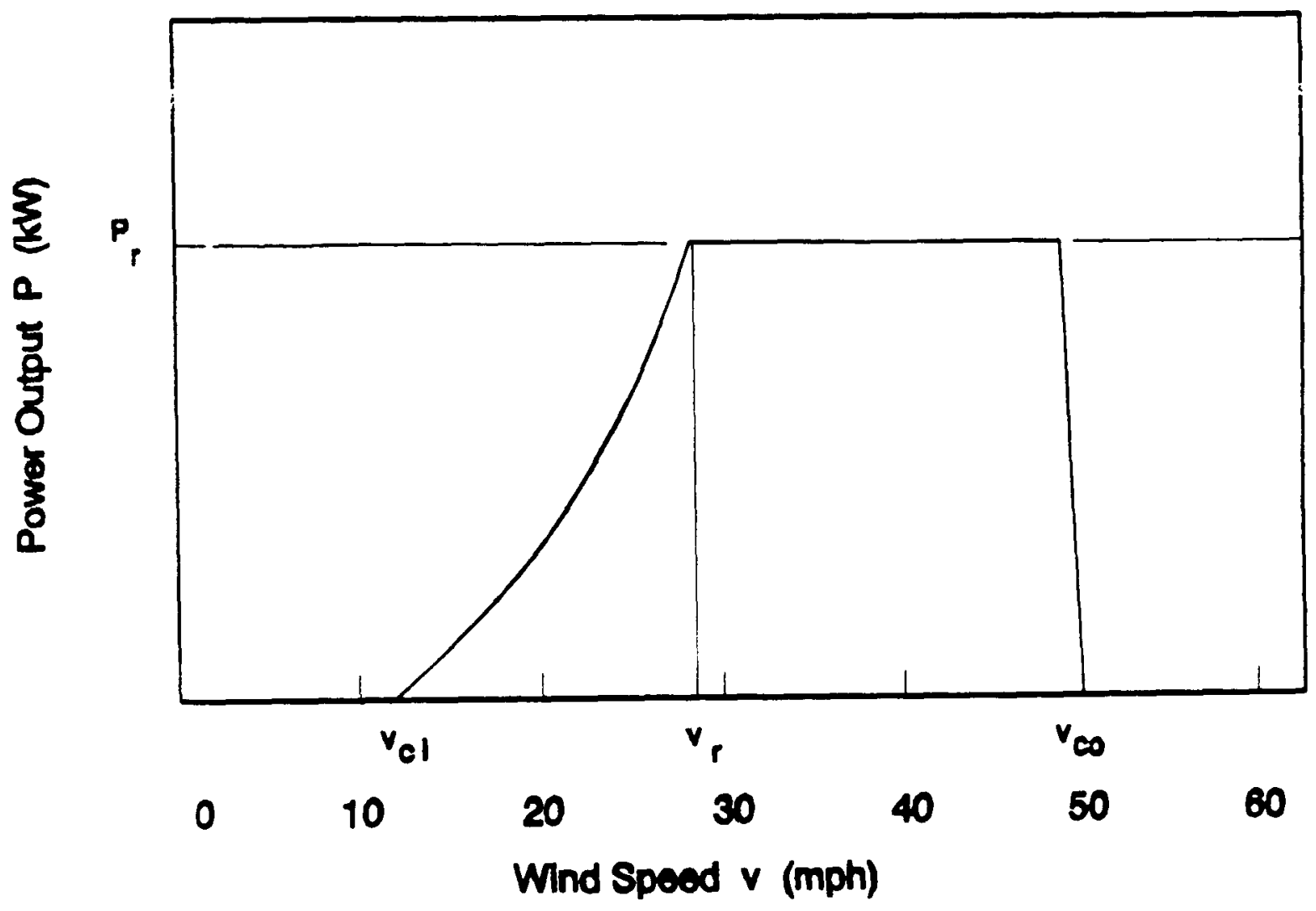

FIGURE 1-6 wind turbine power curve. 
given wind turbine and is uaeful in predicting its annual energy production. We shall use Figure 1-6 to lilustrate simplified equations that describe the conversion wind power to electrical power delivered by the wind turbine.

\section{POWER CONVERSION EQUATIOAS}

Illustrated in pigure 1-7 are the principal loads, torques, and moments resulting from an incident wind flow fleld. The relationship between the power in the wind and the resulting purver flow through the drive train can be described by simplified analytis p.pressions. The simplifying aseumption is that the incident wind flow field ean be characterized solely by the speed $v$, which is conetant in both time and space. This approach, which invoke conservation of mase plus lines. momentum and energy, yielde the simpleat representation of the wind turbine behavior and response to the wind flow field. This approach, used to derive an upper bound to the performance of a wind turbine (the Betz limit), is darived in de Vries (1979) and Eggleston (1987). As sketched in Figure 1-8, it proceede from the power associated with the wind flow described by Equation (1) and yielde the wind turbine performance relations of Equation $(2)$ :

$$
\begin{aligned}
& P_{w}=\epsilon_{2} \rho v^{3} A \\
& P_{.}=\epsilon_{1} \epsilon_{2} \quad C_{p} P_{w}=\epsilon_{1} \epsilon_{2} C_{p} \rho v^{3} A=\operatorname{const} C_{p} v^{3} A
\end{aligned}
$$

Equation (1) showe the dependence of the power in the wind incident upon a rotor of swept area $A$ as a function of the wind speed $v$. Equation (2) describes the electrical power output of the wind turbine resulting from this flow. These equations are defined in terms of the following parametere:

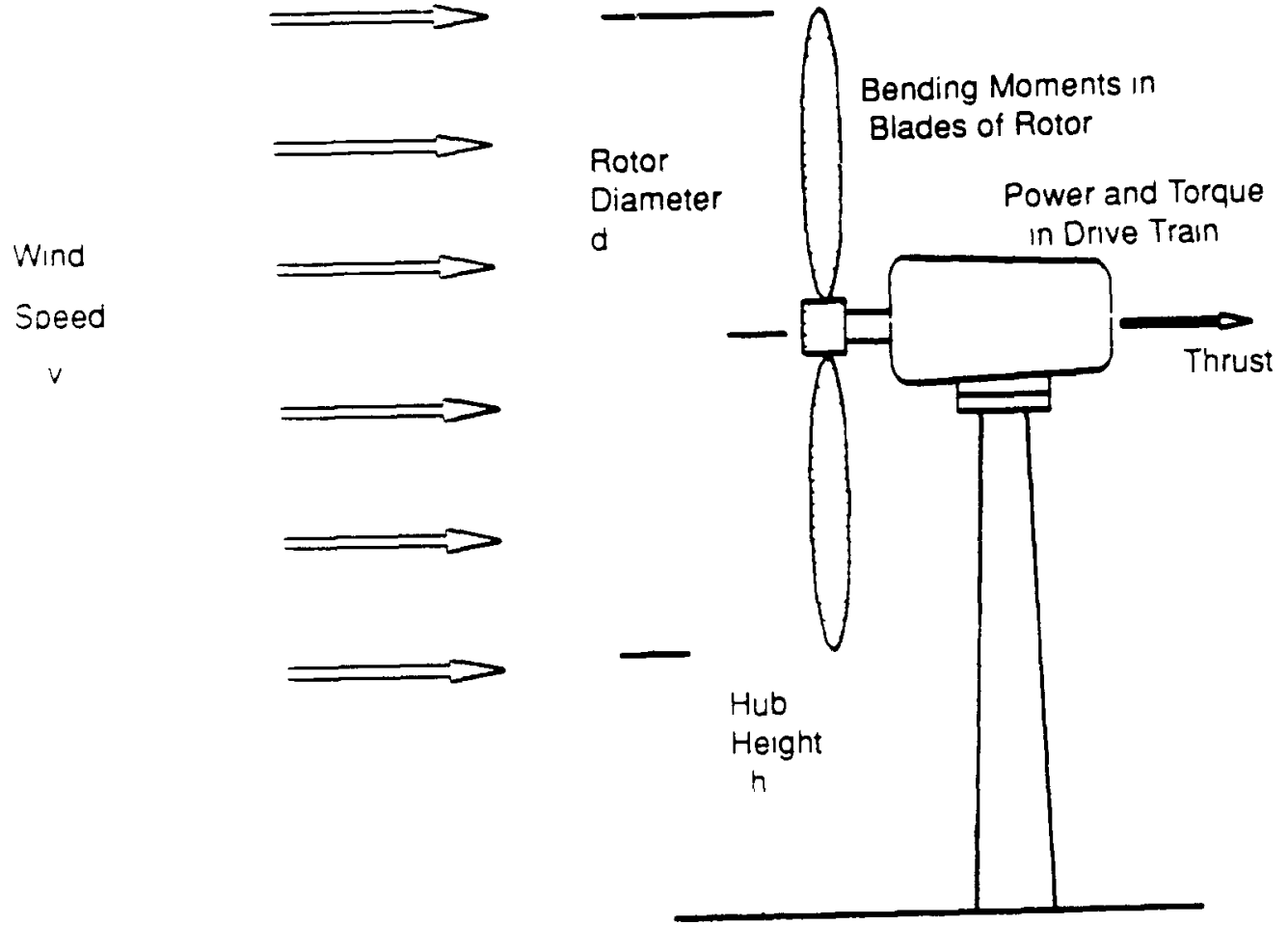

FIGURE 1-7 wind flow field and turbine loads. 


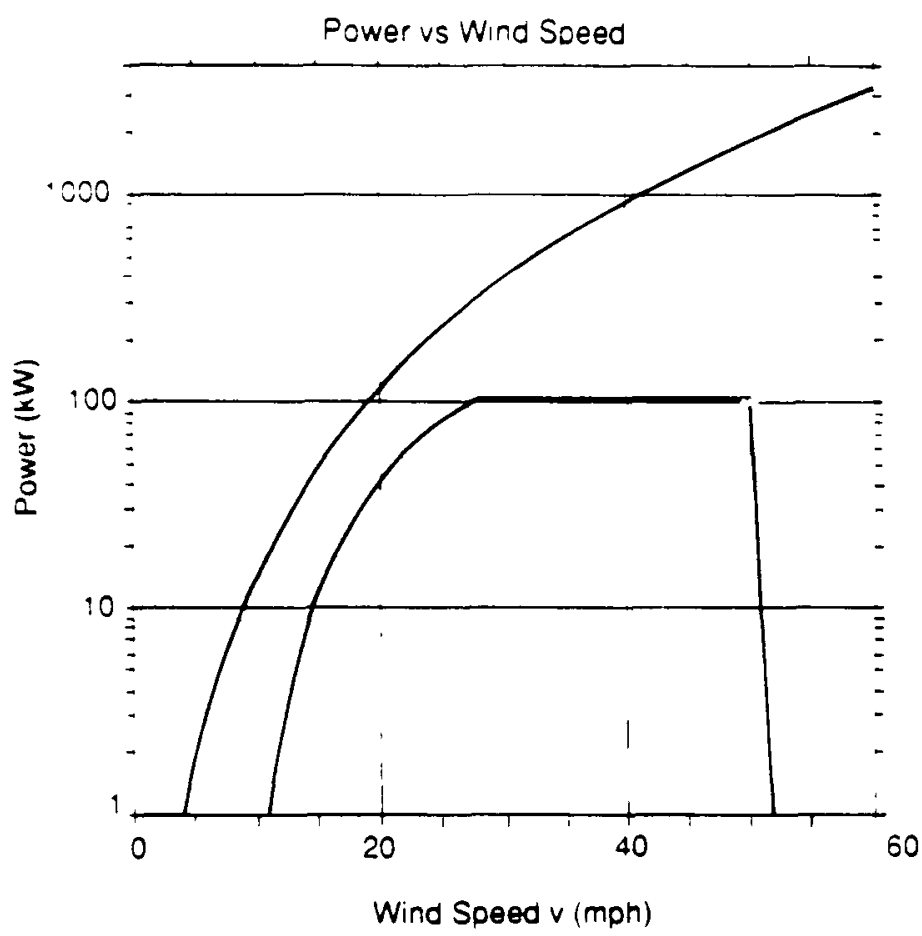

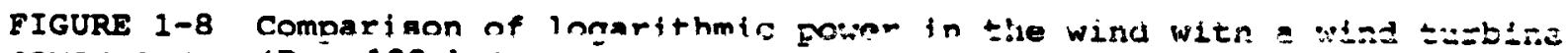
power curve $\left(P_{r}=100 \mathrm{kw}\right)$.

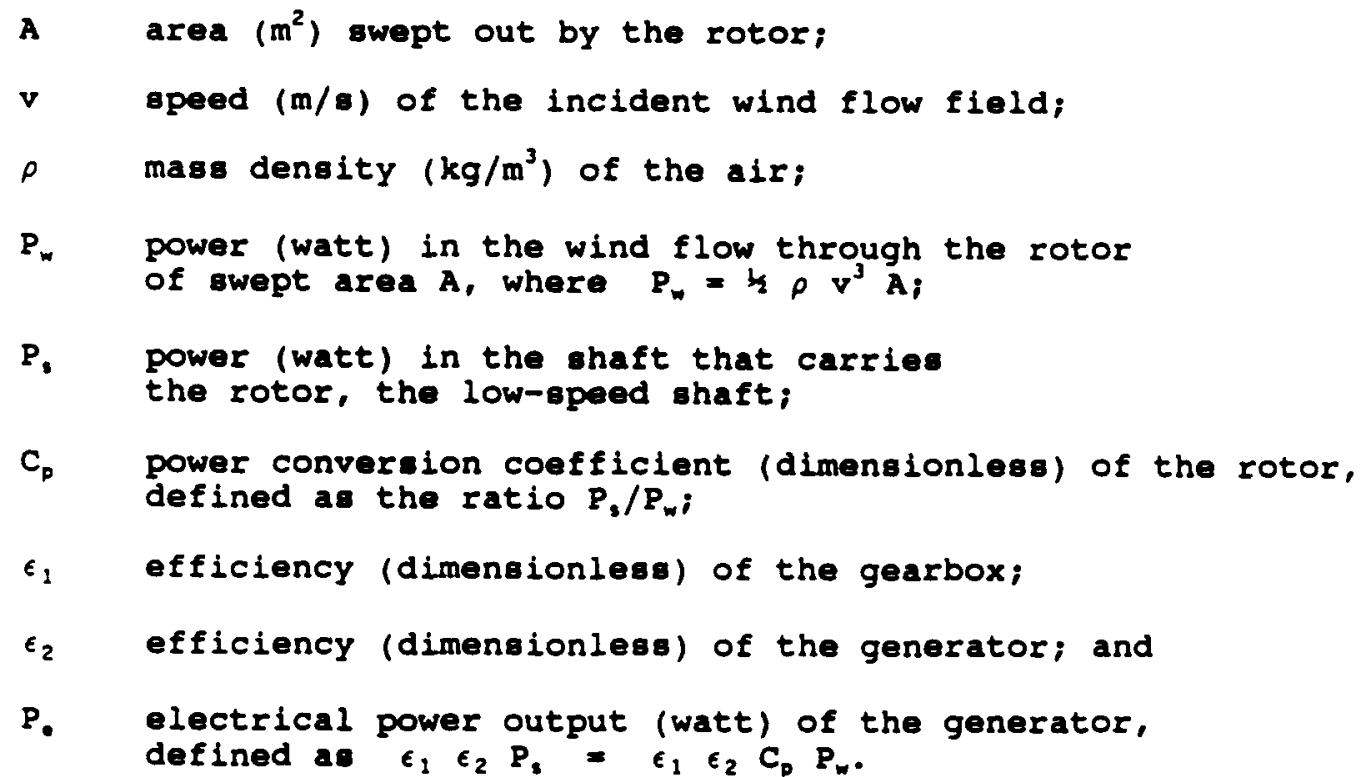

The last portion 0 Equation 12 ; highlights the important dependencies. This relationship indicates that the output power as well as the power flowing through the drive train is proportional to the cube of the wind opeed, to the area of the rotor, and to the power conversion efficiency of the rotor. Under the idealized assumptions of this model, the maximum value achievable by the rotor power conversion coefficient is 16/27, the Betz limit: 


$$
c_{p \max }=16 / 27=0.59
$$

For comparison, the better-performing wind turbine rotors achieve maximum power coefficient values in the vicinity of $C_{p}$ ectuel $=0.45$. This disparity indicates the deficiencies (e.g., neglect of angular momentum) in the model used to derive the Betz limit and, to a limited extent, the potential for improvement in blade performance.

ritese equations illustrate the major problem in wind turbine design: the sontrol of modulation of the power flow through the wind turbine dri ie trai 2. This power flow has both a steady-state, quasi-static component and a fluc "Nating component. For the time being, we continue with the assumptinn $c \dot{f}$ an incident wind flow fleld that is constant in both time and space. This allows us to focus on the power control problem.

The problem is that the power in the wind flow fleld increases as $\mathrm{v}^{3}$. since the rotor area is fixed in practically all designs. Thus, over the 10 to $50 \mathrm{mph}$ operating range cited earlier, the incident wind power increases by a factor of 125. Since the wind turbine is designed to deliver electrical power at the value $P_{r}$, a more reallstic measure of the dynamic range that a wind turbine must accommodate is given by the ratio of the wind peed at cut out to the rated wind speed:

$$
\left(v_{c o} / v_{r}\right)^{3}=(50 / 27)^{3}=6.4
$$

Thus, if the wind turbine's rated power is $P_{r}=500 \mathrm{kw}$, the cubic dependence of $P_{w}$ means that the turbine must be able to accommodate at least $3.2 \mathrm{Mw}$ of power flow in the wind.

To accommodate these power levels directly (in brute force fashion with no control actions) over the typical range of operating wind speeds would place severe economic penalty on the structural design marains of the drive txaln and tower, and foundations. The remedy is to recognize that $c_{p}$ is noi a constant but may be actively or passively controlled. To show this, we rewrite Equation (2) to show the explicit dependence of $C_{p}$ on the wind speed v:

$$
P_{*}=\epsilon_{1} \epsilon_{2} C_{p}(v) \quad P_{w}(v)=\frac{1}{\epsilon_{1}} \epsilon_{2} C_{p}(v) \rho v^{3} A=\text { const } C_{p}(v) v^{3} A
$$

Thus, an upper bound on the power and torque experienced by the drive train is achieved by modulating $c_{p}(v)$. This is done typically by either active blade pitch control or passive stall control techniques. The relationship between the power in the incident flow field and the wind turbine power output (which is functionally the same as the drive train power levels) is shown in the two graphs of Figure 1-8. These are simply plots of Equations (1) and (5) wherein a function $c_{p}(v)$ for a nominal 100-kw wind turbine has been used. The curves in this figure illustrate the need for control of power through the drive train. For the example shown in Figure 1-8, the cut-out wind speed is about $50 \mathrm{mph}$. At this wind speed, the wind turbine must accommodate the power in the wind whose value is more than six times either the shaft power or the electrical power output.

As discussed above, the wind turbine blades provide one means for control of power flow through the drive train. Several variations are used to effect this control. The two techniques currently used most widely are (1) pitch control, wherein the entire blade is rotated about the pitch axis so as to change the power extraction characteristics of the blade, and (2) fixed pitch or stall control, wherein the blade is kept at a fixed pitch angle chosen so that the blade becomes increasingly less efficient as the wind speed increases. These are illustrated in Figure 1-9 along with other variations, including partial-span pitch control, whereis oniy an ot:tboard portion of the blade is rotated about tise pitch axis; the use of ailerons; and the use of deployable tip sections to limit overspeeds. Also illustrated is a control technique seldom used thus far in wind turbine airfoils-pumped spoiling or boundary layer control. 

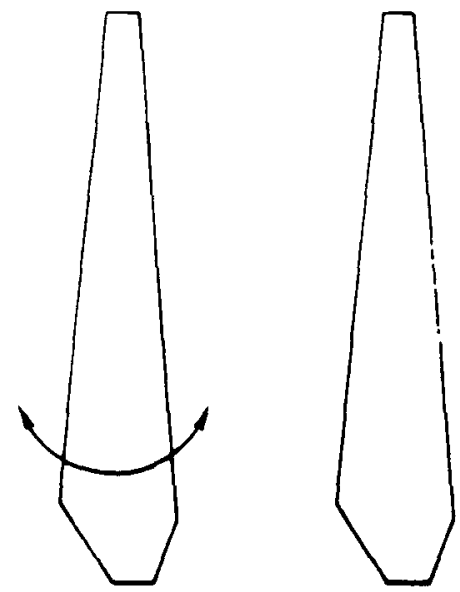

Full - span

Pitch Control

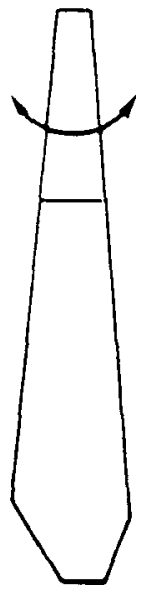

Fixed - pitch, Stall Control

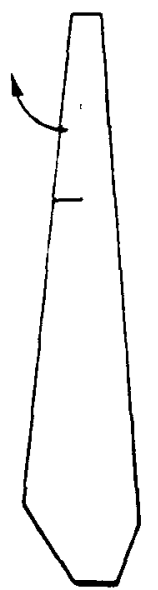

Aileron Control

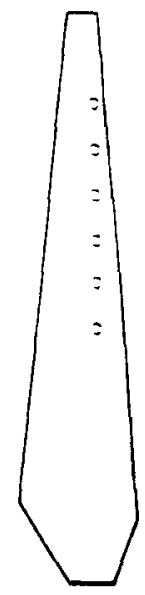

Boundary Layer

FIGURE 1-9 wind turbine blade control methods.

The discussion thus far has dealt with staady state or nonfluctuating loads experienced by the wind turbine stucture and components. There is, in addition, a fluctuating component to the wind turbine loads that arises from several sources. These include vertical wind shear, temporal and apatial turbulence, gravity, and interaction of the rotor with the tower. These sources are discussed next in the context of a more realistic description of the wind flow field.

\section{THS WIXD ENVIRONTLAT}

The discussion thus far of the interaction between a wind turbine and an incident wind flow field has assumed that the wind is constant in both $t$ ime and space over the area swept out by the wind turbine rotor. This assumption results only in the steady-state component of the loads on the wind turbine structure. More realietic deecription of the wind flow field must aleo include those characteristics responsible for the fluctuating component of the wind turbine loads. The fluctuating components are induced by both the steady-state as well as the fluctuating components of the wind. This more complete description will reveal the many ways in which real wind fields extract fatigue lifetime from the materiale of wind turbine structures. We approach this topic by reflecting on the characteristics of the wind timeseries data available to designers of the early wind turbines.

As noted previously, many of the early, first-generation wind turbines suffered major structural failures. Typicaliy, these were machines installed during the period 1981 through 1983. These failures can be attributed to several factors. Predominant among them was a lack of understanding of the dynamic =:age and attack times of the gust structure of the wind flow ileids incident upon the wind turbine. At that time the bulk of the wind data available was based upon standard meteorological practice. Both the wind speed and the wind direction values represented averages over 10 minutes or more. Further, the measurements were taken at the standard meteorological sensor height of $10 \mathrm{~m}$. 
There are fundamental disparities between these wind measurement parameters, the resulting descriptors of the wind flow fleld, and the actual wind flow field incident upon the wind turbines. Thus, it is not surprising, in retrospect, that some aspects of early designs were marginal. First, the relatively efflcient rotors of modern wind turbines respond quickly to wind changes, inducing correspondingly rapid loadings. Thus, the rotor and drive train experience torque and other transients that would not be expected from the 10-minute or longer averages of atandard meteorological measurements.

second, the center of the wind turbine rotor, the hub, sits not at a $10 \mathrm{~m}$ height but more typically at two to three tifes that height. Because wind speeds increase with height in the earth's boundary layer where wind turbines operate, wind speeds are typically highe: at the hub height relative to a $10-\mathrm{m}$ height. This increase of wind spers with height is termed vertical shear. The function often used to model vertical wind shear is given by Equation (6):

$$
v(h) / v\left(h_{1}\right)-(h / h 1)^{a}
$$

This function connects the wind speed $v(h)$ at the height h with the wind speed $v\left(h_{1}\right)$ at the reference height $h_{1}$. The power law coefficient usually chosen as representative has the value $\alpha=1 / 7$. From this relationship we see that the wind speed at height $h=20 \mathrm{~m}$ can be 1.10 times the value at the standard meteorological sensor height of $10 \mathrm{~m}$. similarly, at the height $\mathrm{h}=30 \mathrm{~m}$, the wind speed may be 1.17 times greater in value.

To appreciate the impact of vertical wind shear, consider a rotor of diameter $20 \mathrm{~m}$ eltuated at a hub height of $25 \mathrm{~m}$. Due to vertical wind shear alone, each blade during each revolution will experience a +7 percent (top) and a -8 percent (bottom) variation in wind speed. This maps into a 45 percent variation in the power density (watts/ $\mathrm{m}^{2}$ ) of the incident wind flow field.

Thus, we see that even though the vert:cal wind shear may be time independent, the vertical spatial dependence, when sampled by a rotating blade, induces cyclic loads. Cyclic loads also occur when the blades pass through any atationary wakes or bow waves sssociated with the tower. These cyclic load components are superimposed on the quasi-static loads associated with the average wind speed and power density. Gravity is of course also time independent, but again the rotating blades experience cyclic bending moments due to gravity. The influence of gravity in fact becomes a major limiting factor as wind turbine rotors become larger.

The remainder of the contributors to the cyclic load components are associated with fluctuations in the wind flow field incident upon the wind turbine rotor. These flow fields always have both a time and a epatial dependence over the rotor swept area. While we are unable to treat these fluctuating components adequately in the context of this chapter, the cyclic loads produced by these components are in practice responsible for a significant fraction of the fatigue damage experienced by wind turbine structural components.

\section{FATIGUE CYCLE ACCUNULATION}

We now can form a greatly simplified, lower-bound estimate of the accumulation of fatigue cycles as a function of operating time. The estimate serves to illustrate the very large number of fatigue cycles experienced by a wind turbine rotor and other structural components during the turbine operational lifetime.

In a comprehensive treatment, the sources of the cyclic loadings must include the temporal and spatial structures of the wind flow field itself as well as the cyclic events associated with operation of the wind turbine, that $i s$, rotation of the rotor and blades. For the purpose of forming a simple, lower-bound estimate, we ignore the cyclic loading contributions of the wind turbulence structure and pretend that the wind flow field has only a steadystate component that is constant in both space and time over the rotor swept area. 
In this estimate we thus focus on the effects of gravity, vertical wind shear, and blade-tower Interactions. Ignored are the stochastic loadinge associated with the actual turbulence structure of the wind flow field, including the passage of the blade through cells of spatial turbulence and the effects of yaw and off-axis operation. Ignored also are the fatigue damage effects of wind turbine stop-start events. Although fewer in number, their loading amplitudes and fatigue life extraction may be quite large. The lower-bound fatigue cycle estimate is thus based only on the deterministic sources of cyclic loads. In fact only one source need be considered, as all are associated with and driven by the rotationsl spaed of the wind turbine rotor. To obtain a simple result, no information about the spectrum of loadinge is included. All effects are considered to hav 3 the same unspecified loading amplitudes. Not included are the balance of the deterministic sources; the effects induced by the temporal, spatial turbulence of the wind; and any stop-start effects. All of these neglected effecta act to Increase the rate of accumulation of fatigue cycles. Thus, the estimate is a lower bound on the number of fatigue cycles accumulated over $t i m e$.

With these simplifications, the number of fatigue cycles accumulated as a function of calendar time is given by the function $N\left(t \mid \omega, k, H_{o p}\right)$, where

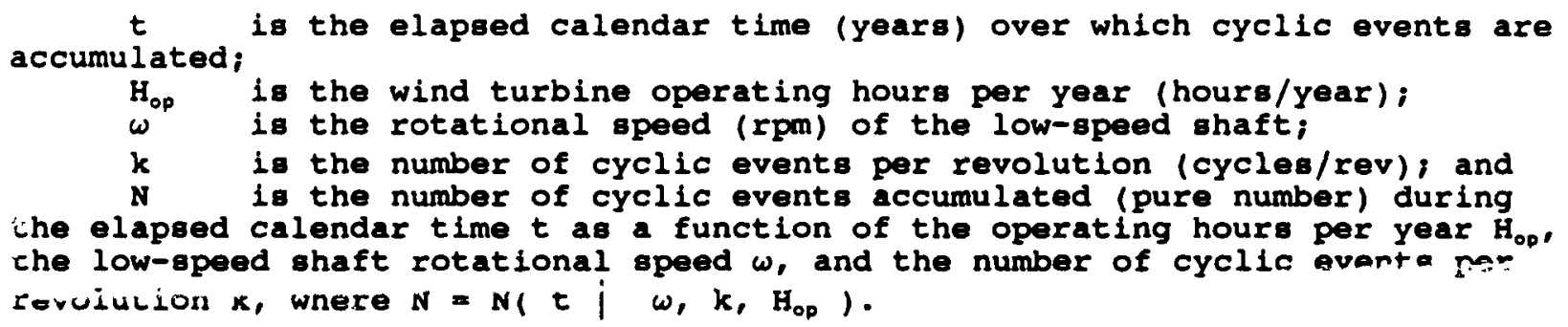

The number of operating hours depends on the wind turbine, its operating strategy, and the wind regime, but typically the value lies in the range of $3000 \mathrm{hr} /$ year to $4500 \mathrm{hr} /$ year. The value $\mathrm{H}_{o p}=4000 \mathrm{hr} / \mathrm{year}$ is used in Figure 1-10.

The range of low-speed shaft rotational speeds considered is 35 to 70 rpm. Wind turbines at the smaller end of the size spectrum typically will operate near the upper end of this range, while larger machines will operate near the lower end.

The parameter $k$, the number of cyclic events per revolution, typically can take on the integer values $k=1,2$, or 3 . Given the present simplifications, from the perspective of a blade, this parameter has the value $k=1$. Similarly, for the cyclic events experienced by the low-speed shaft, this parameter is equal in value to the number of blades. The value $k=1$ is used in Figure 1-10.

For the parameters and their units as defined above, the cumulative number of fatigue cycles is given by the numerical expression of Equation (7):

$$
N=60.0 k \omega H_{o p} t
$$

This function is illustrated in Figure 1-10 as a function of the elapsed calendar time $t$. The parameters $k$ and $H_{\text {op }}$ were chosen to have the values $k=$ 1 and $H_{o p}=4000 \mathrm{hr} /$ year. Curves are given for each of the low-speed shaft rotational speeds of $35 \mathrm{rpm}$ and $70 \mathrm{rpm}$. This estimate shows that the number of fatigue cycles accumulated reaches $10^{7}$ very quickly, in about a year's time. The number of fatigue cycles reaches $10^{8}$ after about 10 years of 


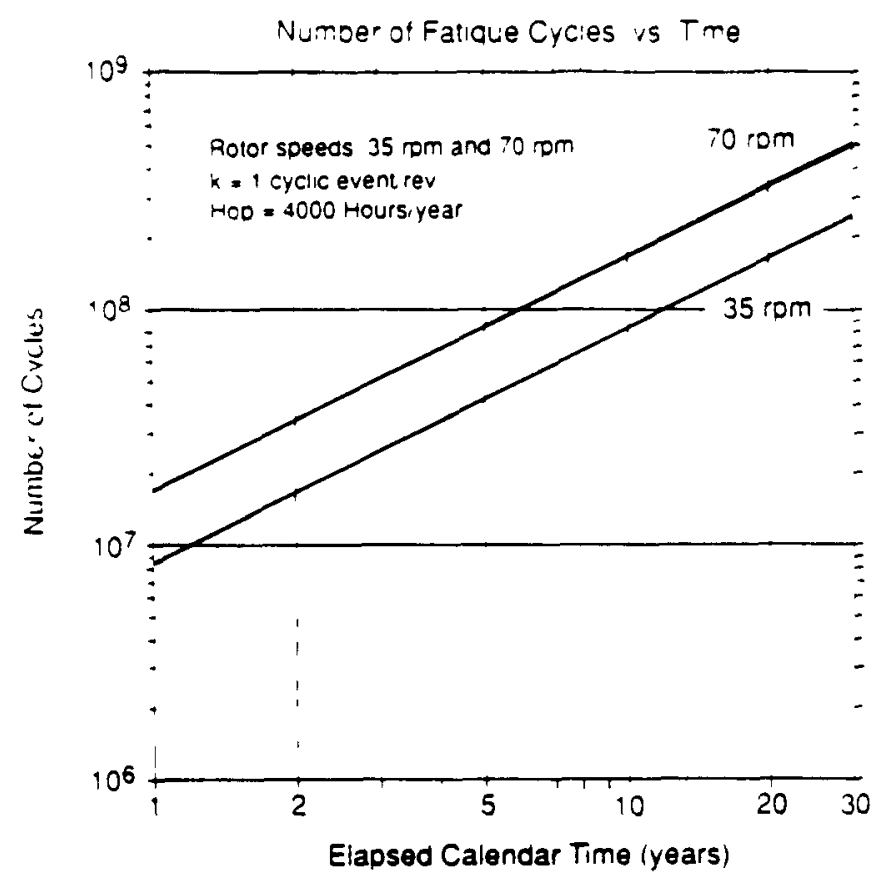

FIGURE 1-10 Accumulation of fatigue cycles.

operation. By 20 to $3 \mathrm{C}$ years of operation (typically the expected lifetime of wind turbines), the cunulative number of fatlgue cycles lies in the range of $10^{8} \div=10^{9} .1$

Th1s extrame accumulation of fatigue cyclen with such a large amplitude range is unequaled by practically any other mechanical or structural oystem. Further, economics are a severe conetraint for wind turbine systems. Wind turbine syotems must operate competitively under an economic ceiling associated with other means of generating power. As a result, the three cost components of wind turbine economics--capital cost, maintenance cost, and overhaul cost--are subject to stringent and demanding requirements. Increased knowledge about the properties of materials can contribute in a major way to the advancement and further utilization of this large-scale, renewable energy source.

${ }^{1}$ This analysis shows that fatigue data at $10^{\circ}$ cycles are needed. However, the magnitude of the task of performing fatigue teats to $10^{\circ}$ cycles should not be underestimated. Test frequencles are 1 imited to around $20 \mathrm{~Hz}$ for fiberglass materials, which means a single test to $10^{8}$ cycles would require about 100 days and $10^{\circ}$ cycles would require about 2 years. When difficulties with test equipment failure and power interrution were considered, fatigue testing to $10^{9}$ cycles is a major undertaking.

Although we have called for fatigue teat data at $10^{9}$ cycles in a number of places in this report, this is an idealized reguirement. Much guidance on design and materials selection would be provided by test data in the $10^{7}$ to $10^{8}$ cycle range. 


\section{REFAREYCES NWD BIBLIOGRNPEY}

California Energy Commisiion. 1984. Wind Energy: Investing in Our Future. Revised Edition, California Energy Commission, Sacramento, California, March. (See also Rashkin and Ringer below.)

California Energy Commission. 1985. Wind Allas. California Energy Commission, Sacramento, California, Apri'.

de Vries, 0. 1979. Fluid Dynamic Aspect $x$ of Wind Energy Conversion. National Aerospace Laboratory, The Netherlands, sponsored by the NATO Advisory Group for Aerospace Research and Development, AGARD-AG-243, July. (available from the National Technical Information Service as NTIS AD/A076315.)

Eggleston, D. M., and F. S. Stoddard. 1987. Wind Turbine Engineering Design. Van Nostrand Reinhold Company, New York.

Electric Power Research Institute. 1986. Proceedings of a Workshop on Prospects and Requirements for Geographic Expansion of Wind Power Usage. EPRI report AP-4794, November. (Reeults of a conference that examined the potential for use of wind power stations in regions of the United states beyond California. See also Solar Energy Research Institute Wind Atlas entry below.

Freris, L. L., ed. 1990. Wind Energy Conversion Systems. Prentice-Hall, Englewood Cliffa, New Jersey.

Gipe, P. 1989. Wind Energy Comes of Aqe in California. Paul Gipe

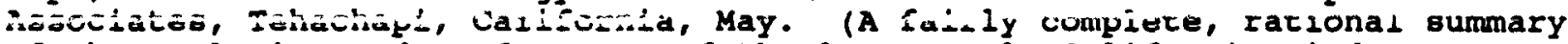
of the evolution and performance of the large-scale california wind power stations, including comparisons with other countries and potential.)

Hohmeyer, O. 1988. Social Costs of Energy Consumption: External Effects of Electricity Generation in the Federal Republic of Germany. Document EuR 11519, Commission of the European Communities, Springer-Verlag, Berlin (English). (Excellent treatise by a staf member of the Fraunhofer Institute of the direct and indirect costs of various classes of energy sources.)

Lynette, R., \& Associates, Inc. 1985. Wind Power stations: 1984 Experience Assessment. Interim Report, Research Project RP 1996-2, Electric Power Research Institute, Palo Alto, California, January. (One of a series of reports sponsored by EPRI that tracked the operations and maintenance performance of a large number of California wind power installations.)

Office of Technology Assessment, U.S. Congress. 1985. New Electric Power Technologies: Problems and Prospects for the Nineties. OTA, Washington, D.C., February.

Pepper, J. 1985. Wind Farm Economics from a Utility's Perspective. Pacific Gas \&lectric Company, San Francisco, California, August. (One of a series of examinations and comparisons of wind farm economics by a utility economist. Later publications appear under the name Janis Pepper-slate, Enertron Consultants, Los Altos, California.)

Pollock, C. 1986. Decommissioning: Nuclear Power's Missing Link. WorldWatch Institute, Washington, D.C., April. (One of a series of papers published by the WCridwatch Ingtitute on the environmental impact of verioug means of power generation.) 
Rashkin, S. 1988. Results from the Wind Project Performance Reporting Sygtem: 1987 Annual Report. California Energy Commission, Sacramento, California, August. (One of a series of quarterly and annual reports that track the energy production performance of the callfornia wind power stations.)

Ringer, M. 1984. Relative Cost of Electricity Production. California Energy Commission, Sacramento, California, July.

Solar Energy Research Institute. 1987. Wind Energy Resolrse :tlas of the United states. Solar Technical Information Program, Report Dos/CH 10093-4, SERI, Golden, Colorado, March. (Excellent treatise on the lor.t lons and quality of wind resources in the United states suitable fc: wind power instaliations.)

Solar Energy Research Institute. 1988. Wind Energy Technical Reading List. Solar Technical Information Program, Report SERI/SP-320-3400 DE88001193, SERI, Golden, Colorado, May. (Bibliography containing references to technical reports from the federal wind research program.)

Stoddard, F. S. 1990. Wind Turbine Blade Technology: A Decade of Lessons Learned, Presented at the World Renewable Energy Congress, Reading, Untted Kingdom, september.

Sutherland, R. J. and R. H. Drake. 1984. The Future Market for Electric Generating Capacity: A Summary of Findings. LOs Alamos National Laboratory, Los Alamos, New Mexico, December. (Among other topics, portrays the component of capital cost attributable to the cost of funds used during construction of a nuclear power station, prior to its becoming a performing, operational asset.)

Utility Data Institute. 1988. 1987 Production Costs: Operatir.g SteamElectric Plants. Utility Data Institute, Washington, D.C., October. 


\section{STRUCTURAL LOADING CHARACTERISTICS}

Among wind turbine failures, those assoclated with structural dynamice are most common. Stresese in the blades oscillate, particularly at connections of the blade with other components of the wind turbine, leading to fatigue fallures. These failures are not adequately predictable based on the current atate of the art. The reasons for this are (1) the inability of current methods to accurately characterize the loading, (2) inadequate response prediction methodology, and (3) a paucity of material teat data at the high-cycle numbers.

In general, there are at least four ways to deal with fatigue-related problems in a structure:

1. improve the material characteristics so that the structure will sustain higher cyclic stresses,

2. lower the operating stress levels by altering the structural/ configuration design,

3. improve the manufacturing process so that quality variations are rinimized, and

4. make the structure so inexpensive to manufacture and maintain $t h=t$

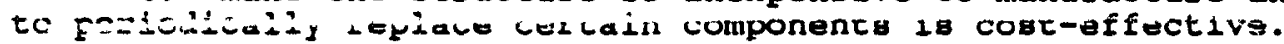

This chapter we concentrates on the second approach--a type of aeroelastic tailoring. Shirk et al. (1986) presented a definition for aeroelastic tailoring and suggested that it become the standard: Aeroelastic tailoring is the embodiment of directional stiffness into an aircraft otructural design to control aeroelastic deformation, static or dynamic, in such a fashion as to affect the aerodynamic and structural performance of that aircraft in a beneficial way." They also pointed out that parallels exist between aeroelastic tailoring and active control methodology. Although active control focuses primarily on the control law, there is nothing to prevent the structure from being modified to assist the active controller in its task. similarly, even in the absence of an external energy source, aeroelastic tailoring itself uses a form of control law to modify the behavior of a structure.

In addition to being a form of passive control, structural tailoring provides a method to optimize the performance of actively controlied gtructures. Shirk et al. (1986) also mentioned that the effective integration of active controls and structural stiffness is another area of potential reward. The aeroelastic benefits derived from deformation control due to structural tailoring and the movement of actively controlled surfaces each have limits. They suggested that the synergistic effect derived by the optimum interaction of each be explored. Issues of controllability and observability of aircraft dynamics are strongly influenced by the flexibility of the structure. Also, simultaneous optimization of control gains and structural properties often becomes prohibitively expensive for large degrees of freedom, and physical insight is often lost in the resulting control law. Belvin and Park (1988) undertook a pioneerina gtudy along this direction. They presented a method ror optimization of closed-loop structural systems, lisiny such structural tailoring schemes as tailoring the thickness to maximize the model stiffness of selected modes. Results were obtained for some simple structures, including a beam and a truss beam, showing the 
importance of structural tailoring to increase dynamlc performance and to reduce the control effort.

Armanios et al. (1990) explored the benefits of tailoring the macro- as well as the micro-structure; that is, they examined altering ply stacking sequence, fiber orientation, and blend of material plies, to contain and resist damage in flexible structures. One of their purposes was to demonstrate that damage tolerance can be designed into a structure. It was shown that for a generic damaged ply model, which includes microcracking, delamination, and fiber fracture and their interaction, damage modes alter the stiffnesses of the oructural component at the damage ite. Therefore, redistribution of j.cral stiffnesses could be used to enhance toughness. Rehfleld and $A:$ ilgan (1987) showed that in closed-cell blades additional couplings arise. uther than those designed in, which must be accounted for. These "parasitic" couplings are extension shear (accompanies bending twist) and bending shear (accompanies extension twist). With these additional couplings the analysis will predict structural stiffnesses smaller (more flexible) than without them.

In light of tine above, structural, elastic, and aeroelastic tailoring concepts are promising for active/passive control of flexible structures. Therefore, development of an interdisciplinary analysis methodology for design, optimization, and control of structures would be useful. Haftka and Kamat (1989) developed an approach for simultaneous nonlinear analysis and optimization of structures. This starting analysis shows how integrated interdisciplinary approaches can lead to more understanding as well as computational benefits.

Various wind turbine configurations have been studied and tried, such as horizontal axis wind turbines (HAWTs) vergus vertical axis wind turbines (VAWTs), stall- vergus pitch-controlled turbines, fixed-vergus free-yaw turbines, up- versus down-wind rotors, constant versus variable rpm, highsolidity slow runnino varsus low-solidity fast running, stiff versus flexible.

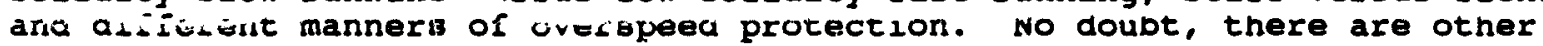
configurations not yet tried (Watson, 1989) or even conceived. A few attempts have been made to study the gains that could be made by elastic tailoring (e.g., Karaolis et al., 1987). These studies did not lead, however, to significant changes in the way wind turbines are designed.

There are many questions to be answered concerning the design of wind turbines. Cost ie one of the primary considerations. Some very inexpensive methods for building blades exist, but will they produce practical blades as far as performance is concerned? For example, it is known that pultrusion can produce blades at a fraction of the cost of present blades. One restriction of such blades, however, is that they must be spanwise uniform. Given the present structural design of HAWTs (i.e., without elastic coupling), this is known to be an energy-inefficient design for aerodynamic reasons. No research has been done, however, to indicate whether such losses could be compensated for by elastic tailoring, thus making pultrusion a practical manufacturing technique. The position of the committee is that the impact of future research on modeling and the design process will be negligible unless configuration, aerodynamic structural design, and materials properties issues are considered together.

\section{IOAD CHARACTERI ZATION}

To successfully design a wind turbine blade structure, it is necessary that a representative model of the system loads be developed. While not necessarily being able to accurately predict these loads, this model should predict realistic peak-to-peak stress levels and oscillatory frequencies. The mechanisms for these stress reversals are reasonably well understood. Blades are exposed to relatively high levele of tyrbulence and random gusts in the air and, in some configurationa, cower shadow effects. These, along with steady and quasi-periodic aerodynamic loads due to steady components of wind and vertical wind shear, coupled with steady centrifugal forces and periodic gravitational forces (in HAWTs) from the rotation create distributed loads along the blades. These distributed loads, in turn, have steady, periodic, and random components. 
The steady, periodic, random loads lead to static and dynamic deformations of the blades; these deformations also consist of steady, periodic, and random components. All these distributed spanwise loads lead to oscillating stresses in the blades, which vary spanwise and over each cross section. Because of the strong influence of aerodynamics and structural dynamics on the internal loads, this problem is very much interdisciplinary. One cannot choose a material for these machinus "out of context" (i.e., without considering the aeroelastic rsper.s of the problem). For additional discussion of the load characterization, wee de Vries (1979).

\section{BTNDE FAILURS EXPERIEACE}

At the blade root, the oscillating stresses are passed into the rotor hub and certain harmonics are passed through the shaft into the tower. Many failures involve the connecting structure between the blade and the hub. Others involve fallures of the steel connectors between the main part of the blade and the bearing, which allows for pitching of the outboard section in stall-controlled machines. Still others involve subassembly joints in the main blade component and chordwise cracking of the blade shell.

In order to put blade failure experience in perspective, it should be noted that the preponderance of such failures have occurred at joints and other discontinuities in the rotor structure. There is a category of blade designs and type that has experienced a high failure rate principally due to defects in manufacture and design. Other manufacturers of blades, however, have not experienced these failures. At present the oldest blades have been in service for about 8 years. Because of a lack of knowledge of fatigue properties and performance at laroe n!mbers =f cycles, it is expected that tnese blades will be replaced atter about 10 year of service--far short of their design life of 30 years.

As a side note, relative advantages and disadvantages of pitchcontrolled versus stall-controlled wind turbine designs are not well understood. While this is not a materials issue, per se, such configuration parameters do influence the structural design, which is, in turn, closely coupled to the material selection. For example, U.S. Windpower blades are of the pitch-controlled variety and have exhibited relatively high reliability based on in-field operations. While all the factors influencing reliability are not clear, configuration will certainly have an impact. A similar statement can be made concerning HAWT versus VAWT configurations. VAWT blades have some advantages concerning loads since they are not subject to once-perrevolution gravitational stress reversals. They do, however, experience a once-per-revolution aerodynamic loading reversal. Considering all the aspects of design, however, one cannot rule out any of the well-known configurations at this time.

High-cycle fatigue is not as serious a problem for most applications in the aerospace industry as it is for helicopters. Some of the same problems in helicopters are also present in wind turbines. Part of the fatigue problem with wind turbine rotors is manifested as leading and trailing edge cracks that form as the blades undergo continual use. Research has shown that, because early design efforts focused almost entirely on blade flapping moments and gave inadequate attention to inplane (chordwise or lead-lag) moments, these cracks were not anticipated (Conover and Young, 1989). Although poor quality control is a factor in the development of these cracks, it would appear that design procedures that do not take all necessary aspects into account are major contributors. Indeed, extant response codes (such as FLAP [Wright et al., 1988)] orovide neither in-plane bending nor torsional contributions to the stress prediction. With composite blades, which typically have three-dimensional stress fields, this is far from adequate.

\section{LESSONS FROY HELICOPTER EXPERIENCE}

The helicopter industry has taken a rather conservative approach to changing the structural and configuration design of the rotor/hub (by this we 
refer to the inboard section of the blade, the blade/hub attachment and pitchcontrol hardware, and the hub itself). Conventional articulated helicopter rotor configurations have flap and lead-lag hinges and pitch bearings. They also require auxiliary mechanical dampers to dissipate energy from ground resonance mechanical instability. Serious talk of so-called hingeleas and bearingless rotors began about 25 years ago, along with hopes of eliminating the mechanical dampers. The actual development and use of such rotors, however, has been slow in coming. Nevertheless, the relatively rlean bearingless rotor designs that are now being adopted are viry cilferent from the conventional articulated rotor designs of 10 to 20 yearz as 2 . The weight, parts count, and drag of the rotor/hub have been significa.itly I-tuced. On many systems the mechanical dampers have been replaced by alastomerlc restraints. The number of components that have to be replaced periodically has been reduced, and the performance and flying qualities of the newer rotorcraft are better (Ormiston et al., 1988). The new designs did not come without cost, however, and any significant change in the way wind turbines are designed will likely require years of research.

Helicopter rotor blades spin at a relatively high angular speed and, although flexible, are effectively stiffened by centrifugal forces. Because of the free rotation in flap and lead-lag directions at the root in articulated rotors, a large component of their motion is as a rigid body. Loads in these configurations are transferred through the hub into the fuselage primarily as shear forces at the roots of the blades. Blade aeroelastic instabilities can be avoided by properly placing the axis of masa centers of the blade. The analyses of 20 years ago used in designing these blades were, for the most part, linear.

When hingeless and bearingless helicopter rotors began to be designed, many new problems surfaced. First, the loads and vibration problims multiplied because of the nonnegligible hub moments. Sersnd; $=$ ritaber of newly observed and sometimes catastrophic instabilities surfaced that had to be avoided. Because of the possibility of these instabilities, the process of designing the blades became more complicated. In fact, to accurately predict the behavior of such a rotor blade, highly sophisticated structural analyseg are required. This is due to a number of factors:

1. Effectively cantilevering the blade root into the hub brings root stresses into the boundary value problem that governg the blade deformation. When combined with already strong axial and lateral loads, these stresses make the problem geometrically nonlinear. Conventional rotor analyses were linear. Early hingeless (not necessarily bearingless) rotor analyses were nonlinear, although they allowed only for moderate rotations due to deformation. The nonlinearity implies that even the linearized atructural dynamics or aeroelasticity analysis (typically carried out in terms of assumed modes) must be conducted relative to a deformed state. This state can only be determined from a nonlinear analysis.

2. In order to control the blade's pitch and reduce the root stresses, a portion of the blade near the root must be very flexible. Because of the wide range of pitch angles through which the outboard portion of the blade must be rotated, rotations of the inboard portion due to deformation may be large. That is, a moderate rotation analysis may not be adequate. This also implies that even the types of assumed modes needed for rapid convergence may be functions of the deformed state of the blade--greatly complicating the analysis.

3. The hardware necessary to control the blade pitch introduces additional load paths (see Fiaure 5-3). There load paths render the structure staticiliy inieterminate and disallow certain simplifications that can be made in a determinate structure.

In addition to these complications, one must also account for the use of composite materials in modern blades. This entails several more aspects of the analysis that must be upgraded. Most blade models are beams of the classical type in which transverse shear deformation is assumed to be 
negligible. It is well known that shear deformation must be accounted for in composite blades.

Also, with blades made of 1sotropic materials, imple engineering beam theories will usually oufflce in the determination of beam et iffness. Except for torsional ot iffnese, the stiffnese conetants are imply integrale of modulus-welghted geometric quantities over the crose section. The reader is rominded that theae integrals fall out from St.-Venant (Interior) elaeticity solutions for the beam that implicitly include the effects of sectional deformation (wazping) in and out of the crose-section plane. When shear deformati in is included, solution of the flexure problem of St.-Venant is required. This problem is of the same order of difficulty as the st.-Venant torsional frehles, and both require some sort of computer solution for irregular-section geometries.

When we generalize this to beams made from anisotropic materials, all of the stiffnese conetants depend on the in-and out-of-plane warping in complicated ways; and, in order to determine the equivalent-beam elastic constants, it is neceseary to solve the st.-Venant (Interior) problem for inand out-of-plane warping with the recognition that these warping dieplacements are coupled. Only for single-celled, thin-walled sections can this be done with sufficient accuracy without a computer. For further discussion of this, see Giavotto et al. (1983) and Atilgan and Hodges (1990). This implies that in order to analyze composite blades, it 1s necessary to undertake two separate analysea: one to get the section properties and one to use them in a response analysis. In addition, if etresses over the blade uection are desired, additional information concerning the strese dietribution for the applicable types of loading may need to be dertved. See Figure 2-1. There are a varlety of computer-based blade analyais methoda in existence that are applicable to the wind turbine problem (Table 2-1). (See, for example, Rehileld, 1985 [analytical]; Bauchau, 1985; Xomatka, 1986, Borri

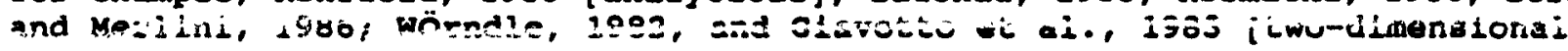
or quasi-chree-dimensional]; and Lee and stemple, 1987 (three-dimensional]). The quasi-three-dimensional methods are solved by discretization of the cross-

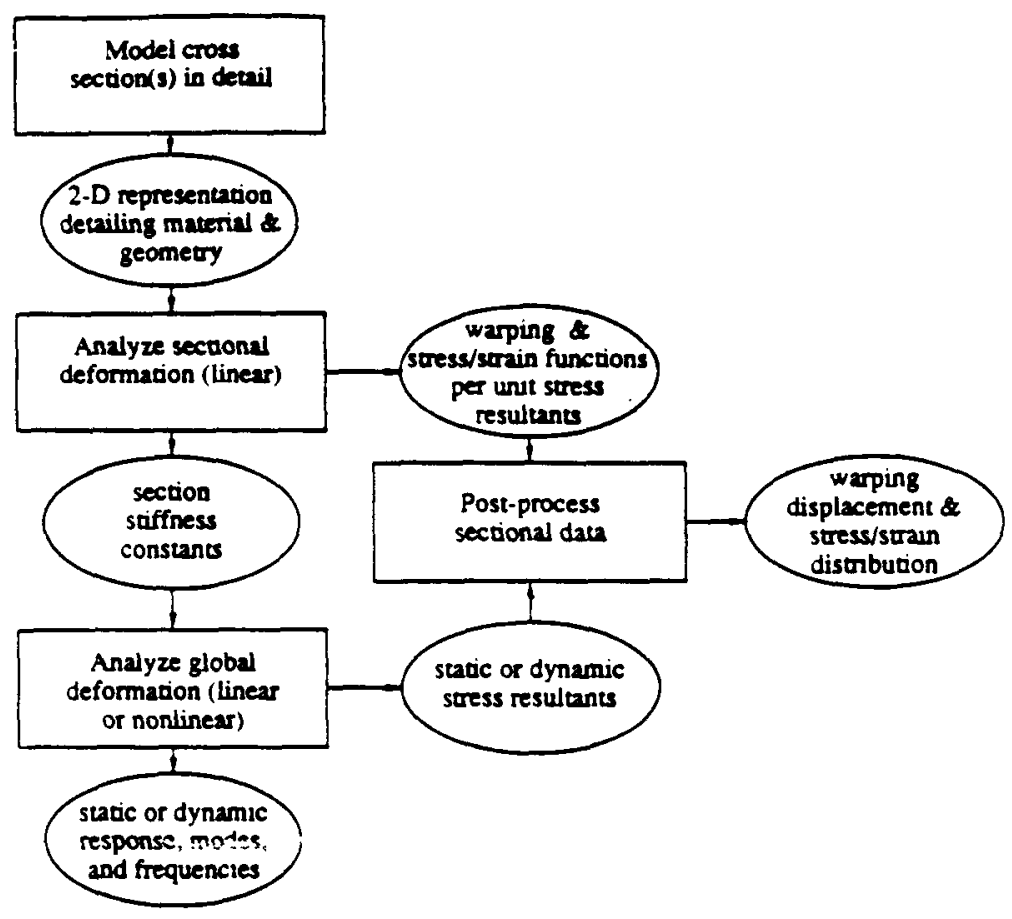

FIGURE 2-1 Process necessary to analyze composite blades. 
TABLE 2-1 Blade Sectional Analysis Codes

\begin{tabular}{|c|c|c|c|c|}
\hline $\begin{array}{l}\text { Principal } \\
\text { Investigator (8) }\end{array}$ & $\begin{array}{l}\text { Name } \\
\text { of Code }\end{array}$ & Restrictions & $\begin{array}{l}\text { Country } \\
\text { of Origin }\end{array}$ & $\begin{array}{l}\text { Analysis } \\
\text { Type }\end{array}$ \\
\hline Bauchau & - & $\begin{array}{l}\text { no i..-plane } \\
\text { warping; } \\
\text { thin ... alled }\end{array}$ & U.S. & $\begin{array}{l}\text { 2-D finite element } \\
\text { (quasi-3-D) }\end{array}$ \\
\hline $\begin{array}{l}\text { Giavotto, } \\
\text { Borri, et al. }\end{array}$ & ANBA & $\begin{array}{l}\text { no restralned } \\
\text { warplng }\end{array}$ & Italy & $\begin{array}{l}\text { 2-D finite element } \\
\text { (quasi-3-D) }\end{array}$ \\
\hline Kosmatka & - & $\begin{array}{l}\text { uniaxial stress } \\
\text { fieldi no re- } \\
\text { strained warping }\end{array}$ & U.s. & $\begin{array}{l}\text { 2-D finite } \\
\text { element }\end{array}$ \\
\hline Lee & - & $\begin{array}{l}\text { no in-plane } \\
\text { warping; } \\
\text { simple section } \\
\text { geometry }\end{array}$ & U.S. & $\begin{array}{l}\text { 3-D finite } \\
\text { element }\end{array}$ \\
\hline Rehfield/Nixon & TAIL & $\begin{array}{l}\text { no in-plane } \\
\text { warpinc; } \\
\text { thin-we? led; } \\
\text { uniaxial oerese }\end{array}$ & U.S. & analytical \\
\hline wörndle & - & $\begin{array}{l}\text { uniaxial stress } \\
\text { field; no re- } \\
\text { otrained warping }\end{array}$ & Germany & $\begin{array}{l}\text { 2-D finite } \\
\text { element }\end{array}$ \\
\hline
\end{tabular}

section plane by finite elements in order to obtain the properties. (The term quasi-three-dimensional indicates that the axial coordinate is handled analytically.) They are far more efficient than a three-dimensional finite element model would be. Unfortunately, however, most of these methods do not treat all aspects of the problem, and some of these methods are too complex for a personal computer (PC). Rehfield's method, the simplest of these methods, was programmed for a PC by Mark Nixon (NASA, Langley). Although Rehfield's analysis takes restrained warping into account, Nixon's code does not. Explicit treatment ofin-plane warping (Poisson contraction and anticlastic deformation) is circumvented by the uniaxial stress assumption. However, Rehfield does not consider initial twist and curvature, which are important for wind turbines. Also, the shear stiffnesses obtained by this code are not sufficiently accurate because of the neglect of out-of-plane st.-Venant flexural warping. Bauchau, Kosmatka, Lee, and wörndle have codes that are more general than Nixon's, but they are also considerably more complex. The committee knows of no industrial users of Kosmatka's and Lee's codes in the In-:ted states. Förndle's code was developed in Germany and, although it. is used by the German helicopter company Dectsche Aéssopace (previously MBB), the committee knows of no users in the United States. Bauchau's code is used in the U.S. helicopter industry. It accounts for restrained warping and initial twist and curvature. It is restricted, however, to the thin-walled case and yields results that are comparable to those of Rehfield's analysis (Bauchau et al., 1987).

The code of Giavotto et al. (1983) (called ANBA) was developed in Italy. Although it is the most powerful of all these codes, it does not account for 
restrained warping (probably not an important 1 imitation for wind turbine blade sections). It is also considerably more computationally intensive than the others, requiring 20 minutes of CPU time (for large problems) on a MAC II running $\mathrm{A} / \mathrm{UX}$. It is commercially available in the United States. While it is evident that there are PC-based tools for determining blade elastic constants, to date there are no codes that incorporate the beam elastic constants into a fully coupled aeroelastic response code for wind turbine blades. The distinction here is very important, and both the determinetion and the incorporation must be compatible in kinematical and onciutrical assumptions (e.g.. if pretwist is to be taken into account, thes botil the sectional and response analyses must include its effects). For ajditic.inl references on the subject of composite blade modeling, see Hodges (1930).

These couplings are very important in the response analysis. Modern fixed-wing aircraft designs have made use of the properties of composites to tailor the structure so that certain performance or stability criteria are met or enhanced. An example of this is the $x-29$ forward swept wing aircraft. Without composites, design of this airplane would not have been possible (see Shirk et al., 1986, for a review of tailoring). With both helicopter and tilt-rotor blades, various investigators have proposed these types of passive tailoring schemes to increase stability margins, decrease weight, avoid high stresses in some localities, and increase efficiency. The chief mechanisms for tailoring in these contexts are couplings between bending and twist deformation modes and between extension and twist deformation modes. For example, Ormiston et al. (1976) incorporated two coupling parameters in a rotor blade, one of which is equivalent to a bendingtwist coupling and the other to an elastic coupling between the flap and leadlag directions. They showed that one could then passively extract some of the damping coming from the air that is naturally present in the heavily damped flap mode and put it where it is needed--in the others:-5 isakly damped leadlag noae. Theoretical and experimental work indicated that the lead-lag damping could be increased by an order of magnitude without noticeably affecting the flap damping.

Current wind turbine rotor blades are quite stiff and heavy relative to helicopter blades. Part of the reason for this is to prevent tower strikes. Given that wind turbine rotors must carry large edgewise gravity bending moments, which argues for using their large planform dimensions to actively carry those moments, it may be that hinges are the most practical way to get large pitch effects with such large and stiff rotor structures. Flap bending/twist coupling could provide small outboard blade angle changes to help a constant-rpm machine retain optimum efficiency over the low wind range, but variable rpm provides a much more effective and versatile way of doing this, and it is on the near horizon. Using extension-twist coupling to provide overspeed limitation for fixed-pitch rotors may be the most potent near-term use of elastic tailoring, as it could simplify rotor construction while removing a lot of rotor cost and also be much more reliable than current mechanical latch mechanisms.

Determining whether wind turbine blades can be made lighter, less expengive, with lower loads (i.e., with longer life), with performance equal to or better than present blades, and free from instabilities should be the goal of any basic and applied regearch directed toward the wind turbine problem. Whatever elastic tailoring schemes are proposed, however, must not compromise on total (manufacturing, installation, and maintenance) cost per year of life. In order to speed up the incorporation of these technologies (along with active control as appropriate), the designer must have access to computational tools. If active control is to be considered for achieving these gains (see Chapter 6 ), the control design should be undertaken in combination with the passive measuroa. 


\section{RECOMTADATION8}

The following areas are recommended for future research:

1. Simple cross-sectional analyses and codes need to be developed for determination of the sectional elastic constants. To accomplish this in an accurato and computationally efficient manner will require additional reserfch. The resulting tools may likely be in the spirit of Rehfield/Nitor vut with additional wind turbine parameters included, such as initial curveiure, initial twist, and taper and with additional attention given to ritaining shear stiffnesses more accurately and accounting for restrained warping. Although ANBA, for example, already deals with all these effects, a Rehfield/Nixon-type code has the advantage of requiring very little cPu $t i m e$ on a PC. Bauchau's code may already meet most of these requirements; what is unknown to the committee is the level of complexity and PC CPU time that the wind turbine industry will deem simple enough.

2. Aeroelastic response analyses need to be developed for the wind turbine problem that incorporate the appropriate types of elastic coupling derived in the analyses mentioned above for the first recommendation. These could be simple modal analyses making use of a few natural modes and a few perturbation modes as described by Bauchau and Liu (1989). (Note that modal analyses and finite element analyses are not mutually exclusive. Modal analyses can be based on finite element models.) The code need only contain a representative model of aerodynamics used to characterize the load spectrum for design purposes. Obtaining this type of aerodynamic model is vital. This itgelf would also require additional research.

3 Formal optimization procedures need to be employed in the systematic investigation of the effects of certain aerodynamic, configuration, structurai, auc collcroi garamecers on the overall design. This w111 require the development of complete simulation tools that are compatible with formal optimization. 


\section{RIFREICEB AND BIBLIOGRAPAT}

Armanios, E. A., L. W. Rehfield, and F. Weinstein. 1990. Understanding and Predicting Sublaminate Damage Mechanisms in Composite Structures. Composite Materials: Testing and Design, ed. by S. P. Garbo, ASTM STP 1059, American Society for Testing and Materials, Philadelphia, pp. 231-249.

Atilgan, A. R., and D. H. Horges. 1990. A Unified Nonlinear Analysis for Nonhomogeneous Anisotr u': Beams with Closed Cross Sections. AIAA Journal, submitted for publicatica.

Bauchau, O. A. 1985. A Beam Theory for Anibotropic Materials. Journal of Applied Mechanics, Vol. 52, pp. 416-422.

Bauchau, O. A., and C. H. Hong. 1987. Finite Element Approach to Rotor Blade Modeling. Journal of the American Helicopter society, vol. 32, No. 1, pp. 60-67.

Bauchau, O. A., B. S. Coffenberry, and I. W. Rehfield. 1987. Composite Box Beam Analysis: Theory and Experiments. Journal of Reinforced Plastics and Composites, Vol. 6, pp. 25-35.

Bauchau, O. A., and S. P. Liu. 1989. Finite Element Based Modal Analysis of Helicopter Rotor Blades. Vertica. Vol. 13, pp. 197-206.

Belvin, K. W., and K. C. Park. 1988. Structural Tailoring and Feedback Control Synthesis: An Interdiaciplinary Approach. In Proceedings of the 29th Structures, Structural Dynami $: 9$, and Materials Conference. AIAA Paper No.

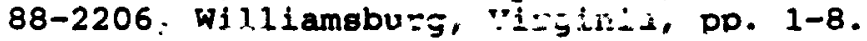

Borri, M., and P. Mantegazza. 1985. Some Contributions on Structural and Dynamic Modeling of Rotor Blades. I'Aerotecnica Missili e Spazio, Vol. 64, No. 9, pp. 143-154.

Borri, M., and T. Merlini. 1986. A Large Displacement Formulation for Anisotropic Beam Analysis. Meccanica, Vol. 21, pp. 30-37.

Conover, K., and J. Young. 1989. Experiences with Commercial Wind Turbine Design. EPRI GS-6245, Vol. 1, April, pp. 3-37 - 3-38.

de Vries, 0. 1979. Fluid Dynamic Aspects of wind Energy Conversion. AGARDAG-243.

Eggleston, D. M., and Forrest S. Stoddard. 1987. Wind Turbine Engineering Design. Van Nostrand Reinhold, New York. Chapters 4, 10, and 12.

Giavotto, V., M. Borri, P. Mantegazza, G. Ghiringhelli, V. Carmaschi, G. C. Maffioli, and F. Mussi. 1983. Anisotropic Beam Theory and Applications. Computers and structures. Vol. 16, pp. 403-413.

Gewehr, H. W. 1980. Development of Composite Blades for Large Wind Turbines. 3rd International Symposium on Wind Energy Systems, Denmark.

Haftka, R. T., and M. P. Kamat. 1989. Simultaneous Nonlinear Structural Analysis and Design. Computational Mechanics, Vol. 4, No. 4, pp. 409-416.

Hodger, D. H. 1990. A Review of Composite Rotor Blade Modeling. AIAz Journal, March, Vol. 28, No. 3, pp. 561-56د.

Hodges, R. V., M. W. Nixon, and L. W. Rehfield. 1987. Comparison of Composite Rotor Blade Models: A Coupled-Beam Analysis and an MSC/NASTRAN Finite-Element Model. NASA TM 89024, NASA. 
Karaol1s, N. M., P. J. Musgrove, and G. Jeronimidis. 1987. Passive Aerodynamic Control Using Composite Blades. Proceedings of Workshop on the Use of Composite Materials for Wind Turbines. ETsU-N-109, Harwell, England, November 4, pp. 71-101.

Kosmatka, J. B. 1986. Structural Dynamic Modeling of Advanced Composite Propellors by the Finite Element Method. Ph.D. dissertation, University of California, Los Angeles.

Lee, S. W., and A. D. Stemple. 1987. A Firite klement Model for Composite Beams with Arbitrary Cross-sectional warping. Esicisedings of the 28th Structures, Structural Dynamics and Material; Conference. AIAA Paper No. 87-0773, Monterey, California, April 6-8, Pp. 304-313.

Ormiston, R. A., W. G. Bousman, D. H. Hodges, and D. A. Peters. 1976. Hingeless Helicopter Rotor with Improved Stability. United States Patent 3,999,886. December 28 .

Ormiston, R. A., W. G. Warmbrodt, D. H. Hodges, and D. A. Peters, 1988. Rotorcraft Aeroelastic Stability (Army/NASA Research 1967-1987). NASA Conference Publication 2495, Vol. 1, PP. 353-529.

Rehfield, L. W. 1985. Design Analysis Methodology for Composite Rotor Blades. Presented at the $7 \mathrm{th}$ DOD/NASA Conference on Fibrous Composites in Structural Design. AFWAL-TR-85-3094, Denver, Colorado, June 17-20, PP. $(v(a)-1)-(v(a)-15)$.

Rehfield, L. W., and A. R. Atilgan. 1987. Analysin, Design and Elastic Tailoring of Composite Rotor Blades. Fins? Parent Jrant No. NAG-1-638. U.S. Army Aerostructures Directorate, Langley Regearch Center.

Rehfield, L. W., A. R. Atilgan, and D. H. Hodges. 1990. Nonclassical Behavior of Thin-Walled Composite Beams with Closed Cross Sections. American Helicopter society, Vol. 35, No. 2, pp. 42-50.

Shirk, M. H., T. J. Hertz, and T. A. Weisshaar. 1986. Aeroelastic Tailoring --Theory, Practice, and Promise. Journal of Aircraft, vol. 23, No. 1, pp. 618 .

Stoddard, F., V. Nelson, R. Starcher, and B. Andrews. Horizontal Axis Wind Turbine (HAwT) Elastic Twist Determination. Final Report. SERI Contract RL6-06013.

Watson, R. 1989. Space Frame wind Turbine. Ninth ASME Wind Energy Symposium. New Orleans, January, pp. 93-99.

wörndle, R. 1982. Calculation of the Cross Section Properties and the Shear Stresses of Composite Rotor Blades. Vertica, Vol. 6, pp. 111-129.

wörndle, R., and H. Mang, 1984. Zur Schubspannungs verteilung und Schubsteifigkeit bei querkraftbeanspruchten, inhomogenen querschitten beliebiger Form aus orthotropen Werkstoffen. Ingenieur-Archiv, vol. 54, pp. 25-42.

Wright, A. D., B. L. Buhl, and R. W. Thresher. 1988. FLAP Code Development and Validation, SERI/TR-217-3125, Solar Energy Research Institute Report, Golden, colorado. 


\title{
MATERIALS PROPERTIES AND LIFE PREDICTION
}

\author{
The characteristics that make composites, especially glass fiber- \\ reinforced and wood/epoxy composites, suitable for wind turbine blades are low \\ density, good mechanical properties, excellent corrosion resistance, \\ tailorability of material properties, and versatility of fabrication mathods. \\ Although glass/vinylegter and glass/polyvinyl composites based on hand lay-up \\ have been the most widely used materials so far, many more types of $f$ ibers and \\ resing have become available recently. The new carbon $f$ ibers are stronger and \\ stiffer, while the new resins provide higher toughness and shorter process \\ cycle time. A number of handbooks are now available to the designers of \\ composites (Lubin, 1982; Engineered Materials Handbook, 1987; Composites \& \\ Laminates, 1987).
}

\section{PIBERS}

The most commonly used and lowest-priced fiber is s-glass fiber. Over

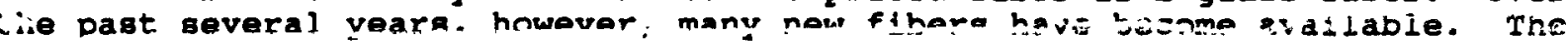
commercially available fibers and their typical properties are lisced in Table 3-1.

While E-glass fiber is most widely used in wind turbine rotor blades mainly because of its low cost, carbon fibers are the fibers of choice in many aerospace applications. Although more expensive, they provide higher specific modulus and specific strength than glass fibers. The advantage of carbon fibers is further enhanced in fatigue. However, carbon fibers are electrical conductors, and their contact with metals may lead to corrosion of the latter. Polymeric fibers guch as aramid and high-density polyethylene are the toughest of all the available fibers and hence can be used where high-impact resistance and toughness are required. These polymeric fibers, however, are weak in compression because of the fibrillar nature of their microstructure.

Recently, a variety of ceramic fibers such as alumina and silicon carbide have emerged mainly as reinforcements for metal and ceramic matrices. These ceramic fibers have better oxidation resistance in high-temperature applications than carbon fibers. However, they are still more expensive than most carbon fibers. Mechanical properties of epoxy matrix composites made with the four most widely used fibers--aramid, carbon, E-glass and s-glass-are shown in Table 3-2. Tensile fatigue behaviors of the first three composites are compared in Figure 3-1.

Since one type of fiber does not have all the desired properties, different fibers can be mixed to make a hybrid composite. For example, in a glass/carbon hybrid composite the glass fiber can improve the impact resistance while keeping the cost down, and the carbon fiber can provide the required strength and stiffness with less weight. The weight savings resulting from the use of a hybrid composite reduces the load on the blade and hence will lead to a longer lifetime. Furthermore, the material savings realized can also compensate partially fur the higrer cost of the carbon fiber. 
TABLE 3-1 Typical Propecties of Fibers

\begin{tabular}{|c|c|c|c|c|c|c|}
\hline Fiber & $\begin{array}{l}\text { Diameter } \\
\text { um }\end{array}$ & $\begin{array}{l}\text { Specific } \\
\text { Gravity }\end{array}$ & $\begin{array}{l}\text { Modulue } \\
\text { GPa* }\end{array}$ & $\begin{array}{l}\text { Teneile } \\
\text { Strength, } \\
\text { GPa }\end{array}$ & $\begin{array}{l}\text { Pailure } \\
\text { Strain, } \\
\text { ? }\end{array}$ & $\begin{array}{l}\mathrm{C} E \mathrm{E} \\
10^{-6} /{ }^{\circ} \mathrm{C}\end{array}$ \\
\hline $\begin{array}{l}\text { E-glage } \\
\text { S2-glasa } \\
\text { Boron } \\
\text { Carbon, PAN based }\end{array}$ & $\begin{array}{l}3-20 \\
10-20 \\
142\end{array}$ & $\begin{array}{l}2.4 \\
2.4 \\
2.5\end{array}$ & $\begin{array}{l}72.4 \\
86.9 \\
400\end{array}$ & $\begin{array}{l}3.45 \\
4.59 \\
2.80\end{array}$ & 0.7 & \\
\hline $\begin{array}{l}\text { High strength } \\
\text { High modulue } \\
\text { Ultza-high modulue } \\
\text { High strain } \\
\text { Intermediate modulue }\end{array}$ & & $\begin{array}{l}1.8 \\
1.9 \\
2.0 \\
1.8 \\
1.8\end{array}$ & $\begin{array}{l}230 \\
370 \\
520 \\
230-260 \\
290\end{array}$ & $\begin{array}{l}2.5 \\
1.0 \\
1.0 \\
3.0-4.8 \\
5.2\end{array}$ & $\begin{array}{l}1.1 \\
0.5 \\
0.2 \\
1.6-2.0 \\
1.8\end{array}$ & $\begin{array}{l}-0.4 \\
-0.5 \\
-1.1\end{array}$ \\
\hline Carbon, pltch based & & & & & & \\
\hline $\begin{array}{l}\text { P25 } \\
\text { P55 } \\
\text { P75 } \\
\text { P100 } \\
\text { P120 } \\
\text { P140 } \\
\text { Silicon carbide }\end{array}$ & $\begin{array}{l}10 \\
10 \\
10 \\
10\end{array}$ & $\begin{array}{l}1.8 \\
2.02 \\
2.00 \\
2 . .5\end{array}$ & $\begin{array}{l}140 \\
380 \\
520 \\
700 \\
820 \\
960\end{array}$ & $\begin{array}{l}1.4 \\
1.4 \\
1.4 \\
1.4 \\
1.4 \\
1.4\end{array}$ & $\begin{array}{l}1.0 \\
0.4 \\
0.3 \\
0.2 \\
0.2 \\
0.2\end{array}$ & $\begin{array}{l}-0.9 \\
-1.3 \\
-1.6 \\
-1.6 \\
-1.6 \\
-19\end{array}$ \\
\hline ses & 140 & 3.0 & 430 & 3.4 & 0.8 & \\
\hline $\begin{array}{l}\text { Nicalon } \\
\text { AVCO } \\
\text { MPDZ } \\
\text { HPZ } \\
\text { MPS }\end{array}$ & $\begin{array}{l}15 \\
6-10 \\
10-15 \\
10 \\
10-15\end{array}$ & $\begin{array}{l}2.6 \\
2.3 \\
2.35 \\
2.6-2.7\end{array}$ & $\begin{array}{l}180-210 \\
300 \\
180-210 \\
140-175 \\
175-210\end{array}$ & $\begin{array}{l}2.5-3.3 \\
2.8 \\
1.8-2.1 \\
2.1-2.5 \\
1.1-1.4\end{array}$ & 1.5 & 3.1 \\
\hline Alumina & & & & & & \\
\hline $\begin{array}{l}\text { FP } \\
\text { Sumitomo } \\
\text { Saff } 11 \\
\text { PRD }-166\end{array}$ & $\begin{array}{l}20 \\
9-17 \\
3\end{array}$ & $\begin{array}{l}3.9 \\
3.2 \\
3.3 \\
4.2\end{array}$ & $\begin{array}{l}345-380 \\
210-260 \\
300 \\
385\end{array}$ & $\begin{array}{l}1.4 \\
1.8-2.6 \\
2.0 \\
2.1-2.5\end{array}$ & $\begin{array}{l}0.36-0.4 \\
0.86 \\
0.67\end{array}$ & \\
\hline Alumina-silica & & & & & & \\
\hline $\begin{array}{l}\text { Fiberfrax } \\
\text { Fibermax }\end{array}$ & & $\begin{array}{l}2.7 \\
3.0\end{array}$ & $\begin{array}{l}100 \\
150\end{array}$ & $\begin{array}{l}1.0 \\
0.8\end{array}$ & 0.5 & \\
\hline $\begin{array}{l}\text { Alumina-borda-silica } \\
\text { Nextel } 312\end{array}$ & 11 & 2.7 & 150 & $1.4-1.7$ & & \\
\hline $\begin{array}{ll}\text { Mextel } & 440 \\
\text { Nextel } 480\end{array}$ & $\begin{array}{l}10-12 \\
10-12\end{array}$ & 3.1 & $\begin{array}{l}200-240 \\
224\end{array}$ & $2.4-2.0$ & $\begin{array}{l}0.9 \\
0.9\end{array}$ & \\
\hline $\begin{array}{l}S_{1}, T 1, C, 0 \\
\text { Tyranno } \\
\text { Aramid }\end{array}$ & $8-10$ & $2.3-2 \cdot 5$ & 200 & 3.0 & 1.5 & \\
\hline $\begin{array}{l}\text { Kevlar } 49 \\
\text { Kevlar } 29 \\
\text { Kevlar } 149 \\
\text { HM-5O } \\
\text { Polyethylene }\end{array}$ & $\begin{array}{l}12 \\
12 \\
12 \\
12\end{array}$ & $\begin{array}{l}1.44 \\
1.44 \\
1.47 \\
1.3\end{array}$ & $\begin{array}{l}124-131 \\
83 \\
186 \\
81\end{array}$ & $\begin{array}{l}3.6 \\
3.6 \\
3.4 \\
3.1\end{array}$ & $\begin{array}{l}2.8 \\
4.0 \\
2.0 \\
4.4\end{array}$ & -2.0 \\
\hline $\begin{aligned} \text { Spectra } 900 \\
\text { Spectra } 1000 \\
\text { Tungeten }\end{aligned}$ & $\begin{array}{l}38 \\
27 \\
13\end{array}$ & $\begin{array}{l}0.97 \\
0.97 \\
19.4\end{array}$ & $\begin{array}{l}117 \\
172 \\
410\end{array}$ & $\begin{array}{l}2.6 \\
3.1 \\
4.0\end{array}$ & $\begin{array}{l}3.5 \\
0.7\end{array}$ & \\
\hline
\end{tabular}

ispa $=1.45 \times 10^{5} \mathrm{pai}$ 
TABLE 3-2 Typical Properties of Unidirectional Composites

\begin{tabular}{|c|c|c|c|c|}
\hline & $\begin{array}{l}\text { E-Glase/ } \\
\text { Resin }\end{array}$ & $\begin{array}{l}\text { REVLAR } \\
\text { ReEin }\end{array}$ & $\begin{array}{l}\text { Graphite/ } \\
\text { Reain }\end{array}$ & $\begin{array}{l}\text { S-Glase/ } \\
\text { Resin }\end{array}$ \\
\hline $\begin{array}{l}\text { Fiber Direction } \\
\text { Modulug, GPa } \\
\text { Strength tension, MPa } \\
\text { Strength compregaion, MPa } \\
\text { Coefficient thermal } \\
\text { expansion microstrain } / \mathrm{K}\end{array}$ & $\begin{array}{l}44.8 \\
1124 \\
896 \\
8.8\end{array}$ & $\begin{array}{l}75.8 \\
1241 \\
276 \\
-4.0\end{array}$ & $\begin{array}{l}145 \\
1517 \\
2068 \\
-0.45\end{array}$ & $\begin{array}{l}56 \\
1980 \\
626 \\
5.5\end{array}$ \\
\hline $\begin{array}{l}\text { Trangverse Direction } \\
\text { Modulus, GPa } \\
\text { Strength tension, MPa } \\
\text { Strenath combresaion. No? } \\
\text { Coefficient thermal } \\
\text { expangion microgtrain } / \mathrm{K}\end{array}$ & $\begin{array}{l}11.0 \\
31 \\
138 \\
22.1\end{array}$ & $\begin{array}{l}5.5 \pi \\
14 \\
30 \\
57.6\end{array}$ & $\begin{array}{l}10.3 \\
48 \\
122 \\
25.2\end{array}$ & $\begin{array}{l}11.4 \\
31 \\
230 \\
23.3\end{array}$ \\
\hline $\begin{array}{l}\text { Shear (Inplane) } \\
\text { Modulus, GPa } \\
\text { Strength, MPa }\end{array}$ & $\begin{array}{l}4.14 \\
71.7\end{array}$ & $\begin{array}{l}2.41 \\
34.5\end{array}$ & $\begin{array}{l}5.52 \\
82.7\end{array}$ & $\begin{array}{l}4.48 \\
71.7\end{array}$ \\
\hline $\begin{array}{l}\text { Poisson Ratio } \\
\text { Axial-transverse }\end{array}$ & 0.27 & 0.34 & 0.30 & 0.27 \\
\hline $\begin{array}{l}\text { Thickness Direction } \\
\text { Modulue, GPa } \\
\text { Poiseon ratio }\end{array}$ & $\begin{array}{l}11.0 \\
0.44\end{array}$ & $\begin{array}{l}5.5 \\
0.38\end{array}$ & $\begin{array}{l}10.3 \\
0.55\end{array}$ & $\begin{array}{l}11.4 \\
0.44\end{array}$ \\
\hline
\end{tabular}




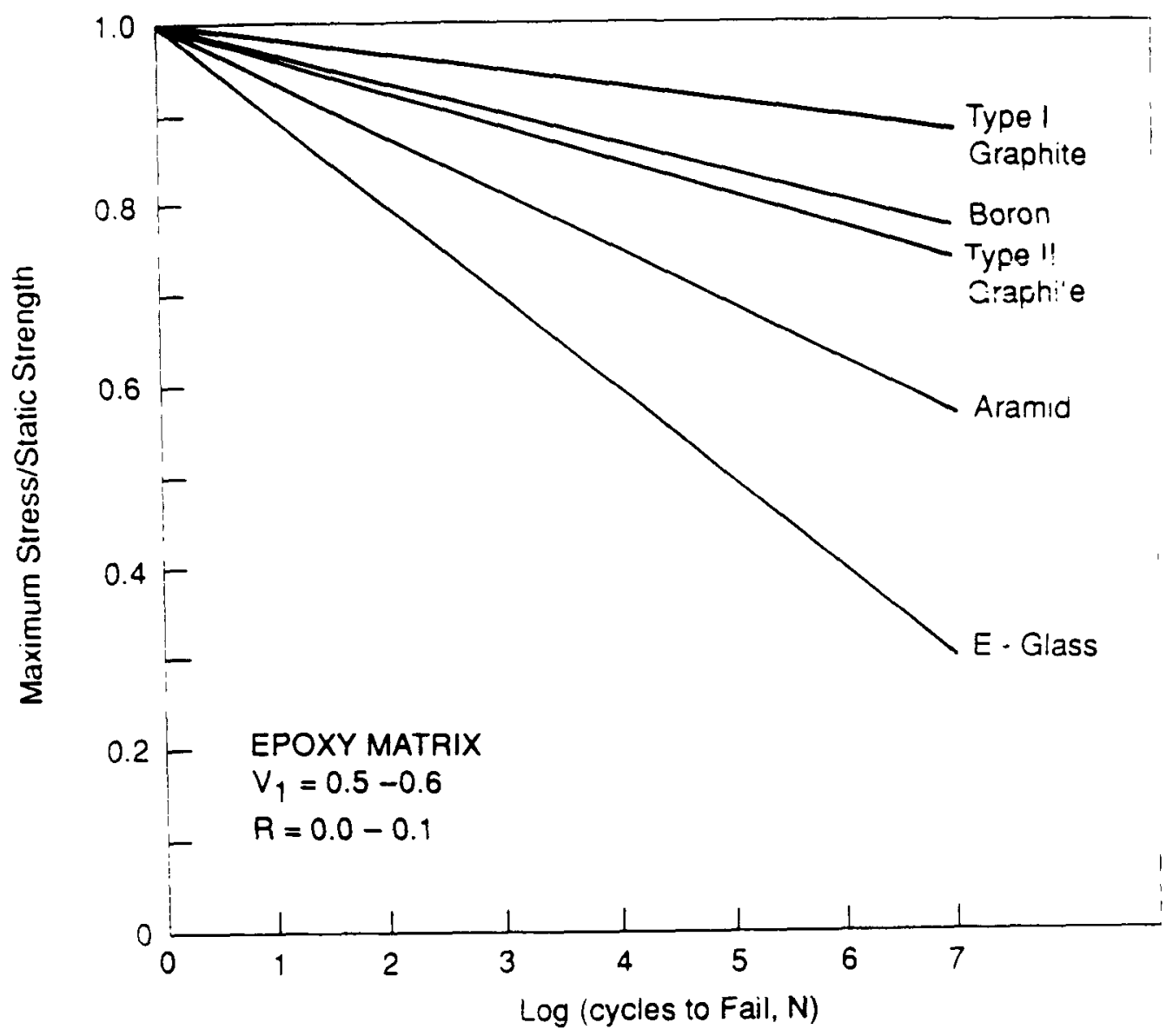

FIGURE 3-1 Trends of longitudinal tensile fatigue s-N data for unidirectional composites with various fibers. Source: Mandell (1990).

To further illustrate the cost differences based on fibers, consider a hybrid composite with a carbon/glass volume ratio $v_{c / g}$. The ratio of the cost of the hybrid composite to an all-glass composite to provide the same structural stiffness is given by

$$
\text { Cost Ratio }=\frac{1+v_{c / g} B_{c} S_{c} /\left(8_{g} S_{q}\right)}{1+v_{c / g} E_{c} / E_{q}}
$$

The parameters in Equation (1) are defined as follows: S, price per unit mass; s, specific gravity; E, Young's modulus; $g$, glass; and $c$, carbon. On the other hand, the weight ratio, defined as the weight of the hybrid composite divided by that of the all-glass composite, is given by

$$
\text { Weight Ratio }=\frac{1+v_{c / g} B_{c} / B_{a}}{1+v_{c / g} E_{c} / E_{g}}
$$$$
\text { E-glass fiber costs around } \$ 2 / 1 b \text {; a high-strength carbon fiber costs }
$$
about $\$ 30 / 1 b$. Thus, an all-carbon fiber composite costs 3.5 times more than 
an all-glass fiber composite to provide the same structural stiffnese at a weight savings of 76 percent. When a 50/50 glass/carbon hybrid composite is used, however, the calculated cost ratio is reduced to 2.9 with a weight savings of 58 percent.

As can be inferred from Table 3-2, the in situ tensile fallure strain of E-glass fiber is as high as 2.5 percent, whereas it is only 1 percent for carbon fiber. However, E-glase fiber has a much lower fatigue ratio than carbon fiber, that $18,0.3$ versus 0.75 at 10 million cycles (Figure 3-1). Therefore, boti fibers have the same fatigue otrain of 0.758 at 10 million cycles. Be:- ind $10 \mathrm{milli}$. cycles, however, the carbon fiber is expected to outlast the jlass fiber. The cost ratio to obtain the same long-term fatigue strength is ihen at least the same as that needed to obtain the same stiffnea:. An additional benefit is that a hybrid composite blade will have a longer lifetime because of the reduced fatigue load resulting from the weight savings. Thus, a careful study is needed to explore the full benefits of a hybrid composite blade from a life-cycle point of view.

Fibers are used in various forms. The commonly used fiber preforms include unidirectional tow, woven cloth, knitted fabric, continuous otrand mat, chopped strand mat, and braid as well as chopped fibers in sheet and bulk molding compounds. Depending on the application and manufacturing process used, one fiber preform may be preferred to others. The various fiber preforms are shown schematically in Figure $3-2$.

Where high strength is required, unidirectional bundles of fibers known as tows should be used. Woven cloths and knitted fabrics are easier to use, especially over complex contours. Woven cloths have disadvantages in that high fiber volume content cannot be attained and the inherent fiber crossovers are susceptible to premature fatigue damage. The fiber cross-overs also result in low compressive strength. While continuous strand mats provide good strength, chopped strand mats are weaker because of the fiber discontinuity. Where delamination is a prime concern and strengthening is required in the A.:. ikness directiua, uraius can work we11.

\section{MATRIX MATERIALS}

The matrix resins commonly used in wind turbine blades are divided into three majer classes of thermosetting polymers: unsaturated polyesters, epoxies, and vinyl esters (Lee and Nevilie, 1967; Launikitis, 1978; Strong, 1989). The unsaturated polyester resins, typically based on the orthophthalic or isophthalic acid, are most widely used because of short cure time and low cost. Despite the long cure time required and higher cost, epoxy resins are gaining greater acceptance due to their superior chemical resistance, good adhesion, low cure shrinkage, good electrical properties, and high mechanical strength. A reasonably good compromise between cost, cure time, and the above-mentioned physical properties is achieved in epoxy-based vinyl eater resins, which have especially shown very rapid growth over the past few years by filling the gap between polyesters and epoxies. The use of all these resins as composite matrices is generally subjected to a temperature limit around $150^{\circ}$ to $200^{\circ} \mathrm{C}$. The upper temperature limit is lower than the glass transition temperature $\mathrm{Tg}$ because above $\mathrm{Tg}$ the resin becomes soft and rubbery, thus losing most of the load-carrying capability.

polyesters, as their name implies, are resins in which recurring ester linkages are an integral part of polymer chain backbone. The most commonly used system--isophthalic polyester resins--is more expensive but is chemically more stable and a little less brittle than orthophthalic resins. The term unsaturated comes from the presence of carbon-carbon double bonds in the polyester chain backbone that provide the location for cross-linking, thereby eventually leading to a tight network. The most common type of crogs-ilnking agent is styrene. The styrene alen lowers the iritial viscosity of the polyester resin to inprove processing of the composite by facilitating impregnation and wetting of fibers. The cross-linking reaction, which is addition polymerization, is triggered by an initiator (sometimes erroneously called a catalyst), such as organic peroxide, that produces free radicals. 

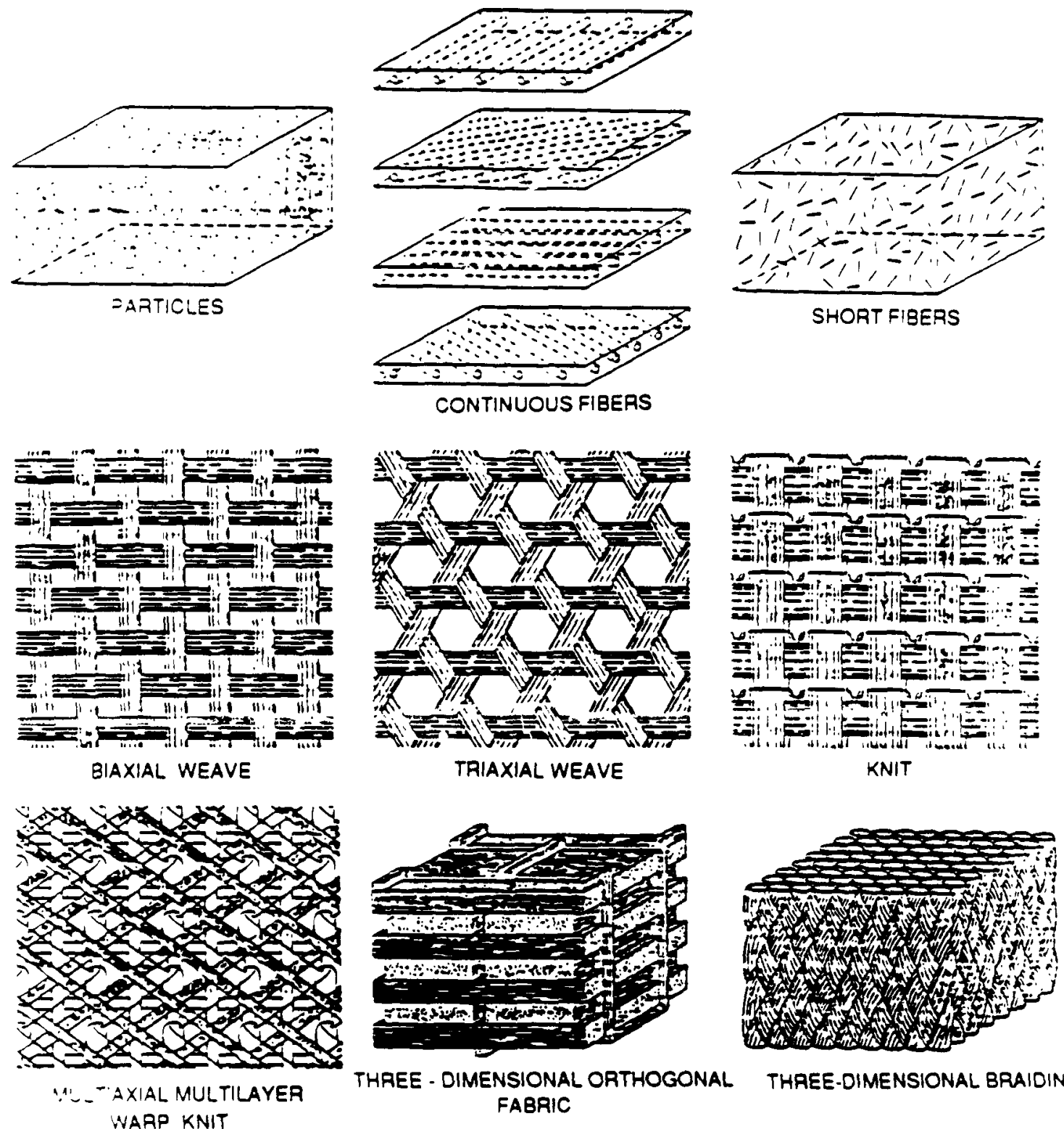

THREE - DIMENSIONAL ORTHOGONAL THREE-DIMENSIONAL BRAIDING FABRIC
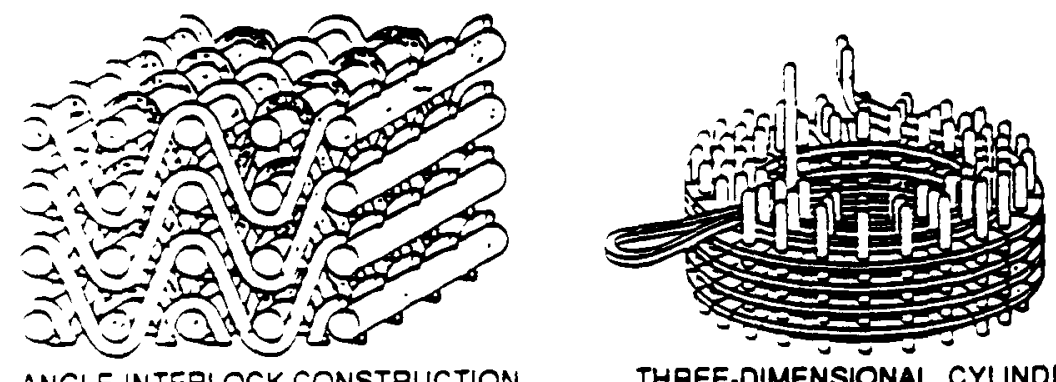

THAEE-OIMENSIONAL CYLINDRIC CONSTRUCTION

FIGURE 3-2 Schematics of various fiber preforms. Source: Chou et al. (1986). 
Many polyester resins are cured at room temperature with a rige in temperature due to the exothermic nature of the reaction. In this case, the typical cure time is several hours or overnight. However, with a proper selection of initiator, the cure reaction can be carried out at an elevated temperature in an extremely short time. Experience in automotive composites has shown that the curing of an unsaturated polyester can be completed in 2 to 3 minutes at $150^{\circ} \mathrm{C}$ with the use of a tert-butyl perbenzoate initiator. Epoxy resing derive their name from the epoxide ring otructure that serves as the principal cross-linking site. Although various types of epoxy resins are produced commercially, so-called diglycidyl et'ser of bisphenol-A (DGEBPA)-type resins (e.g., Shell BPONB28), have ach!eved the widest market acceptance and demonstrated versatility. For applicetionis requiring special properties such as high modulus or higher use tempereture, other types of epoxy resins with higher functionality are used in place of difunctional DGEBPA-type resins. For instance, tetrafunctional epoxy resins of tetraglycidyl methylene dianiline (TGKDA) (e.g., Ciba-Geigy MY720) exhibit improved properties at elevated temperature. Greater strength and improved properties at elevated temperature are also achieved in the resins of epoxidized phenolic novolacs (e.g., Dow DEN438) or tetraglycidyl ether of tetrakis hydroxyphenyl ether (e.g., shell EPON103). All these resins tend to have lower fracture toughness than DGEBPA-type resins.

For polyfunctional epoxy resing, cross-linking or cure is effected by use of polyfunctional curing agents or hardeners. The use of a hardener with higher functionality (e.g., tertiary amine versus primary amine) allows a greater cross-link density of cured resins, which generally improves their physical properties. Lewis acids, such as BF3, are catalytic curing agents that promote the cure reaction but do not themselves serve as direct crosslinking agents. These catalytic curing agents have the advantage of very long shelf life and require significant heat to initiate the reaction. The resultant structure of Lewis acid-cured resin is very tightly cross-linked.

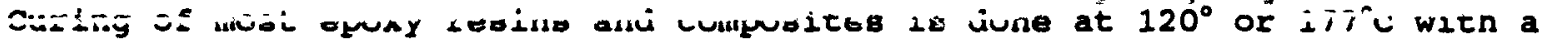
typical cycle time of 2 to 3 hours under the molding pressure of up to 1.4 MPa.

The term vinyl ester can be applied to any number of chemical compounds comprising an ester linkage and terminal unsaturation. There are geveral types of vinyl esters based on epoxy resins as well as nonepoxy resins. However, to the composites industry, the vinyl ester resins usually mean methacrylate esters of epoxy resins (Launkitis, 1978). Unlike polyesters, vinyl esters do not possess internal unsaturation. However, vinyl esters and polyesters are similar in that they both utilize a coreactant or crosslinking agent, such as styrene, and free radical-producing initiators, such as peroxides, to effect cure. As a result, vinyl ester resins can be cured in a very short time like polyesters, but their static strength and modulus properties are similar or comparable to those of epoxy resins. Typical mechanical properties of polyesters, epoxies, and vinyl esters are shown in Table 3-3. While epoxy resins are at the top of the scale as far as mechanical properties are concerned, they require the longest cure time and are the most expensive. For example, epoxy resins cost about $\$ 1.80 / 1 \mathrm{~b}$, whereas unsaturated polyesters cost only $\$ 1.00 / 1 \mathrm{~b}$. Vinyl ester resins fall in between these two resins, costing about $\$ 1.60 / 1 b$. Thus, the final selection of a resin should consider the material cost as well.

The fatigue crack propagation rates of these resins vary with the stress intensity factor range $\Delta R$ in the case of other plastics for structural use (Hertzberg and Manson, 1980). In amine-cured DGEBA epoxy resins, the values for exponent $m$ in the equation for the crack growth per fatigue cycle, da/dN = const. $(\Delta K)^{m}$, range from 7.7 to 20 , which are higher than those for other

plastics. In general, a lower fatigue crack growth rate and a higher fracture toughness are observed with increasing molecular weight between cross-1inks. 
TABu 3-3 Properties of cast Resins

\begin{tabular}{llll}
\hline & Polyester & Vinyl Ester & Epoxy \\
\hline Specific gravity & $1.10-1.46$ & $1.1-1.2$ & $1.2-1.3$ \\
Flexurcl strength, MPa & $60-160$ & $120-140$ & $110-215$ \\
leifide strength, MPa & $40-90$ & $70-90$ & $50-130$ \\
Compreseive etrength, MPa & $90-200$ & - & $110-210$ \\
Tensile elongation, : & $<5$ & $<6$ & $3-4.5$ \\
Modulus, GPa & $2-4$ & $3-4$ & 39 \\
Source: Lee and Neville (1967), Bucknall (1977), Lubin (1982).
\end{tabular}

As discussed previously, all of these resins suffer the problem of brittleness. A brittle resin results in premature matrix cracking in the composite, which in turn facilitates moisture ingress. Although fracture toughness of the resin systems can be raised by increasing Mc or adding diluents, these approaches result in lowering of modulus and temperature resistance (Hertzberg and Manson, 1980; Owen, 1974; Christensen and Rinde, 1979). At present, many commercially available resine utilize toughening agents in the form of discrete particles of elastomers or ductile

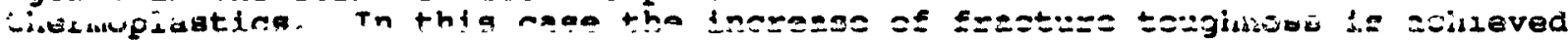
ith a relatively small change of modulus and temperature resistance. roughening of epoxy resins by the inclusion of elastomer particles is well established. Although several different types of liquid or solid elastomers or their hybrids can be used, the most effective way of increasing resin toughness is by using a liquid rubber with specific terminal functional groups (Lee, Riew, and Moulton, 1980; Bucknall, 1977; Riew, Rowe, and siebert, 1976; scott and Phillips, 1975; McGarry and sultan, 1969; Bascom, Bitner, Moulton, and Siebert, 1980; Moulton and Ting, 1981; Lee, 1986). Examples are butadiene acrylonitrile copolymers with carboxyl, amine, or vinyl groups at both ends of the chain which are selected depending on the type of curing agent and curing mechanisms.

When carboxyl-terminated butadiene acrylonitrile copolymer (CTBN) is mixed in liquid state with an amine-cured DGEBPA epoxy resin, their initial compatibility in liquid state followed by phase separation in the solidification process leads to the formation of submicron-sized elastomer particles that are well bonded to the surrounding resin. As a result, adding as small as 5 wt of CTBN to Epon 828 resin increases the fracture toughness $G_{1 c}$ from 350 to $5260 \mathrm{~J} / \mathrm{m}^{2}$. Yet the accompanying decrease of tensile modulus is only 2.5 to $2.8 \mathrm{GPa}$ (Riew, Rowe, and Siebert, 1976). A similar type of elastomer toughening in extremely brittle TGMDA resing $\left(G_{1 c}=80 \mathrm{~J} / \mathrm{m}^{2}\right)$ is 188 effective: a maximum twofold increase with considerable reduction of modulus (Lee, Riew, and Moulton, 1980).

The use of elastomer-toughened epoxy resins as matrix materials has been shown to improve the interlaminar fracture toughness of fiber-reinforced composites, particularly those with woven fabric reinforcement with resinrich areas between the plies (Bascom, Bitner, Moulton, and Siebert, 1980). Despite a high level of constraint on thin films of resin matrix by densely packed surrounding fibers (Scott and Phillips, i\$75), toughening of epoxy matrices also increases the registance of composites against local damage initiation and accumulation (McGarry and sultan, 1969; Bascom, Bitner, Moulton, and Siebert, 1980; Moulton and Ting, 1981; Lee, 1986). However, their effects on fatigue lifetime or fatigue endurance limit of composites have not been fully confirmed. 
In the case of toughening of unsaturated polyester resins, both liquid elastomers with terminal functional groups and ductile thermoplastics are utilized as a secondary phase (McGarry, Rowe, and Riew, 1978; Lee, Howard, and Rowe, 1983). Examples are vinyl- or epoxy-terminated butadlence acrylonitrile elastomers, hydroxyl- or vinyl-terminated epichlorohydrin elastomers, and polyvinylacetate. Compared with elastomer-toughened DGEBPA epoxy resins, the size of elastomer particles formed in situ during cure is much bigger (micron level) because of lower compatibility of the reactive mixture. As a result, the effectiveness of elastomcr toughening of polyester resins is much lower than that of DGEBPA epuxy resins. For instance, by adding 8 wt of vinylterminated polyepichloriydx..n elastomer, the fracture toughness $G_{1 c}$ of isophthalic polyester resirs 1; increased from 60 to $110 \mathrm{~J} / \mathrm{m}^{2}$ with a 23 percent reduction of tensile modulus. However, the use of elantomer-toughened unsaturated polyester resine in short fiber-reinforced composites increases the local damage resistance under Impact and, in certain cases, that of tensile strength as well (MCGarry, Rowe, and Riew, 1978; Lee, Howard, and Rowe, 1983).

In addition to thermosetting resins, many ongineering thermoplastics are available now as matrix resins. Table 3-4 lists those new high-performance thermoplastic resins developed mainly for aerospace applications (Witzler, 1988). Compared with thermosetting resins, the thermoplastic resins offer advantages in prepreg (pre-impregnated laminate) stability and short processing cycle. However, they tend to be weak in solvent resistance and fiber impregnation. Trade-of $f \mathrm{~s}$ between thermosets and thermoplastics as matrices are shown in Table 3-5.

Unidirectional prepregs also are available with commodity thermoplastics such as nylon and PET. Although they are cheaper than the high-performance thermoplastic prepregs, their full potential has not been realized because of the lack of low-cost manufactiring techniques.

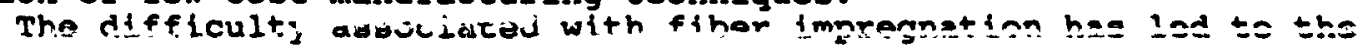

development of commingied yarns and fabrics as well as powder-coated yarns and fabrics. A commingled yarn consists of both reinforcing flbers and thermoplastic fibers. During processing the thermoplastic fibers melt and impregnate the reinforcing fibers (Iynch, 1989). Thermoplastic powder is smaller in diameter than the corresponding thermoplastic fiber and hence is more evenly distributed in the yarn, which facilitates a more uniform fiber impregnation (Hartnes, 1988).

\section{E-GLAS8/PLASTIC COMPOSITES}

E-glass/plastic composites, commonly called glass-reinforced plastics (GRPg), have been widely used in the manufacture of blades of various 8 izes. Typical resing used in GRPg are polyester, vinyl ester, and epoxy. Although polyester resins can be cured in the shortest time, they show large shrinkage and hence may not be appropriate for use in a hot, dry environment such as California, where moisture-induced swelling would be minimal (windpower Monthly, 1987). Vinyl ester resins have good environmental stability and are widely used in marine applications. Epoxy resins have good mechanical properties and dimensional stability. Their drawback is longer cure time and higher cost; however, new epoxy resins are now avallable for pultrusion and resin transfer molding, which require fast curing.

GRP is the main structural material for a number of blades of large machines and is also used as cladding over steel load-bearing frames in others (Phillips et al., 1987). GRP is the most popular blade material used in medium-size machines in Denmark and The Netherlands. As of January 1987, approximately 81 percent of 15,059 wind turbines in the California wind farms had fj.jeíglass rotor blades (Stoddard, 1989; Modern Power Systems, i3jó). Typical properties of a unitirectione 1 -glase/epoxy composite are compared with those of other unidirectional composites in Table 3-2. For all the composites in the, the stress-strain behavior is usually quite linear except in transverse compression and in-plane shear. Another exception is thearamid/epoxy composite, which is quite nonlinear in longitudinal compression also. Elastic properties of multidirectional laminates can be 
TABLE 3-4 High-Performance Thermoplastics Ueed as Matrix Resins

\begin{tabular}{|c|c|c|c|c|c|}
\hline Poiymer & Type & $\begin{array}{l}\text { Trade } \\
\text { Name }\end{array}$ & Mar. *acturer & $\operatorname{Tg}^{*}$ & $\begin{array}{l}\text { Processing } \\
\text { Temperature, } \\
{ }^{\circ} \mathrm{P}\end{array}$ \\
\hline $\begin{array}{l}\text { Polyetheretherketone } \\
\text { (PEEK) }\end{array}$ & Semicryetalline & $\begin{array}{l}\text { APC-2 } \\
\text { (propreg) }\end{array}$ & $I C I$ & 290 & 650 \\
\hline $\begin{array}{l}\text { Polyphenylene } \\
\text { gulfide (PPS) }\end{array}$ & Semicryetalline & Ryton & Phillipe & 185 & 630 \\
\hline Polyarylene ketone & Semicryetaliine & HTX & ICI & 400 & $700-780$ \\
\hline Polyaryiene sulfide & Amorphoue & PAS-II & Phillipe & 410 & $625-650$ \\
\hline $\begin{array}{l}\text { Polyetherimide } \\
\text { (PEI) }\end{array}$ & Amorphous & $\begin{array}{l}\text { Ultem } \\
\text { Cypac } \\
\text { (prepreg) } \\
\text { Cypac } 7000 \text { / } \\
7005\end{array}$ & $\begin{array}{l}\text { GE } \\
\text { (resin) } \\
\text { American } \\
\text { Cyenamid }\end{array}$ & 450 & $\begin{array}{l}\text { Varies } \\
575-650\end{array}$ \\
\hline Polyarylether & Amorphous & Radel C & pmann & 476 & 650 \\
\hline Poiyecheraulfone & Amorphous & HTA & ICI & 510 & 575 \\
\hline Polyamide-imide & Amorphous & Torton & Anoco & 470 & 650 \\
\hline Polyimide & $\begin{array}{l}\text { Pseudo- } \\
\text { thermoplastic }\end{array}$ & $\begin{array}{l}\text { Avimid } \\
\text { LaRC-TPI } \\
2080 \\
9725\end{array}$ & $\begin{array}{l}\text { Du Pont } \\
\text { R-III } \\
\text { Mitsui Toatsu, } \\
\text { Rogers Corp. } \\
\text { Lenzing } \\
\text { Ciba-Geigy }\end{array}$ & $\begin{array}{l}480 \\
482 \\
536 \\
536\end{array}$ & $\begin{array}{l}680 \\
660 \\
660 \\
660\end{array}$ \\
\hline
\end{tabular}

- Ig is the glase traneition temperature, the temperature at which a polymer changes from a rigid glassy olid to a soft rubbery colid.

Source: Johnston and Hergenrother (1987). 
TABrs 3-5 Trade-offs Between Thermosets and Thermoplastics as Matrices

\begin{tabular}{lll}
\hline Property & Thermosete & Thermoplastice \\
\hline Formulations & Complex & Slmple \\
Melt viscosity & Very low & High \\
Fiber impregnation & Easy & Difficult \\
srepreg tack & Good & None \\
Prepreg drape & Good & None to fair \\
Prepreg stability & Poor & Excellent \\
Proceseing cycle & Long & Short to long \\
Processing temperature/ & Low to moderate & High \\
pressure & & Low (potentlally) \\
Fabrication cost & High & Fair to good \\
Mechanical properties & Fair to good & Unknown \\
Environmental durability & Good & Poor to good \\
Solvent resistance & Excellent & Fair to good \\
Damage tolerance & Poor to excellent & Small \\
Data base & Very large & \\
\hline
\end{tabular}

calculated from unidirectional properties using laminated plate theory (Tsal, 1989; Jones, 1975). Tensile stress-strain relationships of several representative $\mathrm{E}-$ Glass/epoxy laminates are shown in Figure 3-3. When a multidirectional iaminate, such as the quasi-isotropic laminate in the figure, is aphiont3? to

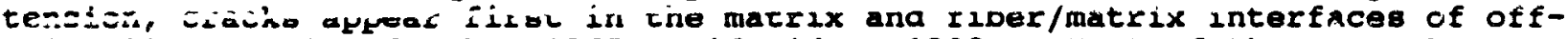
axis plies (Trai and Hahn, 1975; Reifsnider, 1980). Most of these cracks, called ply cracks, are entirely through the thickness of individual off-axis plies. The crack density increases with increasing load until some of the cracks grow as delamination between plies with different fiber orientations. Further increase of load breaks the fibers in the on-axis plies, leading to failure of the laminate as a whole. When the load is along the $0^{\circ}$ dixection, $90^{\circ}$ plies may fail at a strain as low as 0.3 percent although the laminate does not fail until 2.3 percent strain is reached. Thus, failure of a multidirectional laminate is preceded by matrix/interface cracking in the offaxis plies and also by delamination between plies with different fiber orientations.

The ply cracking in general does not lead to immediate failure of the laminate. However, it facilitateg moisture diffugion through the cracks, thereby reducing the durability of the laminate. Even in the absence of cracks, epoxy resins can absorb as much as 7 percent moisture by weight. The absorbed moisture plasticizes the resin, thereby reducing its glass transition temperature. When fully saturated, the glass transition temperature of epoxy resins can be reduced by as much as $100^{\circ} \mathrm{C}$ (Vinson, 1977).

At room temperature, absorbed moisture has a rather minimal effect on mechanical properties. When combined with elevated temperature, however, it can seriously degrade mechanical properties through interfacial debonding and matrix plasticization. The worst combination is thermal spiking to a temperature above the glass transition temperature in the presence of moisture. The thermally spiked specimens show increased moisture absorption and lower strengths (Springer, 1981).

To provide a smooth surface and also to prevent moisture diffusion, a gel coat is frequently applied on the surface of the blade. However, moisture still can diffuae thrisgh the gel coat and collect at the gel coat/composite inteifsce, itsulting in blistering. Thus, the benefits of a gel coat as a means of preventing moisture infusion are not clear (Phillips et al., 1987). Also, it has been found that E-glass/epoxy blades are prone to crazing in the surface finish. In some blades, several small delaminations have been found 


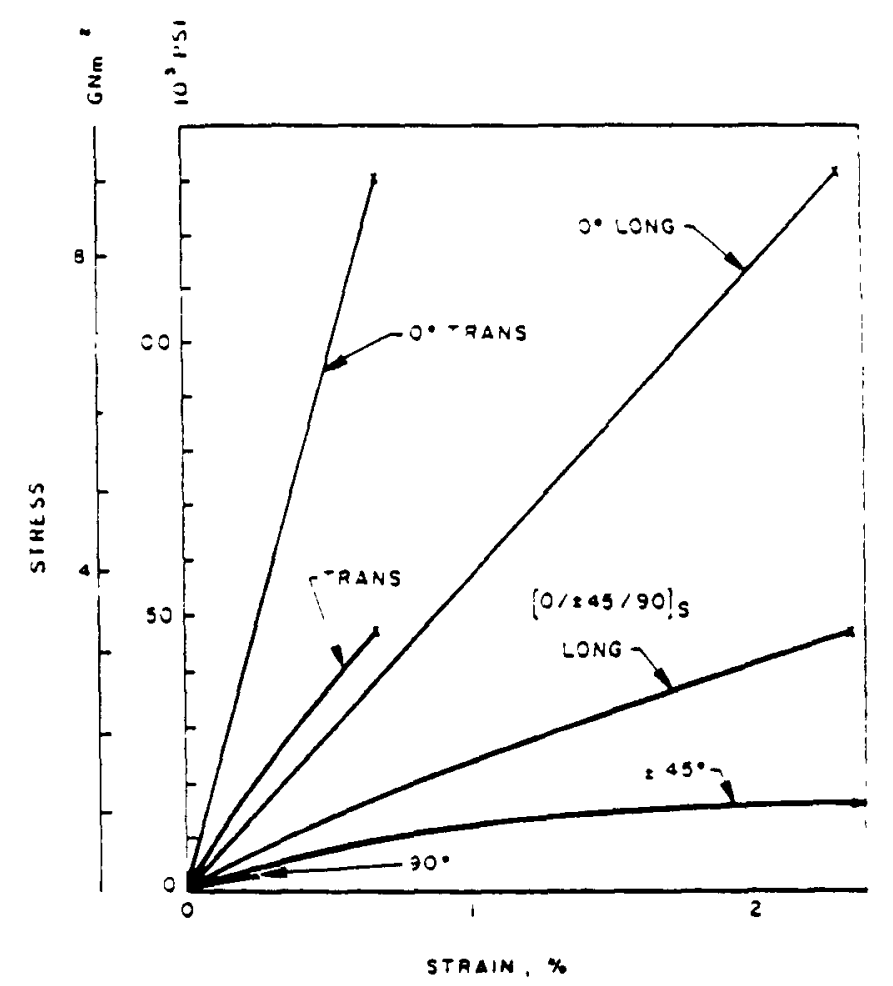

- LGUke 3-: strese-gtrain relationships of glass/epoxy laminates under uniaxial tension (50 volb). (LONG: otrain parallel to loading direction; and TRANS: gtrain (magnitude] normal to loading direction)

under the outer covering of Nexue cloth, and volds were present under the outer layer of fibergiass roving. Although these damages are not critical immediately, they may facilitate water ingreseion, accelerating deterioration of the composite.

The tensile fatigue otress-lifetime (S-N) data of various types of composite laminates can be represented by an equation of the form (Mandell, 1990),

$$
S=\operatorname{UTS}(1-B \log N) \text {, }
$$

where $S$ is the maximum fatigue stress, UTS is the ultimate tensile strength, and $N$ is the number of cycles to fallure. This is the form of the curve in Figure 3-1. The parameter B represents the fraction of UTS lost per decade of fatigue cycles. For E-glase/epoxy laminates, B is about 0.1 regardlese of whether the laminate is unidirectional or multidirectional when the fatigue stress ratio $R=0.1$ (Mandell, 1990). Since very little fatigue data exist beyond 1 million cycles, fatigue strength at 100 million cycles, which is a minimum requirement for wind turbine blade design, is estimated to be 20 percent of the ultimate strength. In terms of strain the fatigue strain at 100 milition cycles is only 0.5 percent although the static ultimate strain is as high as 2.5 percent. In comparison, aramid fiber/epoxy composites lose about 6 percent of UTS per decade, while carbon fiber composites lose only 3 to 4 percent of UTS. Thus, a carbon fiber composite enjoys a higher fatigue strain of 0.7 percent although it has a much lower ultimate tesail= sirain t:han glass/epoxy composites.

The failure sequence of multidirectional laminates under fatigue is quite imilar to that under static teneion when the load is replaced by the number of fatigue cycles. As schematically shown in Figure 3-4, the damage is initiated in the form of cracking of off-axis plies across their thicknese. As fatigue proceeds, the crack density growe rapidly, reaching a plateau. 


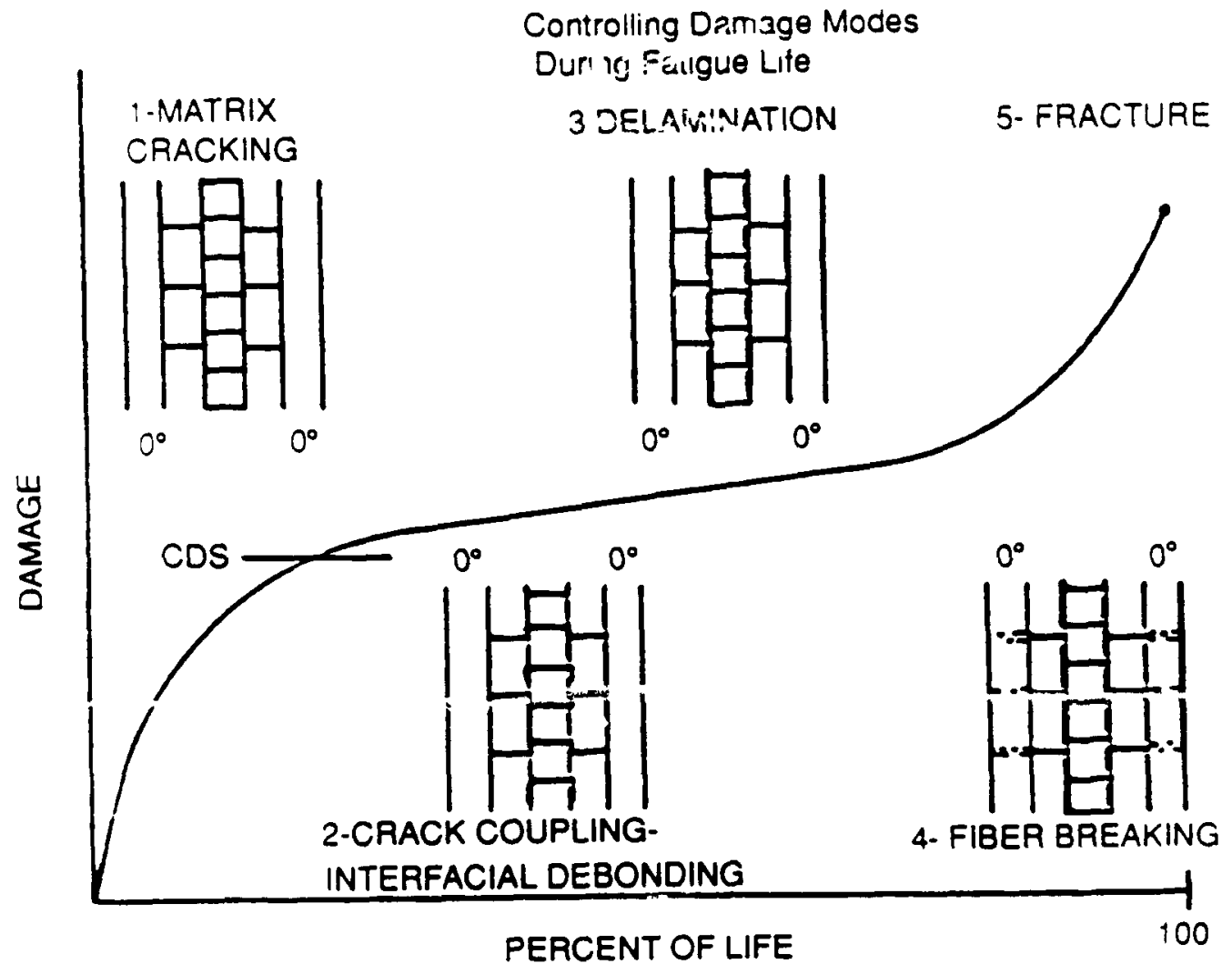

FIGURE 3-4 Modes of damage growth in composite laminate under fatigue. Source: Reifsnider et al. (1983).

Thereafter, the ply cracks grow along the ply interfaces, leading to delamination. Much of the fatigue life is spent in the delamination stage between the ply cracking and fiber failure etagee (Reifenider et al., 1983). The ply cracking stage is especially short in glase composites because the transverse failure strain is much lower than the longitudinal failure strain. The ply cracking and delamination degrade compreseive otrength more than tensile strength when the fibers used in the composite are not so fatlgue sensitive. Delamination facilitates buckling and hence reduces compreseive strength substantially. This is the reason that composite laminates fail in compression under tully reversed tension-compreseion fatigue. In fact, the maximum fatigue stress at $R=-1$ is only about half the maximum fatigue stress at $R=0.1$ (Ven Delft et al., 1987; Bach, 1988). Also, composite laminates are weaker in compreseion-compreseion fatigue than in tension-tension fatigue, especially in the low-cycle region. 
Another consequence of ply cracking and delamination in multidirectional laminates is reduction in otiffnese. For example, the fatigue failure of a quasi-isotropic glass/epoxy laminate at $10 \mathrm{mililion}$ cycles $(R=0.1$ ) can be accompanied by a stiffness reduction as large as 35 percent ( $Z$ weben et al., 1989). Thus, design for fatigue may have to be based on stiffness reduction rather than strength reduction if maintaining sufficient stiffness is more critical.

\section{FATIOU LIFL PREDICTIOU}

The prediction of fatigue lifetime of a rotor blade st ists with the determination of loads applied on the blade. The loads are induced not only by steady winds and turbulence but also by starts and shutdowns of the turbine (Murtha-Smith, 1985). For metallic blades the resulting fatigue load cycles may be determined ueing a rainflow counting algorithm, with each cycle being characterized by a mean fatigue stress and an alternating strers (Murtha-Smith, 1985; Downing and Socie, 1982; Morgan et al., 1989). Once the fatigue cycles are defined, the lifetime is predicted by using a combination of Miner's rule and constant-amplitude fatigue data or a crack growth law (Sutherland, 1989).

It is difficult, however, to predict lifetimes of composite wind turbine blades because their fallure modes are complex and no bufficlent database exists. Fatigue failure of a composite laminate depends on the specific lay-up and atyle of material used. Therefore, the existing data are not likely to be directly applicable to the chosen laminate. Furthermore, although the blade is subjected to multiaxial, variable-amplitude loading that involves several different fatigue strese ratios, most available cata are for uniaxial, constant-amplitude tensile fatigue. Therefore, the current fatigue

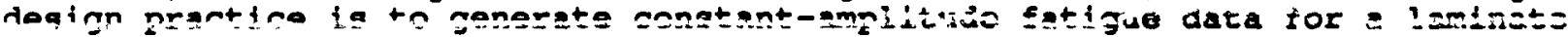
simulating the actual blade lay-up and then use the metals methoitology to predict the lifetime under operational loading (Murtha-Smith, 1985).

Several unique characteristics of composite laminates should be recognized in applying the metals life prediction methodology. First, composite laminates exhibit different hysteresis loops than metals. While the unloading modulus does not change much with fatigue cycles in metals, it decreases with increasing fatigue cycles in composite laminates as a result of ply cracking and delamination. Also, since composite laminates are weaker in compresion, especially under fatigue, the maximum alternating stress on a Goodman curve tends to be located in the positive mean-stress quadrant. Implications of these differences in the application of the metals life prediction methodology have not been examined in detail.

The first appearance of ply cracking in a laminate can be predicted from the fatigue behavior of constituent plies using the laminated plate theory together with a failure criterion (Zweben et al., 1989). After a ply fails, the state of stress changes. This stress redistribution is taken into account when the next failure event is predicted using another failure criterion. This process continues until the laminate fails as a whole.

Although this life prediction procedure is straightforward conceptually, its implementation is rather difficult because of the complex stress analysis involved and the lack of oui criteria for various failure events. An alternate approach is to use residual strength to describe the overall degradation of the composite. Basically, the rate of change of residual strength is postulated as a function of fatigue stresses, similar to a crack growth law. Fatigue failure is then assumed to occur when the residual tensile/compressive strength is reduced to the maximum/minimum fatigue stress. The parameterg involved are determined by fitting the model prediction to the experimental $\mathrm{S}-\mathrm{N}$ data. The staiter in fatigue life is related to the scatter in etatic stxength through the assumption of similitude that a specimen with 3 higher static strength also has a longer fatigue lifetime. variations of this residual etrength approach have been used by several investigators to analyze laboratory fatigue data (Hahn, 1979; Sendeckyj, 1981; Yang and Shany, 1983; Reifsnider, 1980; Hwang and Han, 1989). These residual strength models can predict lifetimes under spectrum loading on the basis of constant-amplitude 
fatigue data. Thus, they can be used instead of Miner's rule, which has been found to be inaccurate for some composites (Bowen et al.., 1984).

While the prediction of final failure is mostly phenomenological, ply cracking and delamination, which are two of the major ubcritical failure modes, have been analyzed mechanistically. A damage growth law similar to the crack growth laws for homogeneous materials can be used to describe the multiplication of ply cracks (Han and Hahn, 1989) and the delamination growth (Johnson, 1985) under controlled conditions of loading and specimen geometry. The subcriticsi aamages may degrade the strength of the main load-bearing plies, thsieby accelerating the final failure and reducing the stiffness (Reifsniaer and Stinchcomb, 1986). Reduced stiffness may change the loading on the blide and eventually cause premature failure. Thus, successful design of blades requizes the ability to predict not only the final failure but also the growth of subcritical damages and the resulting stiffness reduction. Composite structures are seneitlve to out-of-plane loads, which can cause delamination (Whitehead, 1990). These loads are present especially at joints and impact-induced damage areas. While in-plane loads are effectively carried by fibers, out-of-plane loads place an unexpectedly heavy burden on the matrix-controlled strength. Unfortunately, the matrix-controlled strength is sensitive to the presence of defects such as porosity and delamination. Since geometrically complex regions tend to contain a high level of porosity while being subjected to out-of-plane loads, these regions of the blade must be identified and tested for long-term fatigue performance under realistic loading conditions and environments. At the same time, realistic impact energy levels should be established, and their effect on fatigue lifetime should be investigated.

As mentioned earlier, carbon fibers, unlike glass fibers, are almost insensitive to satigue degradation. Experience has shown that fatigue is not a problem in aifcraft wings and fuselage structures, where carbon fiber

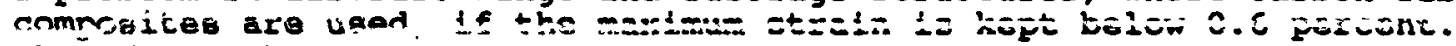
Therefole, the same static knockdown factor can be used as well for fatigue strength to account for the effect of defects (Whitehead, 1990). It is suggested that the current unfavorable economics should not preclude the use of carbon fibers together with glass fibers in wind turbine blades to avold fatigue problems.

\section{TOUGERES CONSIDERATIONS}

Wind turbine blades are expected to benefit from the use of tougher composites in several ways. One obvious benefit is the reduction in matrix cracking and hence a better protection of fibers from moisture degradation. Another benefit is the reduction in stress concentration and hence more efficient mechanical joining. In fact, one of the main causes for the hub failure in Aerostar blades is believed to be the crushing of the brittle polyester resin used. Last, but not least, benefit is found in higher-impact resigtance.

During their lifetime, wind turbine blades are subjected to impact by foreign objects such as rain drops, flying debris, and other objects. Since most impact occurs on the leading edge, proper protection of that leading edge can minimize the impact problems.

Composites are more susceptible to rain erosion than metals. Upon localized impact by rain drops, the matrix resin can be chipped away, exposing fibers. Impact by larger foreign objects can break the fibers, crack the matrix and interface, and induce delamination between plies. Impact damage may also occur during shipping and handling. Unfortunately, even an invisible damage caused by impact can substantially reduce compressive strength

(Williams and Rhodes, 1981). Therefore, a low compressive strength after

impact has been one of the -in obstacles to wider application of composites.

Reduction of impact damage requires the use of tougher resins; yet, too tough a resin may inadvertently transfer too much load to the fibers during impact, resulting in unwanted fiber fracture. A compromise should be made between matrix/interface cracking and fiber break through proper selection of 
resin toughness. Nevertheless, a tough resin usually yields a higher compressive trength after impact than a brittle resin does.

Aa discussed earlier, much progress has been made lately in the development of toughened thermosetting resins for composites. As a result, there are a variety of toughened resins available at present. In addition, the high-performance thermoplastic resins in Table 3-4 all exhibit high toughness.

In general, a tougher resin yields a tougher composite. The relationship between the neat resin tracture energy and the composite interlaminar fracture energy pps..s to be bilinear (Hunston, 1987). When the resin is brittle, the composite has a higher interlaminar fracture energy than the resin fracture energy, mainly sosause of the fiber bridging. As the resin becomes tougher, however, not ill the resin toughness is translated to the composite toughness. In fact, the composite fracture energy is only close to the rule-of-mixtures estimate.

There are other ways of improving the impact resistance of composite laminates. One method is to place a tough resin interleaf between plies to arrest ply cracks and to accommodate large, local shear stains induced by impact. The other is to provide reinforcements in the thickness direction by stitching (Hunston, 1990). These methods can be implemented without incurring too high a cost.

Glass fibers are more resistant to impact damage than carbon fibers. Thus, any scheme of composite toughening is expected to work better with glass fibers than with carbon fibers.

\section{WOOD/EPOXY COMPOSITES}

When the firgt wood/epoxy blade 3 were designed for the 38-m (125-foot) diameter NASA MOD OA wind turbine: the available material properties data were $11 \mathrm{~m} 1 \mathrm{rea}$. A survey of the compression, shear, and bending strength of many wood species was available in the U.S. Forest Products Wood Handbook (1974), along with equations to correct the base values to different moisture levels. Values for along-the-grain modulus of elasticity and across-the-grain tension and compression strength were also available in these 8 . These data were valuable in assessing which species would likely be best suited to wind turbine use and in estimating the weight, stiffness, and static strength of a candidate design. However, only minimal guidance concerning the effects of fatigue, load duration, and component size on long-term allowable strength was given.

Some research on wood fatigue was available from long-term, constantdeflection, bending tests performed in the 19408 by $W$. J. Rommers (1943a, $1943 \mathrm{~b}$ ). These tests did not cover a wide range of $R$ ratios, or allow a clean separation of tension, compression, and shear strength, but they did provide lower bounds for those properties and showed that the base wood material had potentially attractive high-cycle fatigue capability. The effect on strength of the epoxy, or of the butt joints that would be needed to assemble a blade from individual veneer sheets, was simply unavailable, for either static or fatigue conditions. Questions of how moisture and temperature variations would interact with the above in high-cycle fatigue to determine long-term allowable strength were also unanswered. Engineering judgment to extrapolate from a few sources of available test data plus conservative design to cover areas of materlal property ignorance were, therefore, a requirement for the initial design work.

When the initial design studies began to reveal considerable promise for wood/epoxy as a wind turbine blade material, testing of a few key strength features quickly followed. For the base material, this meant some strength testing of fir/epoxy laminate, both with and without typical butt joints. For the critical blade-to-hub connection, it meant botr stati= and fatigue testing of the bonded steel stud load takeoff systen, as the earliest versions of these studs did not have the strength required for the MOD OA application, and rapid design evolution was needed to gain a demonstrated margin against the design loads (Faddoul, 1981). Static and fatigue performance was further demonstrated by a 20-foot test article that was in essence the inboard one- 
third of the full size blade. While a great deal was still unknown about the fundamental material and joint properties at this point, factors critical to this particular design were well enough known that the resulting blades served successfully in the field fOr the duration of the DOE/NASA MOD OA program (Lark et al., 1983; Faddoul, 1983).

Smaller blades for the Enertech 13.4-m (44-foot) diameter and ESI 16.5m (54-foot) diameter machines were designed with about the same level of basic knowledge and also served successfully in the fleld, with cae such machine now having over 25,000 operating hours (Clark et al., 1985). Of the thousands of such blades built and used, none has been retired because of fatigue. Only falluxes from lightning strikes, storms, machine runaway" or similar incidents have been reported.

While the economics of small blades and early wind machines could tolerate some design margin to cover incomplete materials data, larger machines aiming for more cost-effective energy production did not possess as much weight tolerance. This became most evident in the DOE MOD 5A program, which was a teetered, two-bladed upwind design that eventually grew to 122-m (400-foot) in rotor diameter and over $7 \mathrm{Mw}$ in rated power. Steel, GRP, and wood/epoxy were all assessed in the initial rotor trade-off studies, and it became quite clear that the gravity-induced stresses from rotor weight were a significant design driver and that high-cycle material allowables had a big impact on rotor weight and cost. Wood/epoxy was eventually selected for this project, as it showed the lightest weight and least cost. But it was known that major gaps in the material and joint properties data would have to be filled to use the material efficiently and confidently, and so a major test program was initiated to support this design effort. The eventual testing included tensile tests of specimens 9.1-m (30-foot) long, with a $61-\mathrm{cm}$ (24inch) by $15-\mathrm{cm}(6-i n c h)$ cross-section, that took over 1 milition pounds to fail in static tension. Both static testing and fatigue testing of planks up to 5-

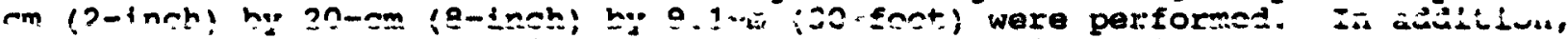
a great many lab-size opecimens were tested. Materials with butt foints, scarf joints, and without joints were compared to quantify the ef fect of joints. Shear testing at joints, both with and without bonding voids, was performed both in fatigue and static loading. While the MOD $5 \mathrm{~A}$ was never built, the legacy of that program was a vast improvement in the depth and breadth of wood/epoxy material property data, only part of which has been mentioned here.

In 1986, Gougeon Brothers, Inc., under a DOE/SBIR (Small Buginess

Innovative Research) award, carried out a study to advance the performance of jointed veneer laminate. This was followed by a Phase II grant to extend the initial joint investigations with more fatigue tests (including micromechanical study of crack propagation at joint sites) and to study a range of other material property topics, such as cross-grain tension $\left(\sigma_{y}, \sigma_{z}\right)$ and rolling shear $\left(\tau_{y z}\right)$ strength (see Figure 3-5) in both static and fatigue loading as a function of $81 z e$ and the mechanical and cost performance of graphite fiber augmentation between the veneer layers for high-stress applications.

The work covering the MOD 5A experience has been prepared by NASA and was recently released (spera et al., 1990). The experimental data from these extensive research efforts, along with in-house work at Gougeon Brothers, and material research published as part of the British wood/epoxy wind turbine blade efforts (Ansell et al., 1987; Bonfield et al.), have tremendously advanced current knowledge of these material properties, even though some gaps in the data still remain. A discussion of some of the main features of these data follows to outline a number of the major lessons learned, some of which may also be applicable to GRP or other candidate blade materials.

The static tension and compression strengths of wood/epoxy laminate are distirstly different and respond differently to various factors. For instance, 1088 of along-the-grain strength with increasing size 28 much more severe in tension than in compression.

This reduction of strength with increasing size is called size effect. It is a stochastic process due to the accumulation of material defects as item size/volume increases. The worst such defect in the stressed volume 1 imits 


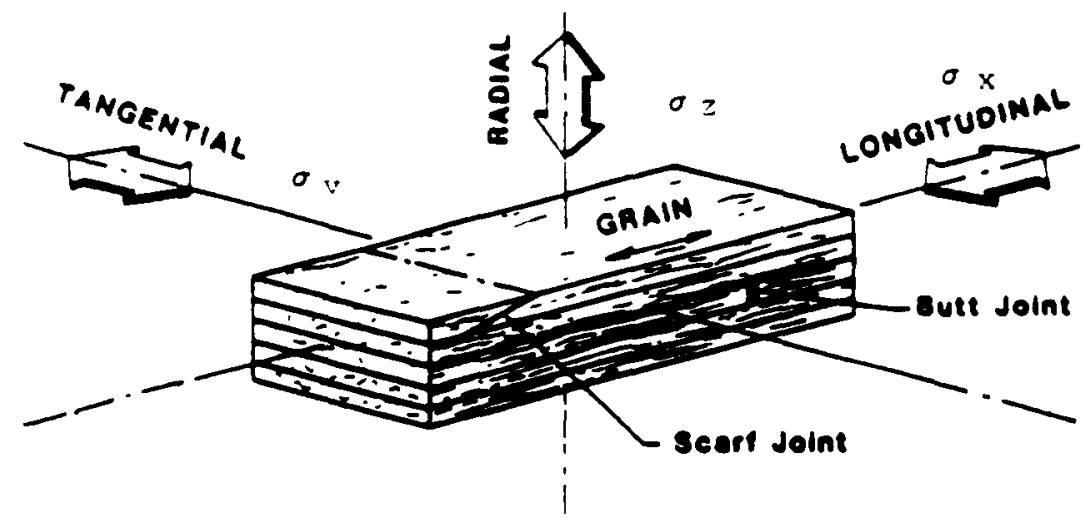

LAMINATE DIAECTIOMAL PROPERTIES

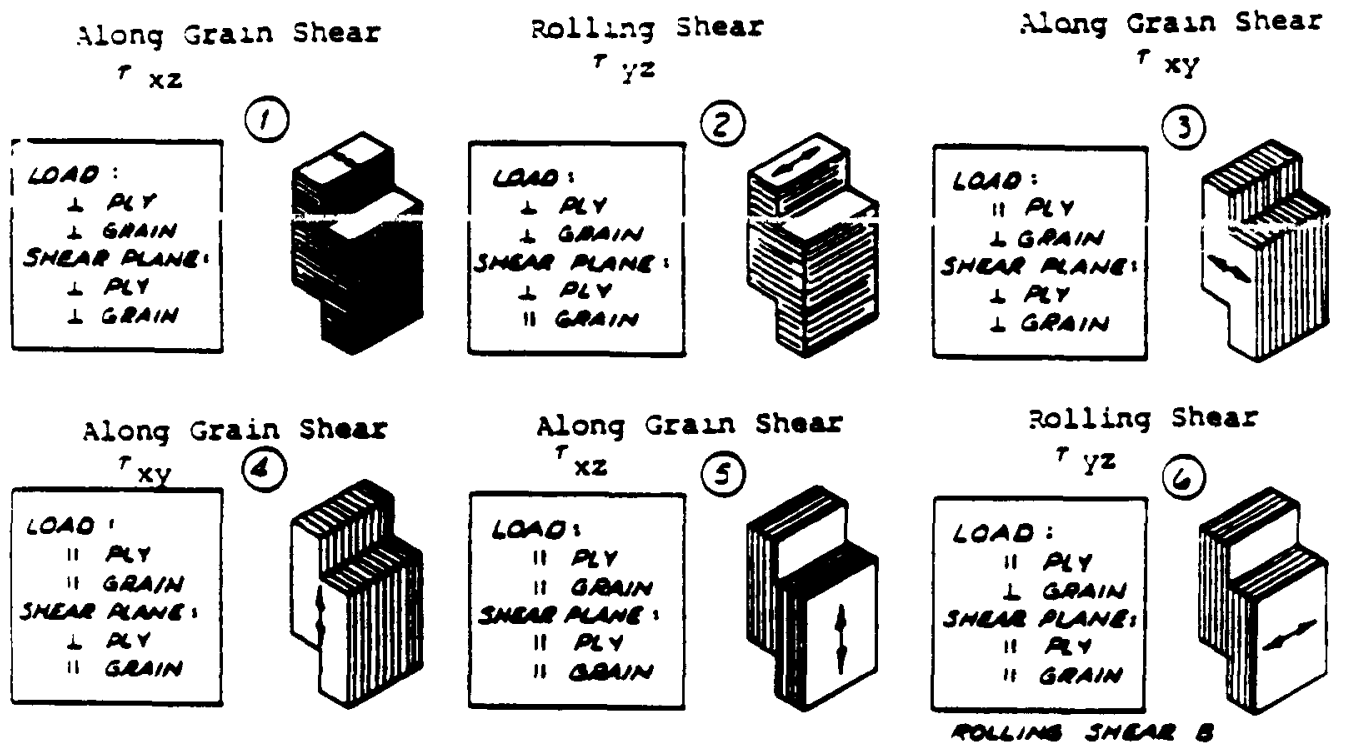

NOTES:

1. Arrows indicate grain direction (X-direction)

2. Loading direction in vertical all six cases:

3. Symbol :

II : parallel to.

1. perpendicular to . 
strength in a statistical fashion. A tiny specimen of fir may show static tensile strength nearly twice its static compression strength, but for laminated members the size of large wind turbine blades, the static tension and compression strength will be about equal. This is due to a much more rapid loss of strength with size for tension than for compression. Early tests of $81 z e$ effect relied on beams in bending (Bohannan, 1966), but due to the nonlinearity of stress through the thickness resulting from crushing on the compression side, it was difficult to cleanly separate the tension and compression stresses at fallure. This nonlinear effect is why a stick snaps on the tension side whan bent, despite its greater tension strength capability. For adequate sess design of large wind turbine blades, this "gize effect" must be separat sd, understood, and accounted for, as the strength correction relative to mall laboratory samples can easily reach a factor of 2 in tension. Fortunately, size effect is now reasonably well quantified for static tension in wood/epoxy, although the less severe static compression case is otill not well quantified.

While size effects along the grain $\left(\sigma_{x}\right)$ are design drivers because they directly affect the allowables in the primary structure of the wind turbine blade, across the grain strength $\left(\sigma_{y}\right.$ and $\left.\sigma_{z}\right)$ (analogous to through the ply strength $\sigma_{z}$ for GRP) (Figure 3-5) shows far bigger static strength differences and 日ize effect (Barrett, 1974; Barrett et al., 1975; Weibull, 1939). For typical wood/epoxy laminates, across the grain tensile strength may be only one-fourth of the across the grain compression strength, and perhape onetwentieth of the along the grain tensile atrength (Table 3-6). Making matters worse is the fact that size effect in cross-grain tension is much more severe than along the grain, and differences between atrength levels measured with small samples in the laboratory and those for large structures in the field could exceed a factor of 5. The upshot of this is that cross-grain tension stresses that may sam $=2$ madsst as to be of little concern to the unwary designer could in fact lead to tracture initiation and eventual failure of large, expensive blades in the fleld.

In contrast to the potentlally dangerous crosg-grain tension case, across the grain "rolling" shear has been found to exhibit a very modest size effect, and lab data can be safely applied to large static structures with very little correction. This also appears to be the case for cross-grain compression, although the data are rather incomplete for that case.

It has been known for some time that both temperature and moisture have a direct effect on the static strength of timber, and this holds true for the derivative wood/epoxy laminate as well, with some adjustments. Temperature effects are essentially those of the wood species used since it carries the bulk of the stress, and, given that temperature is relatively constant throughout a thick laminate, laboratory samples can be used to predict laminate effects (Figure 3-6). On balance, temperature effects are modest and fairly well understood, and, like GRP, it is the upper temperature extreme that must be accounted for in design. Ten to 30 percent strength reductions would not be unusual in a computation of worst-case static strength compared to room temperature.

Moisture effects are modified for wood/epoxy laminate to the extent that the epoxy seals out liquid water entirely and is a fairly effective barrier to the passage of molsture in the form of water vapor. As a result, a large structure will not respond to the short-term moisture fluctuations in its environment, but will instead come to equilibrium with the average humidity over a period of months to years (Figure 3-7). Static tension strength shows a much more modest effect from moisture in the normal outdoor range than does compression strength (Figure $3-8$ ), but accurate design may require taking both into account depending on which property limits a specific design. If typical 12 perment wood moisture content reference data are used in design, most use environments are already covered, but a 10 Jr 20 gercent strength credit may be available for dry environments, such as the california wind farms. 
TABR 3-6 Typical' static strongth, TYpe 110 Laninate

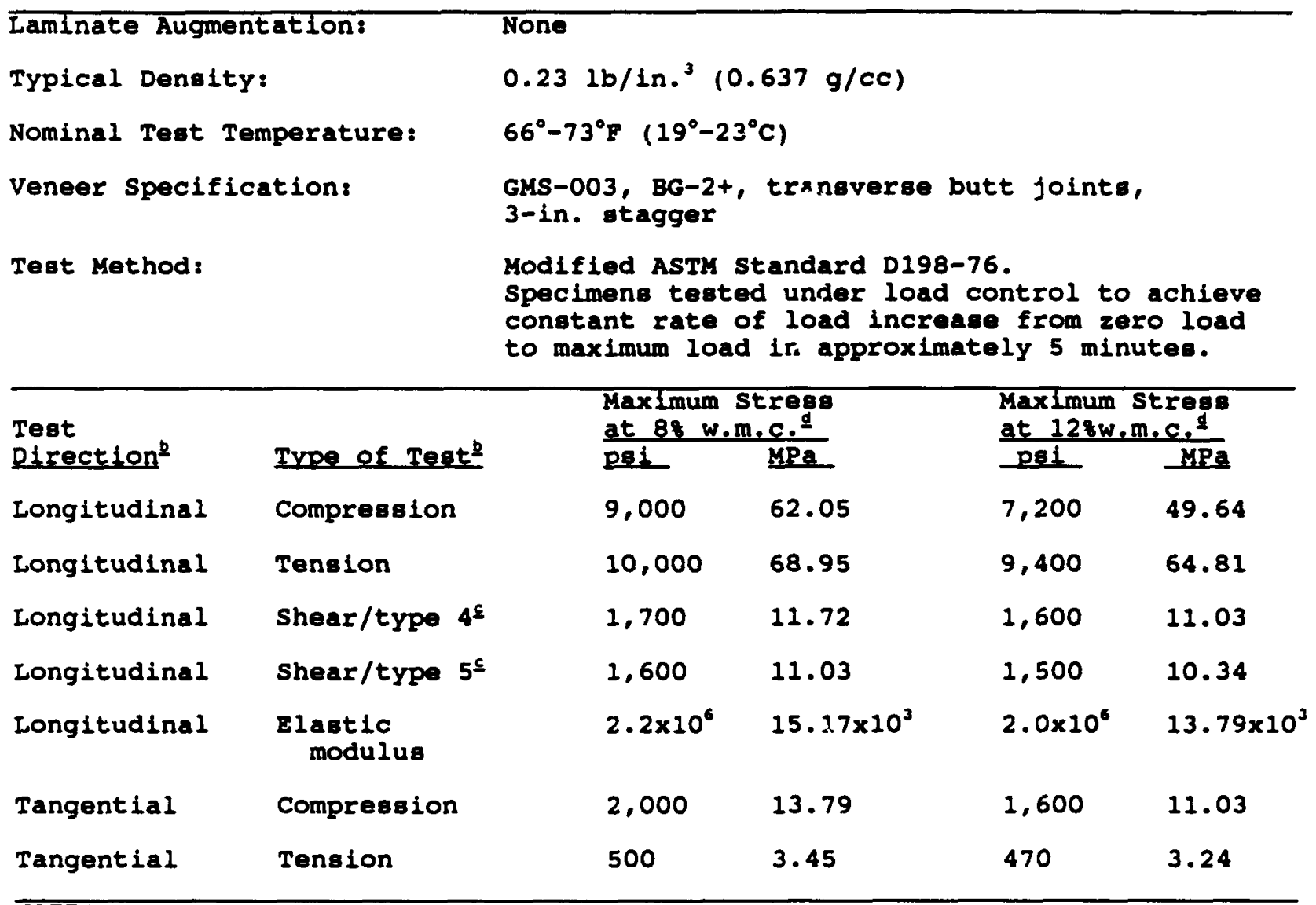

\section{NOTES}

- These typical properties represent a composite of laboratory test data from specimens having various moisture contents and uniformly stressed volumes ranging from 19.5 in. $^{3}$ to 194.0 in. $^{3}$ (319.5 to $\left.3179 \mathrm{cc}\right)$. Properties are representative of structures similar to small wind turbine blades. Larger structures are characterized by lower mechanical properties. Adjustments in properties due to size effects and other conditions are considered by Gougeon Brothers in engineering each application.

b See Figure 3-5 for illustration of stress directions.

c See Figure 3-5 for laminate shear orientations.

d Asgumed wood moisture content. 


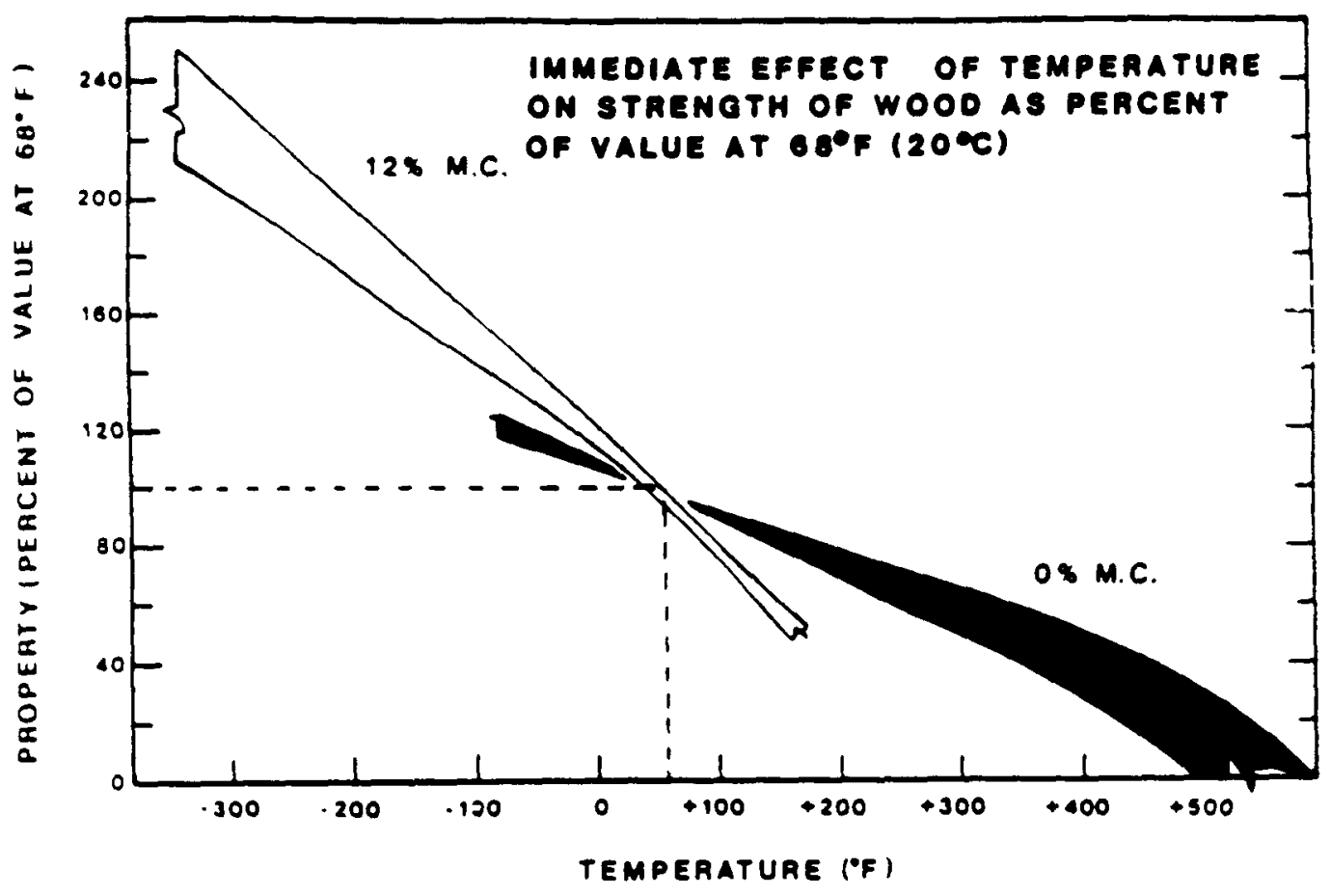

FIGURE 3-6 hood strength change due to temperature at two moisture coniltions (H.C. = moisture content).

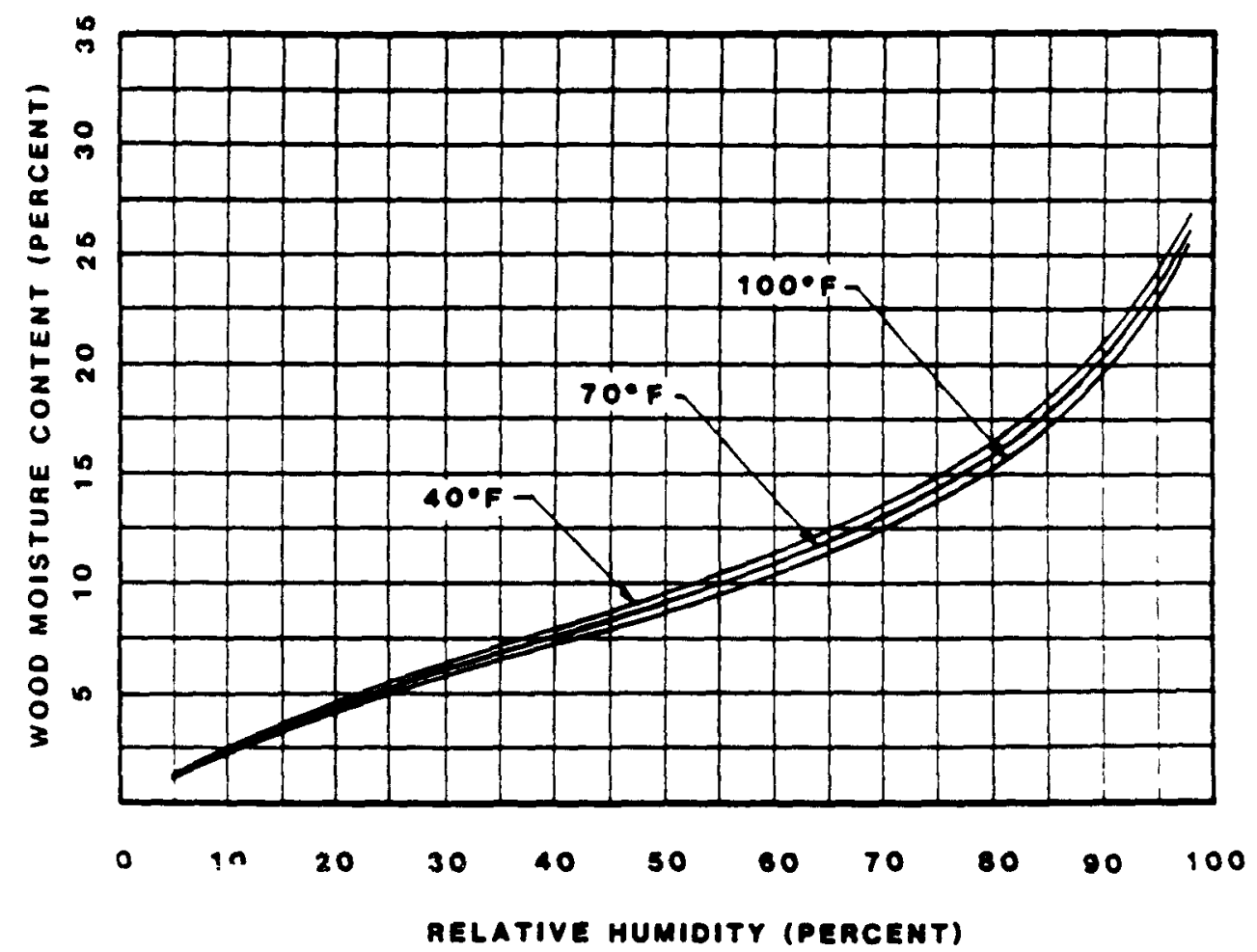

FIGURE 3-7 Wood moisture content versus atmospheric relative humidity. 


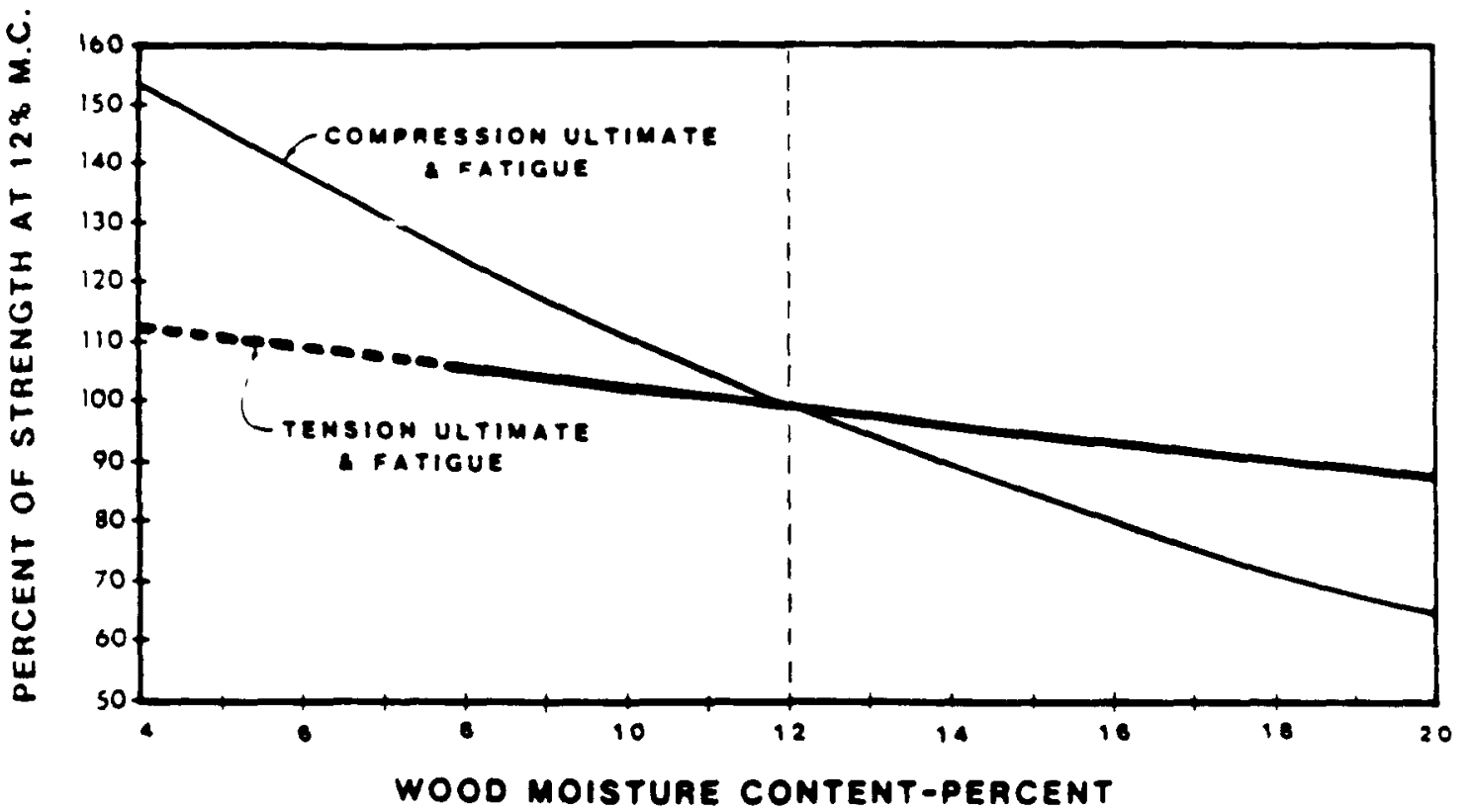

FIGURE 3-8 Effect of moisture content on laminate mechanical properties.

It has long been known that duration of load has a direct effect on the static strength of timber beams ${ }^{1}$ (Gerhards, 1977; Barrett and Foshi, 1978). For a 10-year steady load duration, the maximum load would be about 60 percent of that which could be carried in a test whose duration was only minutes. Limited test data confirm that duration and associated rate of loading effects exist in wood/epoxy laminates as well, but at present these data cannot be used to make accurate predictions for long field exposure. Separate data for tension and compression over a sufficientiy long time span simply are not available. Also, there is reason to suspect that stabilization of the moisture level within the laminate due to the epoxy will retard the creep rupture mechanism compared to the unprotected timbers of earlier testa. However, no theory for estimating this, or reliable data for engineering use, is currently available, so the rather large traditional strength reduction must still be used until better information becomes available.

All of the above effects continue to play a role in determining the safe fatigue strength of wood/epoxy laminate, but their description, interaction, and quantification become more complicated for fatigue compared to atatic strength. To provide a logical separation of tension from compression fatigue effects, Department of Energy (DOE) laminate testing has concentrated on three primary loading cases: $R=0.1$ tension (Figure $3-9$ ), where the load in always tension and the least tensile stress is one-tenth of the largest; $R=0.1$ compression (Figure 3-10), where the load is alway compressive and the least conipressive stress is one-tenth of the largest; and $R=-1$ Isverged axial

'This is due to viscoelastic relaxation, which leads to creep rupture failure under large steady loads. 


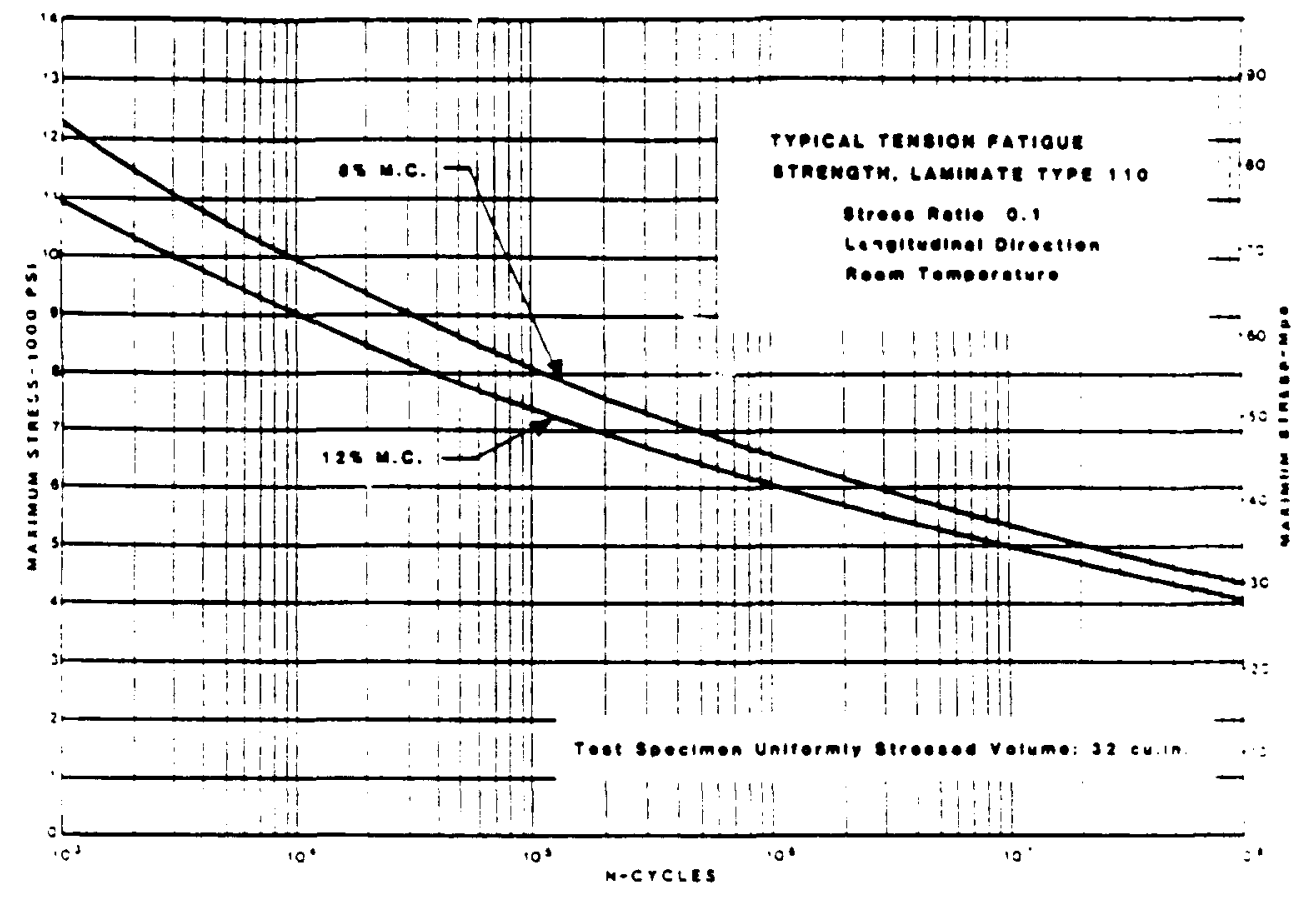

FIGURE 3-9 Typical tensile fatigue strength of wood/epoxy laminate.

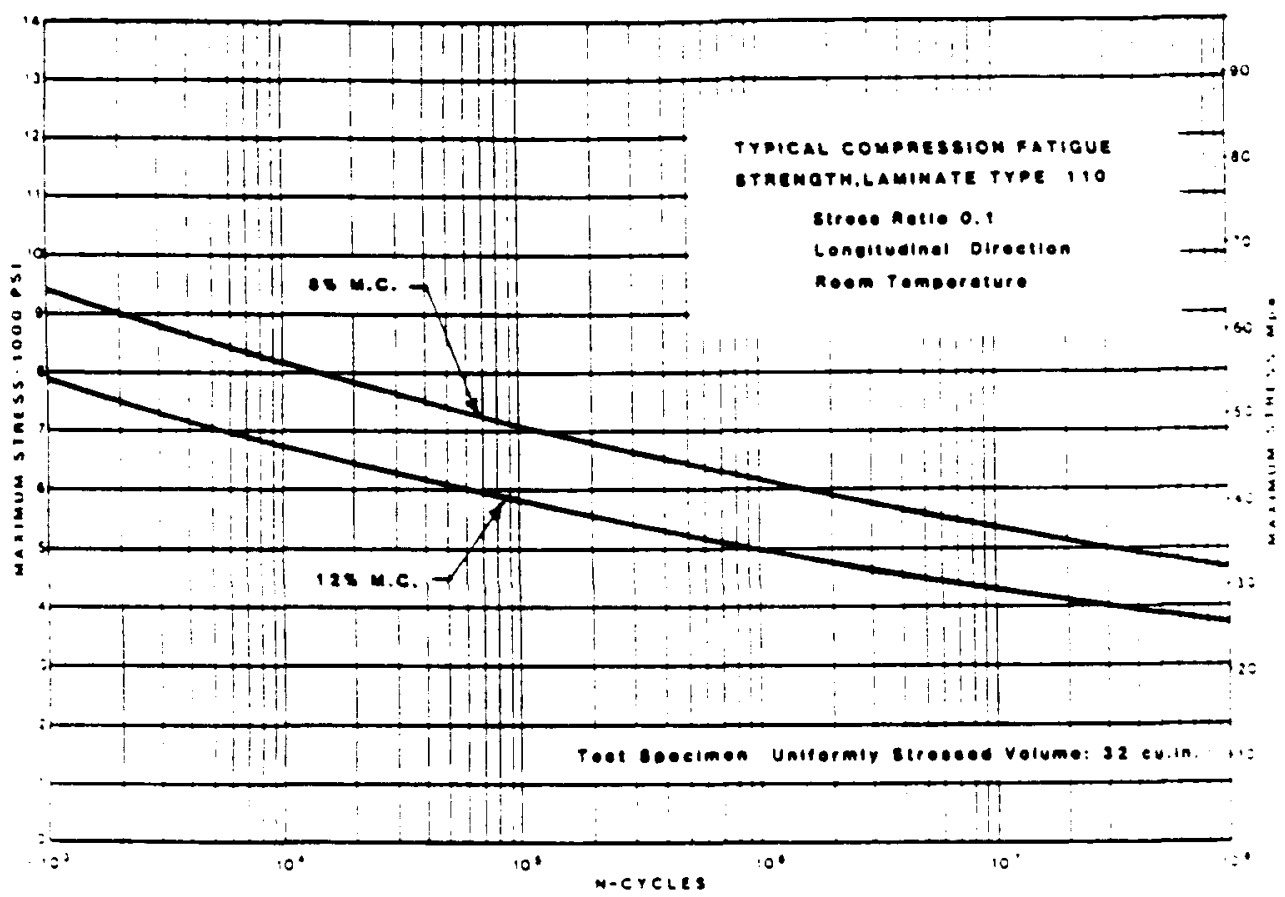

FIGURE 3-10 Typical compression fatigue strength of wood/epoxy laminate. 


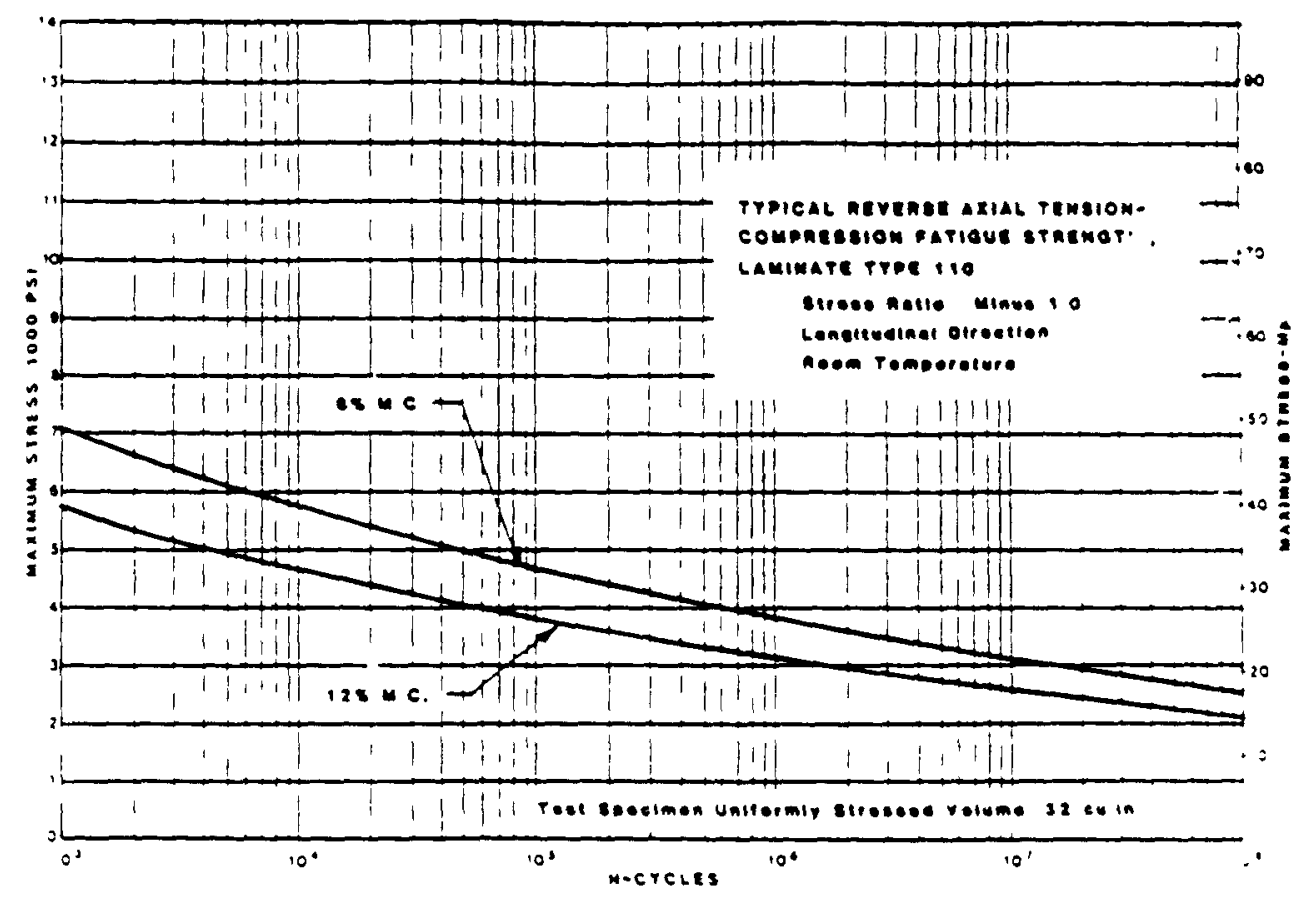

FIGURE 3-11 Typical reversed stress fatigue strength of wood/epoxy laminate.

(Figure 3-11), where the stress alternates between equal levels of tension and compression on each fatigue cycle. As is seen, the first two cases are pure tension and pure compression, and the last involves both tension and compression to reveal interaction effects. These cases correspond reasonably well to major design-driving stresses in many wind turbine blade designs. The nonreversing $R=0.1$ tension and compression loads are similar to those found in the upwind and downwind blade structures due to aerodynamic lift in the blade, while loads that are nearly fully reversing will be found near the blade's leading and trailing edges due to the deadweight gravity bending moment.

Testing (both with and without joints in the laminate) shows the lowest strength levels and most rapid loss of strength with increasing cycles for the reverged load $R=-1$ case. Strength levels for $R=0.1$ tension fatigue can be 50 to 100 percent higher than for reverse axial, but the rate of strength loss with cycles is similar. Depending on size, compression strength will generally be somewhat lower than tension at low cycles, but its gtrength loss rate is only about two-thirds of that for tension, so it can cross over and exceed tensile otrength at higher cycles, particularly for large blades. These strength 1088 rates tend to be $s$ for each type of loading over a wide range of cycles. Consequently, the data plot as a straight line on a log-log stress versus number of cycles (S-N) plot. This linear trend certainly holds valid up to $10^{7}$ cycles; there are not enough data beyond that to determine where or if a fatigue endurance limit exiats. That knowledge could be valuable for better assessment of very high cycle strength and life, but the appropriate data are expensive and time consuming to obtain. Current lifa and gtrength assessments are forced to assume that the 1088 of strength shown at lower-cycle levels continues at the same rate to arbitrarily high cycles.

The effect of size on strength varies dramatically with the type of loading. While size effect for static tenslle strength along the grain shows strength loss that can be a factor of 2 between laboratory samples and large 
blades, it becomes worse for tension fatigue where it can reach roughly a factor of 3. For fully reversed $R=-1$ fatigue, the size effect drops back about to the 2:1 level of static tension. Size effect data for compresaion fatigue and static compression strength are minimal, but size effect appears to drop further to perhaps $1.5: 1$ for $R=0.1$ compression fatigue and to some lesser but ill-defined value for static compression (Spera et. al., 1990). Recent research work in 8 ize effect in the secondary material properties of cross-grain tension and rolling shear was not able to cover the range of $R$ ratios needed to draw conclusions aimilar to the above, but it revealed a new phenomenrn di:a to carefully controlled sample design and test structure, namely that. gize effect is more severe for higher-cycle levels. While rolling shear shcwed Jiry little 108 s of strength with size in static tests, that was no longer true at $10^{6}$ cycles; and while cross-grain tension did show substantial size effect in static tests, it again became considerably greater at $10^{6}$ cycles. An associated effect is that the fatigue curve slope, the rate of strength $108 \mathrm{~s}$ with cycles, is larger for the larger specimens. So not only do larger specimens start out with a lower initial static strength, that strength is lost faster on a fractional basia in fatigue than it is for smaller samples (Bertelsen and Zuteck, 1991).

These lessons in size effect are important and will be increasingly so as wind turbines grow larger for economic reasons. There is good reason to suspect that size effect will occur in all materials currently contemplated for future wind turbine rotors, including GRP and metals, particularly for high-cycle fatigue. We now have experimental proof that low levels of size effect in static tests are no assurance of its absence in high-cycle fatigue, and designs undertaken in ignorance of these effects could lead to expensive or even dangerous failures in future large-scale machines.

The interaction of long-term environmental effects with the fatigue process has bees partially addressed in wood/epoxy design by running fatigue tests at range of temperature and moisture levels. However, it was found that the cycle rates typlcal for long-auration tests arove substanciai moisture from the test specimens, thereby elevating their strength and fatigue performance. This may not occur in the same way at the lower-cycle rates and intermittent use that occurs in the field, so caution must be exercised lest the elevated performance of laboratory samples lead to excessive high-cycle fatigue expectations in the field.

The effect of veneer splice joints on strength is much more pronounced in fatigue than in static strength. Early work quickly highlighted this and showed that 10 to 20 percent strength loss could easily occur owing to these tiny joints distributed throughout the laminate. The effects were particularly apparent in tension and in high-cycle fatigue. The first attempts to combat this by using beveled scarf joints between the veneers met with only limited and frustratingly intermittent success. In the large-scale fatigue specimens, performance was decidedly poor, and zipper-like failures through large numbers of joints often occurred. This puzzing state of affairs has been investigated at length in the recent Small Business Innovative Research (SBIR) research work and was traced to expanding gas driving resin from the foints during the vacuum molding process (Bertelsen and zuteck, 1991). The path to higher-performance joints through mitigating this effect now seems clear in principle, but a practical manufacturing method has yet to be proven. The important general lesson is that defect-driven failure modes that are hard to spot in small specimens tested in static or low-cycle loading may emerge as major issues in bulk specimens tested to moderately high cycles. It is difficult to see how the high-cycle fatigue performance of large structures can be assured without at least a few tests of large-volume specimens to elevated cycles. Fortunately, considerable data of this sort now exist to support the most critical design areas of large wood/epoxy wind turbine blades. However, those data are by no means complete, and comparable data for design in GRP are unzyailen?

Practical limits to the amount of materials data available will always exist, and perfect knowledge is not necessary to execute a successful design. The benefit of improved materials knowledge is that a more appropriate design that sidesteps pitfalls without undue cost can be provided and can be put into service with a much lower uncertainty as to its operating envelope and 
expected life. The record of wood/epoxy blades in the field has been excellent despite early materials data limitation due to confining the design window to stay within available knowledge. A wider degign window ls now available due to knowledge accumulated over the past decade. This will be needed in addressing the larger, more cost-effective designs that are needed in the future. A still broader design window can be opened by addressing the known shortfalls in the existing data and any additional ones that may be revealed as further advanced blade design occurs.

\section{PEEUMCENDATIONS}

When designed and manufasturesc properly, glass/polymer and wood/epoxy rotor blades can provide tens if thousands of hours of operating time. The recent advances in composites technology, however, may provide an excellent opportunity to further improve the blade cost/performance. The knowledge base gained over the past two decades in the aerospace industry can now be used to assess these more efficient blade designs using advanced composites. What is needed is a focused research to refine the design along with improved materials knowledge in certain key areas. Specific recommendations for further research are described below, in the order of priority:

1. Long-term fatigue data should be generated to at least 100 million cycles for the most useful composite laminates and critical elements containing manufacturing defects, under appropriate environmental conditions. Separate tension and compression fatigue data should be generated so that independent lifetime projections for upwind and downwind portions of blade skin can be made. Fully reversed fatigue data should also be obtained for the projection of life against edgewise gravity loads. Moderate-cycle $R$ ratio data may be needed to fully define meterial fatigue response. The data should include documentation on the morea ant growth of damage as well as the effect of damage on properties.

2. At least a few large specimens of the favored composite laminates should be tested in moderate- to high-cycle fatigue to quantify the fatigue gize effect allowance that must be made for large rotors in the primary loading regimes. All loading cases are needed for GRP. For wood/epoxy, size effect in static compression and compression fatigue is not yet quantified. Sui tests comparing small and lazge specimens of matched parent material are needed to fill this gap in the data.

3. Spectrum loading data to assess the available cumulative damage models are not yet available but are needed to fully quantify high-cycle life predictions. A life prediction methodology should be developed to predict blade lifetimes based on constant-amplitude fatigue data. It should also be able to predict the modes and growth of damage.

4. A database should be established for wind turbine blade materials. It should include mechanical properties on fibers, matrix resins, and composites, including wood/epoxy. An extensive search of all fatigue data on both GRP and wood/epoxy should be conducted and the results included in the database.

5. Benefits of hybrid composites should be explored through design and limited testing. Design studies should investigate savings on blade weight and life-cycle cost. The best hybrid reinforcement appears to be carbon for either GRP or wood/epoxy.

6. Duration of load and creep effects are incompletely understood for wood/epoxy laminate. It appears that epoxy stabilization of moisture levels reduces creep rate and magnitude, but data to verify and quantify this for design are needed. Furthermore, moisture correction for laminate in the 5 to 12 percent operating range is still based primarily on old literature data. A better database would improve life predictions.

7. Promising fiber preforms should be identj fied and examined under

fatigue. Low-cost processability should be taken into consideration.

8. Environmental effects, including ultraviolet exposure, moisture absorption, and temperature fluctuations, should be delineated for the candidate composites and surface coatings.

9. Tough new resins should be examined for their applicability to rotor blades. 


\section{RETERENCES NID BIBLIOCRNPHY}

Ansell, M. P. 1987. Layman's Guide to Fatigue. The Geoff Pontin Memorial Lecture, eponsored by British Tradewinds. Wind Energy Conversion, ed. by J. M. Galt, Mechanical Engineering Publications Ltd., London.

Ansell, M. P., P. W. Bonfield, and K. T. Tria. Fatigue Testing of Laminated Wood for Generator Blades. School of Materials Science, University of Bath, England.

Bach, P. W. 1988. High Cycle Fatigue of Glassfiber Reinforced Polyester. Presented at the IEA Workshop on Fatigue in Wind Turb:res in Harwell, United Kingdom.

Barrett, J. D. 1974. Effect of Size on Tension Perpendirular to Grain Strength of Douglas-Fir. Wood and Fiber.

Barrett, J. D., and R. O. Foschi. 1978. Duration of Load and Probability of Failure in Wood. Part II. Constant, Ramp, and Cyclic Loadings, Canadian Journal of Civil Engineering, Vol. 5.

Barrett, J. D., R. O. Foschi, and S. P. Fox. 1975. Perpendicular to Grain Strength of Douglas-Fir. Canadian Journal of Civil Engineering, Vol. 2 .

Bascom, W. D., J. L. Bitner, R. J. Moulton, and A. R. Siebert. 1980. The Interlaminar Fracture of Organic Matrix, Woven Reinforcement Composites.

Bertelsen, W. D., and M. D. Zuteck. 1991. Investigation of Fatigue Failure Initiation and Propagation in Wind-Turbine-Grade Wood/Epoxy Laminate

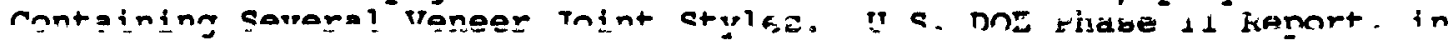
preparation.

Bohannan, B. 1966. Effect of Size on Bending Strength of Wood Members. U.S. Forest Service Research Paper, FLP 56, May.

Bonfield, P. W., and M. P. Ansell. Fatigue Testing of Wood Composites for Aerogenerator Rotor Blades. School of Materials Science, Bath University, England.

Bowen, D. H., C. W. A. Maskell, D. C. Phillips, T. W. Thorpe, G. M. Wells, and N. J. M. Wilkins. 1984. Materials Aspects of Large Aerogenerator Blades. Proceedings of the European Wind Energy Conference, Hamburg, West Germany, October 22-26, p. 281 .

Bucknall, C. B. 1977. Toughened Plastics. Applied Science Publishers.

Chou, T.-W., R. L. McCullough. and R. B. Pipes. 1986. Composites.

Scientific American, Vol. 254, October, p. 193.

Christensen, R. M., and J. A. Rinde. 1979. Transverse Tensile

Characteriatics of Fiber Composites. Polymer Engineering Science, Vol. 19, 506.

Clark, R. N., F. C. Vosper, R. G. Davig, and W. E. Pinker. 1985. Operational Data From Bushland Wind Turbines. Final Report. U.S. Department of Agriculture (USDA), Agricultural Research Service, USDA Conservation and Production Research Laboratory, Bushland, Texas. Prepared for Electric Power Research Institute, Palo sito, Califínia.

Composites \& Laminates. 1987. Edition 1. D.A.T.A., Inc.

Downing, S. D. and D. F. Socie. 1982. Simple Rainflow Counting Algorithms. International Journal of Fatigue, Vol. 4, p. 31. 
Engineered Materials Handbonk. 1987. Vol. 1. Composites. ASM International. Faddoul, J. R. 1981. Test Evaluation of a Laminated Wood Wind Turbine Blade Concept. DOE/NASA/20320-30, NASA TM 81719, May.

Faddoul, James R. 1983. Examination, Evaluation, and Repair of Laminated Wood Blades After Service on the Mod-OA Wind Turbine. DOE/NASA/20320-53, NASA TM-83483, October.

Garrad, A. D., and U. Hassan. 1986. Dynamic Analysis of Wind Tr.rbines for Fatigue Life Prediction. Presented at the 8th BWEA Meeting in Cami-idge, United Kingdom.

Gerhards, C. C. 1977. Effect of Duration and Rate of Loading on Strength of Wood and Wood-Based Materials. USDA Fore日t Service Research Paper, FLP 283.

Gougeon Brothers, Inc. 1985. Engineered Laminates. Technical Bulletin $\# 1$, Bay City, Michigan, April.

Hahn, H. T. 1979. Fatigue Behavior and Life Prediction of Composite Laminates. Composite Materials: Testing and Design (5th Conf.), ASTM STP 674 , p. 383.

Han, Y.M. and H. T. Hahn. 1989. Design of Composite Laminates with Ply Failure. Proceedings of the 34th International SAMPE Symposium, p. 529.

Hartness, T. 1988. Thermoplastic Powder Technology for Advanced Composite Systems. Proceedings of the 33rd International SAMPE Symposium, p. 1458.

Hertzberg, R.W. and Manson, J.A. 1980. Fatigue of engineering Plastics. Academic Press, New York, p. 124.

Hunston, D. 1987. ASTM STP 937.

Hunston, D. 1990. Advanced Materials and Material Forms. Presented at the NRC Workshop on Assessment of Research Needs for Wind Turbine Rotor Materials Technology, Washington, D.C., January 22-23.

Hwang, W. B. and K. S. Han. 1989. Fatigue of Composite Materials - Damage Model and Life Prediction. Composite Materials: Fatigue and Fracture, 2nd Vol., ASTM STP 1012, p. 87.

Johnson, W. S. 1985. Delamination and Debonding of Materials. ASTM STP 876.

Johnston, N. J., and P. M. Hergenrother. 1987. High-Performance

Thermoplastics," Proceedings of the 32nd International SAMPE Symposium, SAMPE, p. 1412 .

Jones, R. M. 1975. Mechanics of Composite Materials. Scripta Book Co.

Kinloch, A. J. and Young, R.J. 1983. Fracture Behavior of Polymers. Applied Science Publishers.

Kommers, W. J. 1943a. Fatigue Behavior of Wood and Plywood Subjected to Repeated and Reversed Bending Stresses. U.S. Forest Products Laboratory Report No. 1327.

Kommerg, 9. I. 1943b. The ratigue Behavior of Douglas-Fir and Sitka Spruce subjected to Reversed Stresses Superimposed on Steady Stresses. U.S. Foresk. Products Laboratory Report No. 1327-A.

Lark, R. F., M. Gougeon, G. Thomas, and M. D. Zuteck. 1983. Fabrication of Low-Cost Mod-OA Wood Composite Wind Turbine Blades. DOE/NASA/20320-45, NASA TM-83323, February. 
Launikitis, M. B. 1978. Chemically resistant FRP Resins. Technical Bulletin of Shell Chemical Company.

Lee H., and K. Neville. 1967. Handbook of Epoxy Resins. McGraw-Hill, New York.

Lee, B. L., C. K. Riew, and R. J. Moulton. 1980. Rubber Toughening of Tetrafunction-I Epoxy Resin. 12th National SAMPE Technical Conference.

Lee, B. L., F. H. Howard, and E. H. Rowe. 1983. Effect of Matrix Toughening on the Crask Resigtance of SMC Under Static Loading. 38th Annual Conference of SPI, Segrion 9-A.

Lee, S. M. 1986. Compression After Impact of Composites with Toughened Matrices. SAMPE Journal, March/April.

Lubin, G., Ed. 1982. Handbook of Composites. Van Nostrand Reinhold, New York.

Lynch, T. 1989. Thermoplastic/Graphite Fiber Hybrid Fabrics. SAMPE Journal, vol. 25 , p. 17.

Mandel1, J. F. 1990. Fatigue Behavior of Glass Fiber Composites. Presented at the NRC Workshop on Assessment of Research Needs for Wind Turbine Rotor Materials Technology, Washington, D.C., January 22-23.

McGarry, F.J. and J. N. Sultan. 1969. Crack Phenomena in Crosg-Linked Glassy Polymers. ASTM STP 460, ASTM.

McGarry, F. J.. E. H. Rowe, and C. K. Riew. 1978. Improving the crack resistance of BMC and SMC. Polymer Engineering Science, Vol. 18, p. 78.

Modern Power Systems, July, 1986, p. 19.

Morgan, C. A., A. D. Garrad, and U. Hassan. 1989. Measured and Predicted Wind Turbine Loading and Fatigue. Presented at the EWEC Conference in Glasgow, 1989 .

Moulton, R. J., and R. Y. Ting. 1981. Effects of Elastomeric Additives on the Mechanical Properties of Epoxy Resins and Composite Systems.

International Conference on Composite Structure.

Murtha-Smith, S. 1985. Loads and Fatigue Evaluation of Hamilton Standard WTS-4 Wind Turbine. Proceedings Wind Power ' 85 , San Erancisco, August 27-30, p. 136 .

Owen, M. J. 1974. Fatigue Damage in Glass Fiber-Reinforced Plastics. In Composite Materials, Vol. 5, ed. by L. J. Broutman, Academic Press, New York.

Phillips, D. C., J. McCarthy, A. G. Davis, and J. E. P. Stott. 1987. The Use of Glass Reinforced Plastics and Advanced Composites for Wind Turbine Blades. A Review of Experience in Their Use and of Relevant Design Procedures and Codes. Department of Energy, United Kingdom, June.

Properties of Epoxy Resins, Hardeners, and Modifiers. 1982. Adhesive Age, April.

Reifsnider, K. L., Ed. 1980. Damage in Composite Materials. ASTM STP 775.

Reifgnider, K. L., E. G. Henneke, W. W. Stinchcomb, and J. C. Duke. 1983. Damage Mechanics and NDE of Composite Laminates. Mechanics of Composite Materials. Recent Advances. Pergamon, New York, p. 399. 
Reifsnider, K. L., and W. W. Stinchcomb. 1986. A Critical Model of the Residual Strength and Life of Fatigue-Loaded Composite Coupons. Composite Materials: Fatigue and Fracture, ASTM STP 907, ed. by H. T. Hahn, p. 298.

Riew, C. K., E. H. Rowe, and A. R. Siebert. 1976. Rubber Toughened Thermosets. In Toughness and Brittleness of Plastics, ed. by R. D. Deanin and A. Crugnola, American Chemical Society. Washington D.C.

Rosato, D. V. and C. S. Grove, Ji. 1964. Filament Winding. John Wiley \& Sons, New York.

Scott, J. W. and D. C. Phillips. 1975. Carbon Fiber Composites with Rubber Toughened Matrices. Journal of Materials Science. Vol. 10, p. 551.

Sendeckyj, G. P. 1981. Fitting Models to Composite Materials Fatigue Data. Test Methods and Design Allowables for Fibrous Composites, ASTM STP 734, ed. by C.C. Chamis, p. 245.

Spera, D. A., J. B. Esgar, M. Gougeon, and M. D. Zuteck. 1990. Structural Properties of Laminated Douglas Fir/Epoxy Composite Material. NASA Reference Publication 1235, Report No. DOE/NASA/20320-76, May.

Springer, G. S., Ed. 1981. Environmental Effects on Composite Materials. Technomic Publishing Co.

Stoddard, F. S. 1989. Field Problems with Wind Turbine Rotorg. Presented at the First Meeting of the NRC Committee on Assessment of Research Needs for Wind Turbine Rotor Materials Technolojy, Washington, D.C., November.

Strong, A. B. 1989. Fundamentals of Composites Manufacturing. Society of Manufacturing Engineers.

Sutherland, H. J. 1989. Analytical Framework for the LIFE2 Computer Code. Sandia Report SAND89-1937 UC-905.

Tsai, S. W. 1989. Composites Design, Think Composites.

Tsai, S. W. and H. T. Hahn. 1975. Failure Analysis of Composite Materials. Inelastic Behavior of Composite Materials, ed. by C. T. Herakovich, AMD-Vol. 13, ASME, p. 73.

Van Delft, D. R. V., F. Hagg, and P. A. Joosse. 1987. The Influence of Fatigue Design Line Criteria on the Rotor Blade Design. Wind Energy Conversion 1987, ed. by J. M. Galt, Mechanical Engineering Publications Ltd., London.

Vinson, J. R., Ed. 1977. Advanced Composite Materials--Environmental Effects. ASTM STP 658.

Weibull, W. 1939. A Statistical Theory of the Strength of Material, Royal Swedish Academy of Engineering Sciences, Proc. 151.

Whitehead, R. S. 1990. Damage Tolerance of Composites. Presented at the NRC Workshop on Assessment of Research Needs for Wind Turbine Rotor Materials Technology, Washington, D.C., January 22-23.

Wilkins, N. J. M. 1984. Materials Aspects of Large Aerogenerator Blades. Prncoesings of the European Wind Energy Conference. Hamburg, West Germany, October 22-26, p. 281 .

Williams, J. G. and M. D. Rhodes. 1981. The Effect of Resin on the Impact Damage Tolerance of Graphite/Epoxy Laminates. NASA TM 83213, October.

Windpower Monthly. 1987. June, p. 10. 
Witzler, S. 1988. High-Temperature Thermoplastics: A Progress Report. Advanced Composites, March/April, p. 56.

Wood Handbook. 1974. Wood as an Engineering Material. U.S. Forest Products Laboratory, Agriculture Handbook No. 72 .

Yang, J. N. and D. Shanyi. 1983. An Exploratory Study into the Fatigue of Composites Under Spectrum Loading. Journal of Composite Matarials, vol. 17, p. 511.

Zweben, C., H. T. Hahn, and T. -W. Chou. 1989. Mechanical Behavior and Properties of Composite Materials, Vol. 1. Technolmi = Publishing Co. 


\title{
WIND TURBINE ROTOR DESIGN ISSUES
}

\author{
rind turbine rotor blades are a high-technology product that must be \\ Froduced at moderate cost for the resulting energy to be competitive in price. \\ This means that the basic materials must provide a lot of long-term mechanical \\ performance per unit cost and that they must be efficiently manufactured into \\ their final form, including the cost of sufficient quality control. Unless a \\ material choice and fabrication system can satisfy both of these requirements, \\ it will not be appropriate for advancing the state of the art for economical \\ production of power from the wind. \\ Both fiberglass-reinforced and wood/epoxy composites have been shown to \\ have the combination of strength and low material and fabrication costs \\ required for competitive blade manufacture. Their fabrication requirements \\ and constraints, the current state of their materials database, and the areas \\ where further research could advance their efficient use are, however, often \\ quite different. The gradual evolution of wind turbine configuration and \\ rotor designs also places a continuing demand on both syatems to meet new \\ requirements. In turn, the strengths and limitations of each material system \\ also feed back into the process of system configuration gelection and detailed \\ design, as any design that cannot be efficiently produced will be at a \\ competitive cost disadvantage. A really good design will already include the \\ compromistu necessary so tnat lt can ve etfectively manuiacturea wili \\ acceptable quality in the material system chosen. A number of these \\ considerations are discussed below.
}

\section{AIRFOIL EVOLUTION}

Early wind turbine blades typically used airfoil shapes borrowed from helicopter or low-speed aircraft use, such as the NACA $23 \times x x$ or $44 x x$ serieg (Figure 4-1). These airfoils have shapes that are everywhere convex and in particular do not have a concave or reflex aft portion. While these were a natural starting point, they were found to be sensitive to the buildup of insects on the leading edge, which caused substantial loss of power output for many wind turbine designs.

Further evolution of airfoil choice in view of field experience has led to the use of the more modern Wortmann or NACA laminar designs, as well as the aft loaded LS-1 type. These airfoil designs generally employ a reflex or concave aft portion, which feature is also evident on the special-purpose SERI wind turbine airfoils (Figure 4-2). That concavity effectively eliminates certain manufacturing processes, such as filament winding, from consideration for producing the outer airfoil shell. While it also forces some modification to the female mold fabrication technique, both fiberglass and wood/epoxy composites have successfully been produced in reflex shapes without significant cost penalty.

Precise control of airfoil geometry is quite important in providing blades with consistent aerodynamic properties. Small variationg in outboard airfoil camber $\left( \pm 1 / 4\right.$ percent of chord) or twist $\left( \pm 1 / 4^{\circ}\right)$ can lead to gubstantial aerodynamic imbalance and rotor and turbine life reduction. For stall-controlled machines, nff design peak power can furt:her reduce costeffectiventsu $L_{y}$ eltner overstressing driveline and generator components, and thereby increasing replacement costs, or by reducing total power output and revenue. 

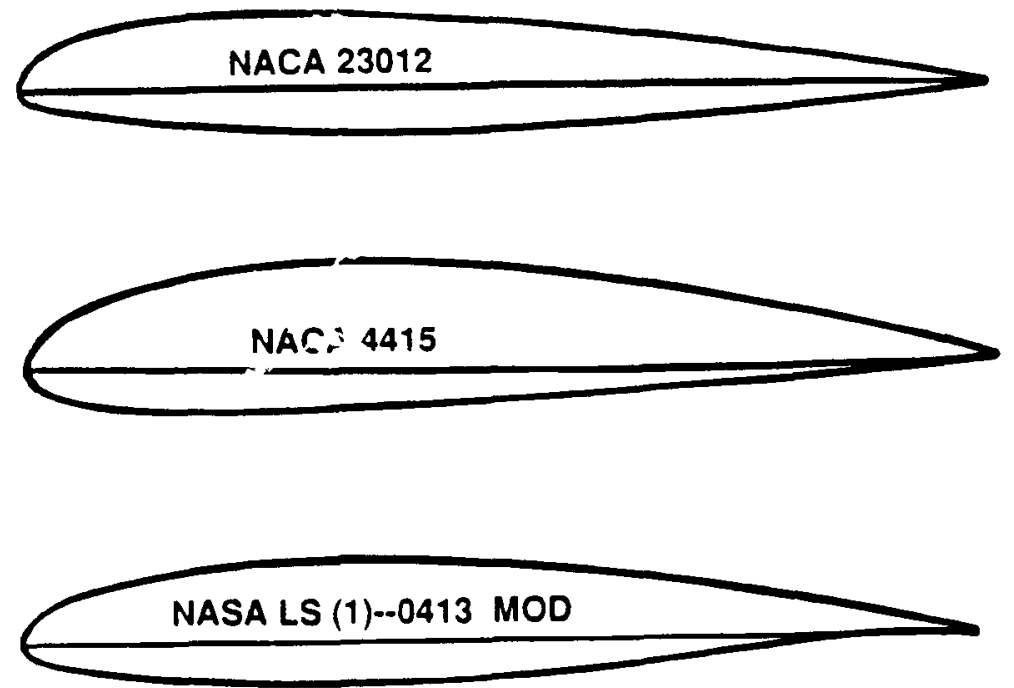

FIGURE 4-1 Commonly used early HAWT airfoils. Source: Tangler (1990).

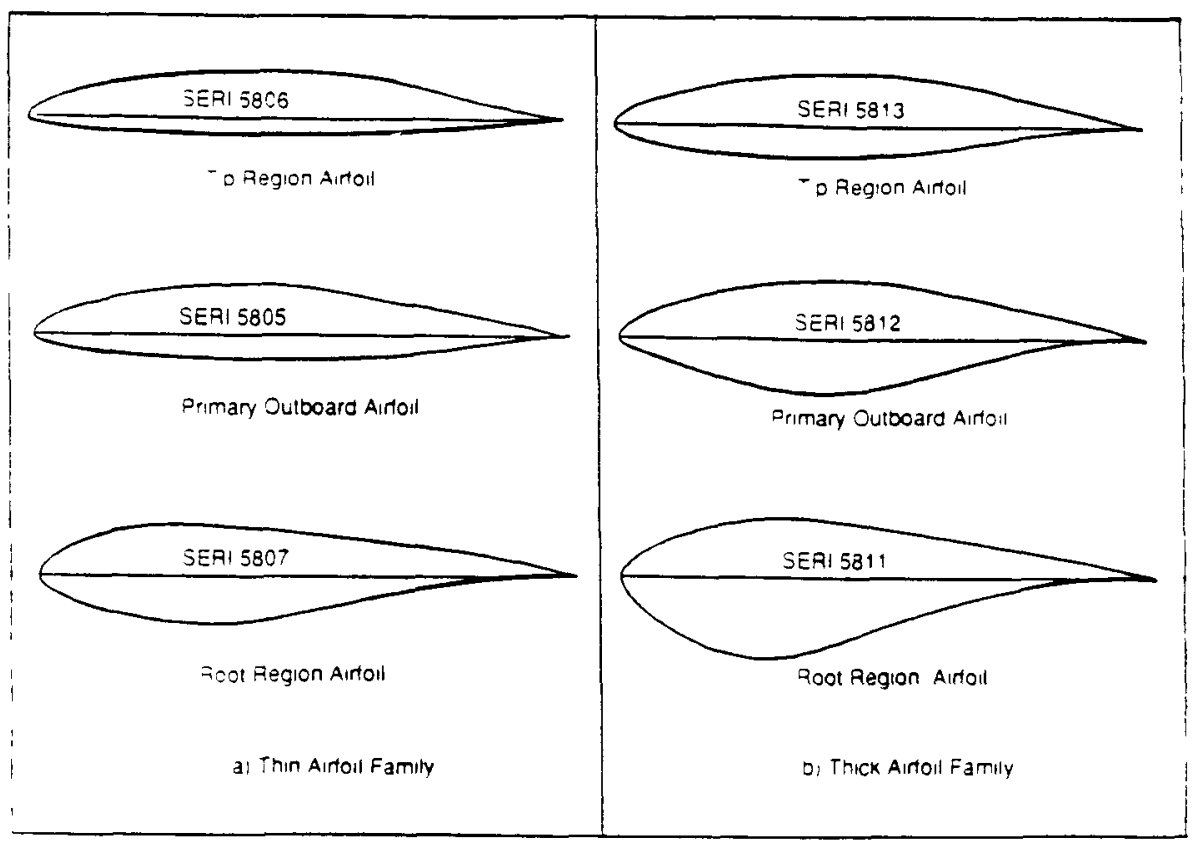

FIGURE 4-2 SERI advanced wind turbine airfoils. Source: Miley (1982). 
This need for aerodynamic consistency and accuracy has led to the adoption of molding as the fabrication nethod of choice for both fiberglass and wood/epoxy composites, as it provides control right at the outer aerodynamic surface, which determines ultimate performance. Both material systems are able to provide the complete range of outboard airfoil shapes currently of interest. While the outboard portion of the rotor changes little with material choice, the inboard region is a different matter. Fiberglass rotor blades often incorporate a large amount of inboard planform area and twist, and may carry the maximum chord quite far in toward the rosi (Figure 4-3) (Stoddard, 1989). For a given rotor diameter, this wili produce the most power, albeit at the cost of a significant increase in total blade surface area and materials. The flat sheet nature of the veneers $280 d$ in wood/epoxy construction does not lend itself well to large inboard planform and the twist and the double curvature surfaces that result. Instead, a gradual transition from the inboard airfoil shape to an oval root is performed over the inner third of the blade (Figure 4-4). To regain the minor power loss due to lessened inboard planform area, a slight increase in blade length is provided. since the turbine rotor designer is free to sweep energy out of the flow at whatever radius provides the least rotor cost, this is an effective solution because the cost of the slight extra length is small compared to the large reduction in inboard planform area. Low wind start-up torque is reduced, which could be a limitation for some turbine designs, but the reduction of planform area also reduces storm wind loading on the turbine as a whole, so the cost trade-off at the system level may or may not be favorable depending on start-up requirements.

\section{AERODYNAMIC TIP BRARES}

Turhine deaigna: which ingomprate fuli wau jiade pitch control. can use that system to provide aerodynamic shutdrwll. Many current turbine designs, which use a mechanical brake for normal shutdown, do not have full span pitch control and must therefore depend on some other method of aerodynamic braking for safety. A great many methods have been tried, but most machines have used either a pivoting outboard tip section or a rotating tip plate.

The pivoting tip design has been dominant for the Danish fiberglass

blades. The usual arrangement employs a centrifugal latch that releases the tip when an overspeed condition occurs. The $t i p$ is then allowed to move outboard, and a cam rotates it (in pitch) until it is perpendicular to the plane of rotation, thereby providing the drag needed to slow the machine aerodynamically. The typical arrangement to accomplish this uses steel parts for the mechanism, including cam, follower, attachment feet, and the structural tubes, which carry the tip loads back into the inboard blade. The feet that form the attachment to the blade are typically glassed (i.e., embedded in resin/fiber) onto one of the blade shelis to secure the mechanism to the inner blade and to secure the tip to the pivoting tube.

Tip failuxes have been observed with this system, typically near the cut that separates the tip from the inner blade. That is where the bending moment in the tube is at the maximum, and indenting or scuffing from a loosely fitting bearing or collar can help initiate a failure. Damage in this area due to saw cuts, welding, or other manufacturing operations has also been known to lead to tube failure. These problems are not generally due to insufficient fatigue knowledge of the steels used, but rather to manufacturing and quality control issues, and the fact that a small geometric cross section for the embedded tube leads to rather high working stresses. The bonded retention of the assembly to the blade has generally been quite satisfactory (Poore and Patterson, 1990; I=s Adard, 1989; Faddoul, 1981).

Composites can be considered as a replacement for steel in tnis hignstress fatigue application. Fiberglass, while strong enough, has a low modulus that leads to large angular deflections and consequent problems with bearing alignment. Carbon fiber has the stiffness, strength, and fatigue endurance 

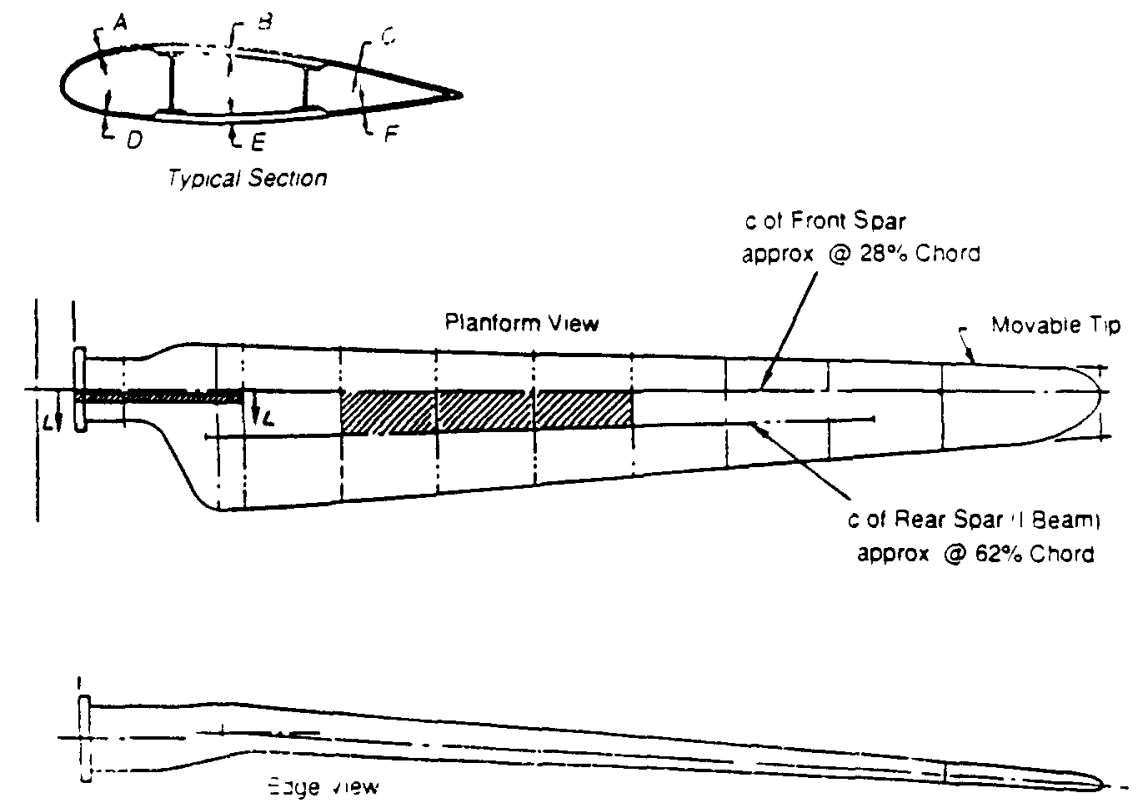

FICURE 4-3 Nine-meter GRP wind turbine blade. Source: stoddard (1989).

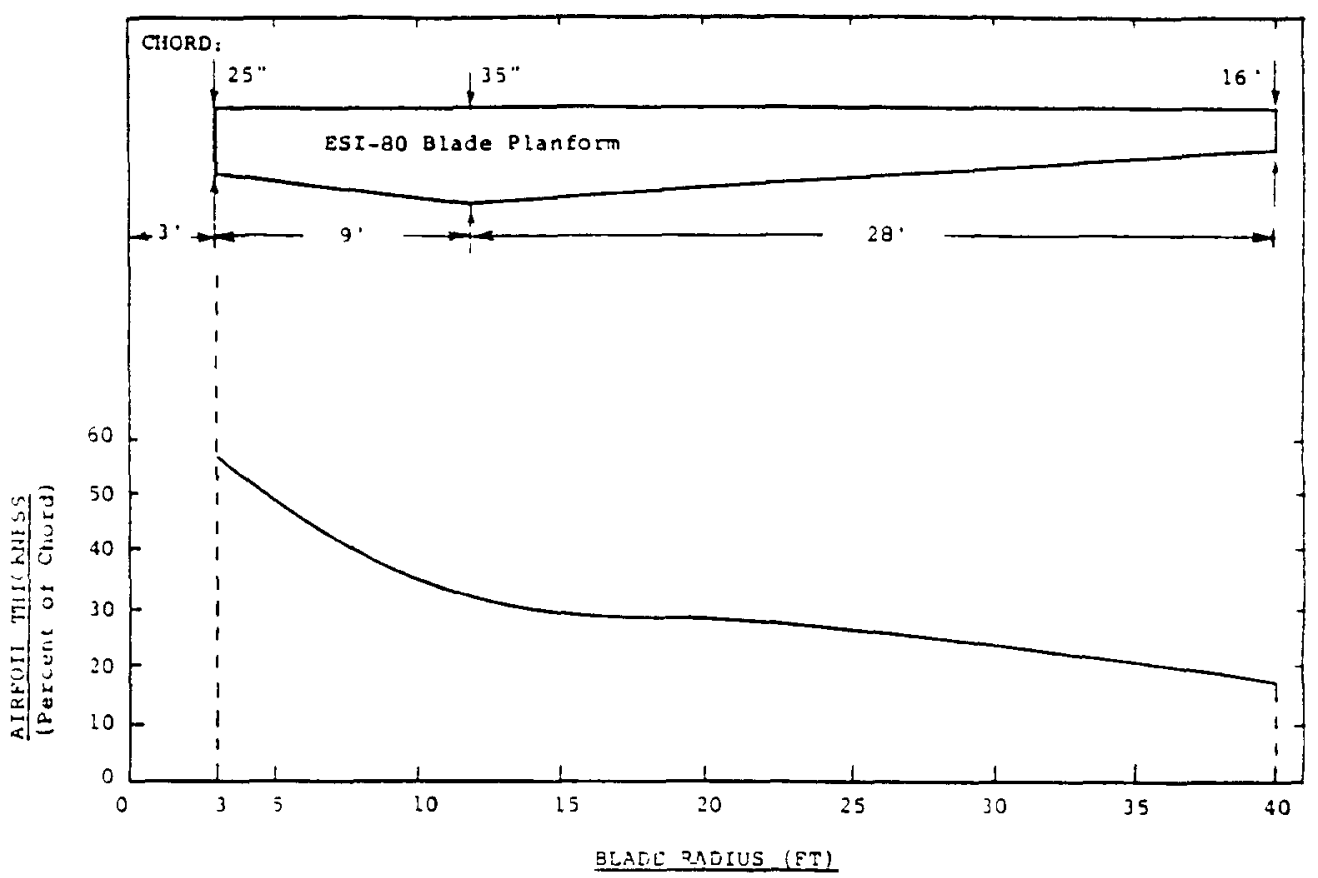

FIGURE 4-4 Eleven-meter wood/epoxy blade airfoil thickness distribution and planform. Source: Musial et al. (1985). 
needed for the tip tube application, but it is considerably more costly than steel. However, as the cost of carbon fiber drops, the weight savings and corrosion resistance that it provides may make it attractive for this application.

The wood/epoxy composite blades produced by Howden also use the pivoting tip arrangement. While operating hours and machine numbers are not nearly as large as for the Danish designs, application with the wood/epoxy material system has not shown any unusual problems to date.

The Enertech and e.SI designs of U.S. origin both used pivoting tip plates for overppeed protection. These were retained in place using threaded rod epoxy bonder inte a veneer buildup at the blade tip. The load takeoff principle is identicis to the well-tested root stud method and has proven highly reliable is service, except for cases of maseive overspeed due to failure of the latch mechanism to deploy. This is not a material knowledge or fatigue problem.

Future wind turbines may employ techniques such as outboard blade allerons or boundary layer control for overspeed protection. Such methods are not only potentially preferable from an aerodynamic standpoint, but also require much less disruption of the primary load path within the blade and could thereby reduce the possibility of long-term fatigue failure as well.

BIADE ROOT RETENTION

Glass-Reinforced Plastic (GRP) Blade Roots

For both fiberglass and wood/epoxy composites, the blade-to-hub interface requires a high-performance fatigue design that can take loads from the composite blade structure into a metal hub assembly. Mating these dissimilar materials in high-cycle fatigue has been a serious design challenge in both material systems.

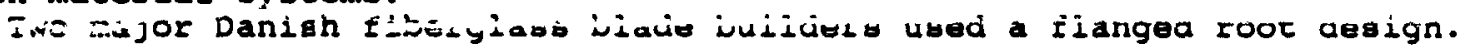
One variation, called the Hutter root after its originator, used thick unidirectional roving bundles wrapped around tubular bushings within the flange (Figure 4-5). These thick bundles bent around the root radiug and terminated well up inside the root tube, so that an extensive bonding area was provided to the skin and spar reinforcing. Since the bolts attaching the blade to the

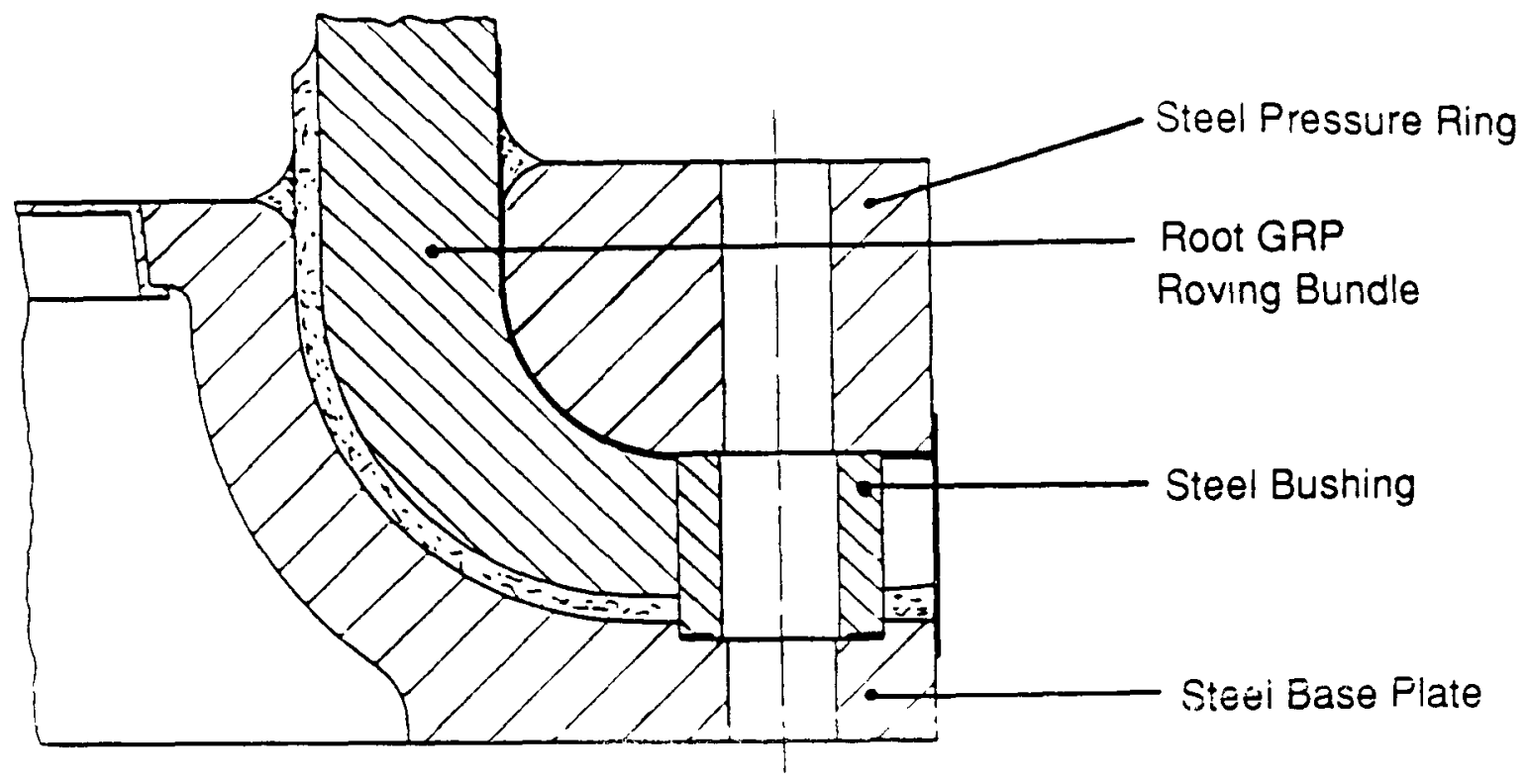

FIGURE 4-5 Flanged GRP Blade root design. Source: Stoddard (1989). 
machine passed through the flange bushings, the blade was mechanically captured both via the bolts;bushings and the flange clamping plates. polyester-based filler material was used to fill the gaps between the hub, metal clamping plates, and the GRP flange to render the assembly as stiff and free of movement as possible.

The other major variation of the flanged root used root roving material that was molded uniformly outward to form the flange, after which the flange drilled and metal bushings were added. While the extra security of a wrap around the bushings was no longer present, rechanical clamping between the hub and flange plates provided positive muthanical capture. While filler material was again used to resist movement and rurder the final assembly as solid as possible, like the Hutter root, this derign egain not depend a metal-to-GRP bond. Given the modulus and strain values of these designs, some motion between metal and GRP appears virtually unavoidable in the long run. Both of these flanged root designs encountered considerable trouble in service (Stoddard, 1989). Partly due to quality control and manufacturing problems, and partly due to the inevitable shrinkage of polyester upon cure, the GRP flange was often not clamped well between the hub and flange plates. Once some gap occurred, the blade root was free to move somewhat and could then begin to reduce the filler material to powder. At the same time, the GRP bundles would begin to move relative to the ateel flange plates (Figure 4-6) and would often floss deep grooves into their surfaces due to the repetitive motion. LOss of root stiffness and the appearance of fine powder at the root were the symptoms of this degeneration. It was estimated by stoddard (1989) that this problem was observed on 5 to 10 percent of the blades in service and was expected on 30 to 50 percent of the blades, given operation and management attention. This amounts to over 20,000 blades.

A procedure called a root pack was developed to deal with these root problems. In essence, the flanges were removed, and fresh filler material was

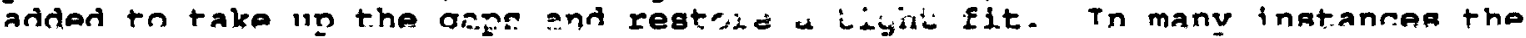
bushings were shortened or recesses ware machined into the flange plates so that the bolt pretension could clamp directly against the GRP flange. Bushings with a carefully selected crushing stress were also employed in some of the later designs, so that the GRP and steel bushing could each share some of the bolt preload, which was the original design intent of all the flange designs. It should be pointed out that some known flanged blades have over 5 years of operation with no problems and no root pack.

There is no doubt that the root pack procedure extended the useful life of many blades in the field. However, the increased clamping stresses within the GRP may now be taking a toll, as long-term tensile failure right through the fiber bundles has now begun to appear (Poore and Patterson, 1990). While a well-designed, well-manufactured flanged root may offer life of several years, it does not yet appear able to offer the desired decades of life. This is true even though the blades in question are generally less than $10 \mathrm{~m}$ in length. Life expectancy is only likely to get worse as larger blades with increased gravitational bending moments are designed.

Another class of fiberglass root design is based on a tapered metal tube that is bonded to the root region of the blade (Figure 4-7a). The tubes may be interior, exterior, or both and may occur with or without through bolts. For its long-term fatigue performance, this class of roots generally depends on a metal-to-GRP bond to transfer load via shear from one material to the other. These steel root tubes are provided with a steel flange so that they can be bolted to the hub assembly. The increased amount of metal required for this class of retention may be more costly compared to the types where the flange is formed directly from the GRP. However, roots of this sort appear to be reliable when properly designed and manufactured and have served well up to the present time. 


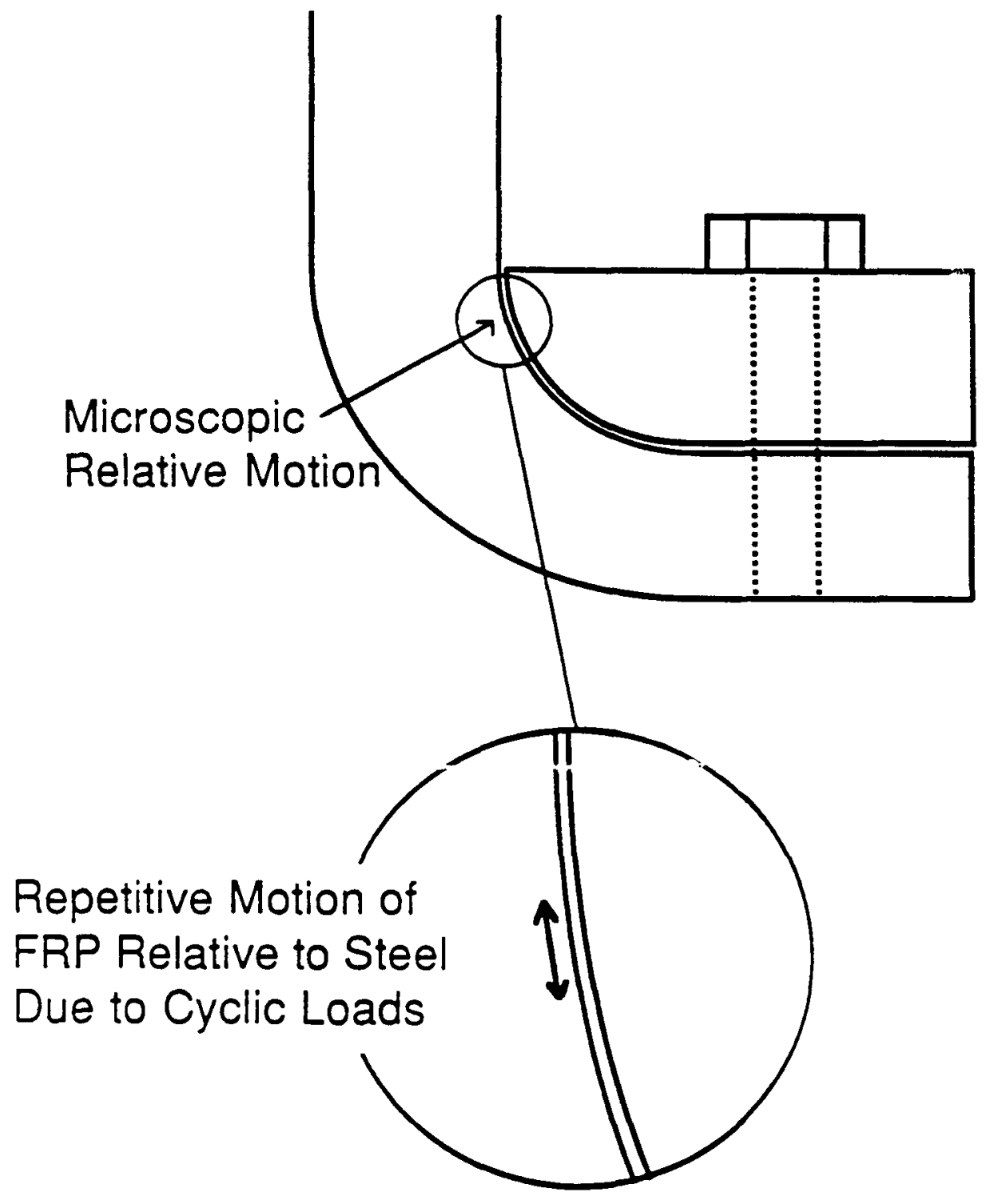

FIGURE 4-6 Flanged root design limitation due to steel/GRP strain incompatibility. 


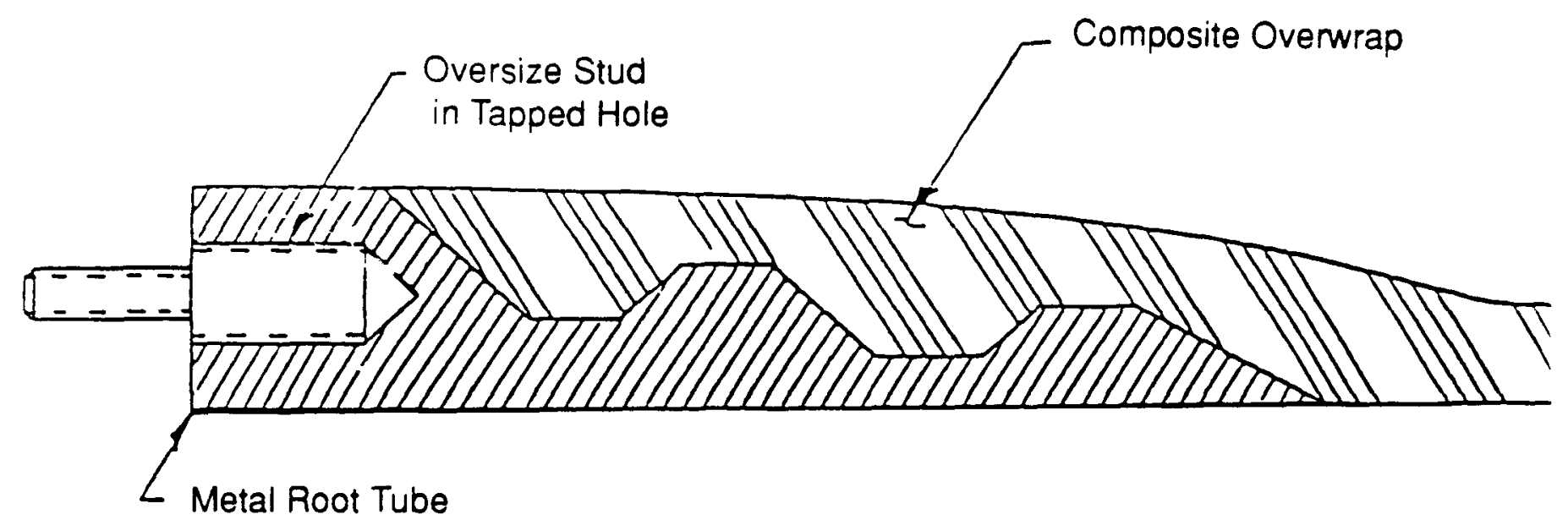

FIGURE 4-7a Bonded steel root tube GRP hub design.

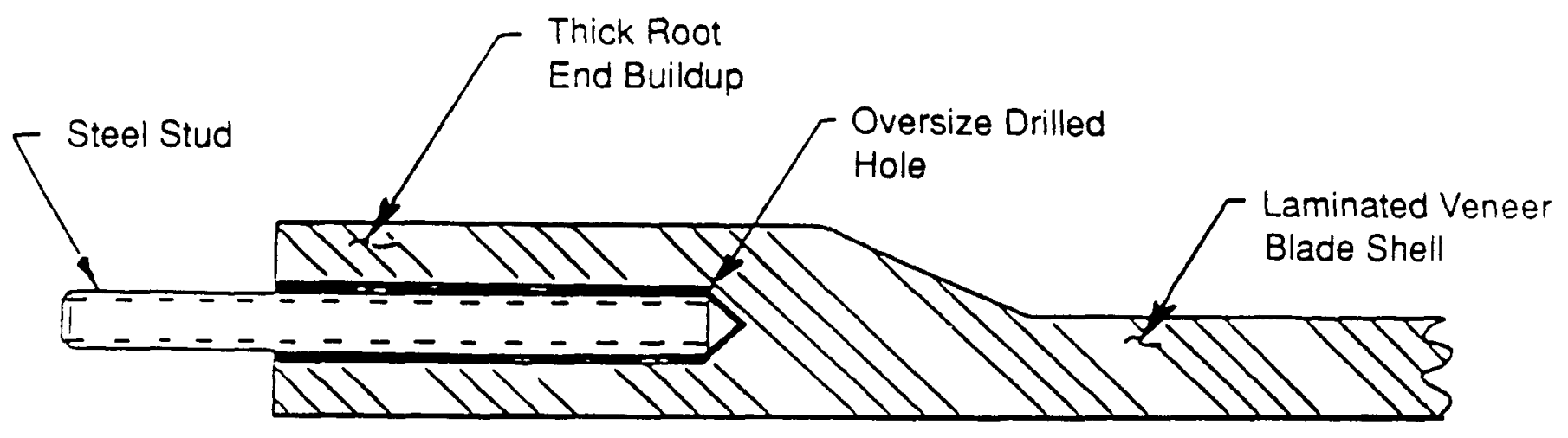

FIGURE 4-7b wood/epoxy blade root. 


\section{WOOD/EPOTY BLADE ROOTS}

The method of root retention for wood/epoxy composite blades has evolved along a quite different path than the flanged roots typical of GRP blades. While internal tubes with bolted flanges were briefly considered in the earliest days of the National Aeronautics and Space Administration (NASA) MOD $O A$ program, they were quickly rejected as too costly and difficult. Attention was directed instead to the use of thruaded steel studs, epoxy bonded directly into a thickened region of roct laminate (see Figure 4-7b). Since the MOD OA program required supporting a sear $-y$ 18.3-m (60-foot) blade on an 0.5-m (18.625-inch) bolt circle to natch the existing hub, high mechanical performance was a necessity right from the start. While a simple bonded, threaded rod could not meet the one-time load and fatigue requirements, tapered designs were soon created that could meet the requirements with some margin to spare (Faddoul, 1981).

Once the difficult requirements of MOD OA had been met, the small blade root designs for Enertech and ESI were not difficult, as a relatively larger and more optimally shaped oval bolt pattern could be specified at the time of blade design. This allowed a reduction in the number of studs, from the 24 of MOD OA to only 10 or 12 for the smaller blades. Since the cost of the studs themselves is a substantial portion of the total root cost for a wood/epoxy blade, this reduction of part count was important from a cost standpoint. For the 20.4-m (67-foot) Westinghouse blades, a return to 24 studs was appropriate due to the much increased loads of that $600-\mathrm{kw}, 43.3-\mathrm{m}$ (142-foot) diameter machine.

The two primary manufacturing concerng for a stud root are that the epoxy completely fill the drilled hole without significant voids and that the studs be accurately coplanar so that 3 tresses are not induced when mated to the wind turbine hub. Prors: $27:-m e t$ and procedures have been developed to achieve these ends, and many fatigue tests of bonded studs, both singly and in whole roots, have shown that the system can readily tolerate the minor variations of a good manufacturing process.

Field experience with the Gougeon bonded stud root has been excellent. While some roots have failed in cases of machine runaway, these were at loads well beyond any intended design conditions. Fatigue failure has not been recorded for any of over 4000 blades in the field, with known use hours on some units at or beyond 25,000. Recent examination of a stud from the largescale Westinghouse machine, with 17,000 hours, showed no evidence of fatigue damage. The extensive static and fatigue testing, which supported the early degign efforts for this root retention type, apparently provided a solid basis for successful field application (Faddoul, 1981).

Other efforts to employ wood/epoxy-bonded studs have not been uniformly successful. The Howden $33-\mathrm{m}$ turbine used this basic approach but is known to have had root problems. This choice of material system and root type is not enough to ensure success by itself. As in other parts of the wind turbine rotor, appropriate engineering design practice and fabrication technique are also required for success.

Theoretical analysis has indicated a small $108 \mathrm{~s}$ of performance when the bonded stud is used with GRP rather than wood/epoxy, but the performance levels are not reduced enough to prevent their successful application to that material system. Indeed, some of the Danish blades are now produced this way, rather than with the original flanged root designs.

\section{BTADE JOINING}

Efficient field joining of blade sections has not yet emerged as a mainr issue for blade design and manufacture, because mort of tuday's machines are small enough that shipping the blades in one plece is not much of a problem. However, conceptual studies have indicated potential cost and weight advantages for two bladed rotors that are essentially one continuous structural piece due to the use of a composite "flow through" hub (Figure 48). This system entirely eliminates the normal root retention and, in 

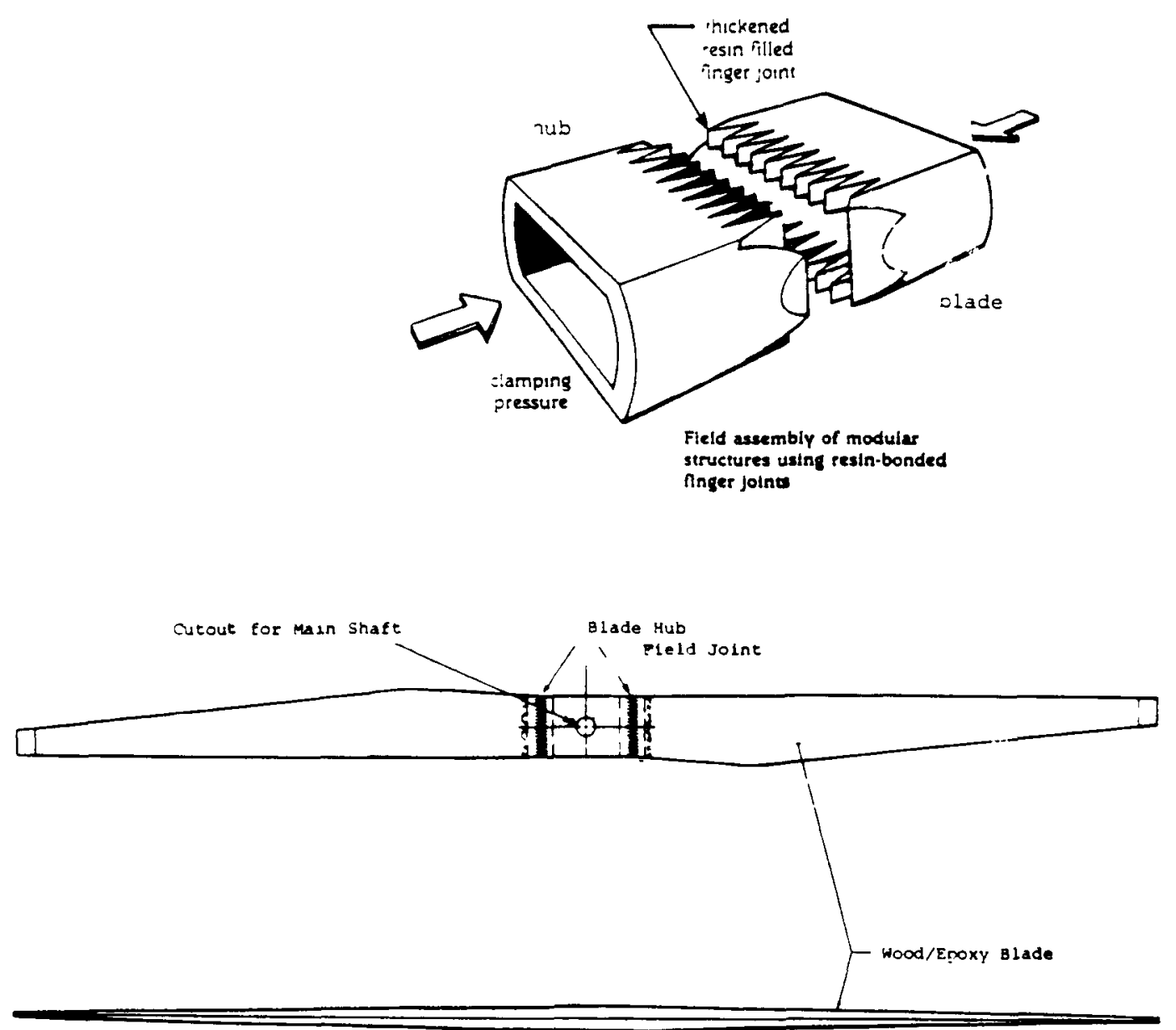

FIGURE 4-8 All-wood/epoxy composite Hub. Source: stroebel et al. (1984).

conjunction with a teeter system, needs to carry only net thrust and torque to the wind turbine. The resulting design is structurally efficient and should have excellent long-life fatigue potential, but it will require some form of field assembly to allow rotors to be shipped in pieces of convenient size. A cost-effective, fatigue-proven joining system for both fiberglass and wood/epoxy surely seems within reasonable technical reach but has not been developed and verified at this time. Such a field joining technique would also be of great value for vertical axis machines, whose curving blade shape makes them particularly difficult to ship in large pieces. Many other ways to use such a system to reduce machine-installed cost may be discovered once it is available and optimized.

\section{BIADE DESION CONSIDERATIONS Piberglass Blades}

The least-expensive structural material for fiberglass blade construction is unidirectional roving. This is a high value-added material 
for the manufacturer and, due to its straight fiber path and low resin content, is also one of the best-performing fiberglase forms on the basis of strength and stiffness to weight. It is therefore of economic and structural advantage to employ this material for as much of the primary structure as possible, consistent with efficient fabrication. Its limitations are that it does not have the thickness uniformity of fabrics and does not distribute well onto vertical or near-vertical mold surfaces. This can lead to fabrication diffir.-1ties near the blade root. Thile conventional filament winding and transverse filament tape ara not applicable to the most recent classes of airfoils, with their ger.erally reflex trailing edge regions, these fabrication techniques could still be considered for the primary structural spar in a spar/skin blade construction. It would be necessary for spar fabrication by winding to be very low cost to compete effectively with the unidirectional roving reinforcement mentioned above, but there may be designs or production levels for which that is possible. The method would gain considerably if gome of the cost or complexity of root formation could be included efficiently in spar construction, as might be the case for winding directly over the root fitting. While spar/shell construction has many attractions, it must overcome at least two significant structural handicaps. The first is that it is difficult for the epar to be atiff enough edgewise to prevent large strains in the blade trailing edge, which would lead to early shell cracking and failure. This could be handled by putting more active material in the blade shells so they carry more of the edgewise loads themselves or by the addition of a unidirectional trailing edge spline. The second handicap is that material concentrated in the spar rather than spread through the blade shell results in thinner fixin laminates, which then need more buckling support and are easier to damage in the field. Simply put, it is difficult to beat the structural

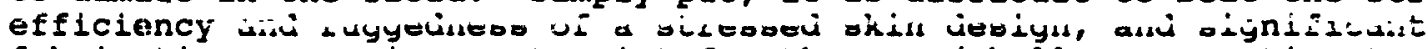
fabrication economies must exist for the spar/shell construction to be competitive with it. This is fundamental in assessing likely blade fabrication or material improvements.

The foregoing notwithstanding, it should be pointed out that several Danish blades, such as LM, MAT, and Vestas, are currently produced with spar/ghell construction and are performing successfully. WEG is producing a wood/epoxy spar/GRP tail panel hybrid that also is performing well. Only time and further economic competition can show if such designs will prove to be the most cost-effective in the long run.

Even stressed-skin fiberglass blades often need panel stiffening in the relatively flat aft blade area, especially inboard where the span from shear web to trailing edge can be particularly large. Expanded foams are often used to provide the required panel support, due to their light weight, moderate cost, and easy formability. However, foams can be impact damaged by rough handing, and their long-term fatigue properties are not well characterized for the numbers of cycles typical of wind turbine blades, particularly under conditions of variable outdoor environment or in the presence of damage. Honeycomb is another skin-support possibility, but it has received little attention due to its cost and greater formability problems compared with other choices.

A panel-stiffening material used in a great many fiberglass blades to date is a felt-like material called core mat. Core mat is inexpensive and easy to conform to complex blade shapes. It is very light in the resin-free condition and, while it does absorb considerable resin, still has acceptably low density once bonded in place. Since this material is somewhat fibrous in nature, it may have rather good long-term fatigue properties, but at present this useful component of blade fabrication is not characterized in long-term fatigue. However, it can be ald that shell-cracking problems seen in the field do not apcear iu be caused by core mat limitations for the kinds of lifetimes and cycle counts currently achieved. This situation could change for larger blades with larger panel sizes and deflections, but data for a quantitative assessment of these possible problems do not exist.

Since most blades are formed in female half-shell molds, joining of the blade shell halves and the interior shear webs is a major part of the overall manufacturing process. A mixture of polyester resin and talc called 
plasterite has been extensively used as a filler in the joining operations by certain fiberglass blade manufacturers. This material is stiff enough to attract considerable load when used in large quantity, as has often been the case, but is not possessed of fibrous reinforcement for strength and crack stopping in long-term fatigue. Another problem is shrinkage after fabrication, which builds in residual tensile stresses that the material is not well suited to handle. The only real attraction of this material appears to be its low cost, since th unfavorable combination of etiffness without strength appearg to leac to high-cycle shell cracking, after crack origination in the bulk plasterite bonding material. Adequate fatigue characterization of this material does not erisc, and it may be an impending problem for many blades now in use in the field. Other, better-suited, fillers with greater fatigue capability and suitable cost, handling, and health properties may be an important component in providing long-term blade ilfe at a competitive cost. Test data to identify, select, and predict the performance of better fillers are not available to the blade industry at this time.

Another area of concern to the blade designer is the gelection of blade skin-reinforcing materials. It is well known that conventional fabrics with a lot of fiber crimp due to the weaving process suffer in high-cycle fatigue due to resin breakdown and fiber stress concentrations at the intersections in the weave. So materials with less fiber crimp will be preferred in high-cycle fatigue wind turbine applications. However, this still leaves a wide selection of reinforcement styles across a broad range of costs in terms of the basic fiberglass chosen. A question of the role and durability of chopped mat and double bias constructions in the high-cycle environment also exists. Test data to allow a rational choice of the most cost-effective reinforcement are scant.

Another basic question exists in the choice of resin system. While

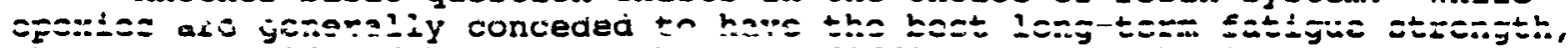
they are considered by some to be more difficult to work with and too expensive for wind turbine blade fabrication. Current production has, therefore, concentrated primarily on the low-cost polyester system, with some designers opting for the somewhat higher-cost vinylester systems. While there is no doubt that vinylester is stronger at low- and moderate-cycle levels, it also appears to have a much larger fatigue effect than polyester. Some current data appear to suggest (Burrell et al., 1986) that, at 10 million cycles and above, polyester may, in fact, outperform the more expensive vinylester. An appropriate resolution of this question would obviously benefit cost-effective blade manufacture.

\section{Wood/Epoxy Blades}

The fundamental fatigue database for wood/epoxy composite is in good condition compared to that for GRP, as has been pointed out elsewhere. However, a number of topics to further improve the cost-effective use of this material system do exist. One of these, the cost-effective field joining of fabricated pieces for advanced rotor types, has already been mentioned. Additionally, research work by Gougeon Brothers completed under an SBIR contract to the Department of Energy (Bertelsen and zuteck, 1989) has shown that advanced laminate oplice joints can allow bulk laminate mechanical performance to approach that of unjointed material, but proving out practical manufacturing methods to realize this promise has not yet been accomplished. Another area of possible interest is that of alternative species to the Douglas fir used for the bulk of the previous work.

All of the above topics could improve the effectiveness of the wood/e.puxy material system within the current design envelope. Ho*:avel, substantial gains may also be made by exponiing the design envelope for the material. As was mentioned previousiy, the veneer sheets used with this construction technique constrain the acceptable blade geometries because they can accept only a very small level of double curvature without splitting or creating excessive resistance to the vacuum-molding forces. In this regard the problem is much like that for molding thermoplastic sheets, which are also relatively stiff and lack the convenient "drape" of conventional fiberglass 
materials. There may be many ways to move beyond current restrictions. For instance, high-temperature forming processes may be able to push the wood veneer into its plastic range and provide forming possibilities that roomtemperature molding cannot. Or it may be possible to preprocess the veneer into a form that is much more conformable than the current full veneer sheets but that is still easy and efficient to handle. The fact that the database for wood/epoxy is in good condition for wind turbine blade fatigue design does not mean that further significant advances in this material system are not available, but rather that they may lie in scmewhit different areas than for fiberglass.

Finally, both material systems can benefit srom explicit feedback into the aerodynamic design process, so that the grapes specified exploit the strengths and cost efficiencies of each to the best overall effect.

Whichever material system is used, long-term fatigue performance will benefit from using simple external shapes with primary load paths that are as straight as possible, particularly in the highly loaded root and root transition areas. Minor power losses due to simplification of the inboard rotor geometry can be offset by a slight increase in rotor length, resulting in a potentially lighter and lower-cost blade of equal energy capture performance and superior long-term fatigue life. New blade designs should explicitly consider this structurally beneficial approach at the aerodynamic design phase.

\section{RECOMOGNDATIONS ${ }^{3}$}

GRP

1. Fatigue data that can resolve whether polyester or vinylester is the appropriate resin for high-cycle wind blade use should be obtained. Common E-

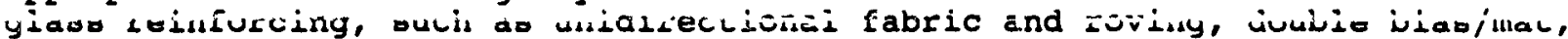
knit triaxial, and chopped strand mat should be investigated to determine which perform best with these low-cost resing.

2. Filled bonding material (such as plasterite) appears to have caused fatigue failures of blade shells. Testing to identify and fatigue qualify a low-cost bonding material would be valuable.

3. Static and fatigue data (including shear) to define the mechanical performance of core mat or other low-cost core material are needed to assure that fatigue design goals will be met.

\section{Wood/Epoxy}

1. Provide proof of the static and fatigue performance of a low-cost field joining technique for use with flow-through rotor concepts and future large or complex shape rotors (such as MOD 5 or Darrieus).

2. Investigate the potential for low-cost techniques to mold wood/epoxy laminate into double curvature shapes that cannot be made with current methods. Confirm fatigue performance of the resulting laminate.

\section{Generic}

Both GRP and wood/epoxy rotors could achieve cost and fatigue benefits from an all-composite one-piece rotor design. The potential life-cycle benefits of such designs should be studied and appropriate composite hub designs identified.

${ }^{1}$ The recommendations made here are those the committee deemed to be of high priority for research. 


\section{REFRRGICES AND BIBLIOGRAPEY}

Bertelsen, W. D., and M. D. Zuteck, 1989. Investigation of Fatigue Failure Initiation and Propagation in Wind-Turbine-Grade Wood/Epoxy Laminate Containing Several Veneer Joint Styles. September. DOE/SBIR, Contract DEAC02-86ER80385, Phase 2 Report, Gougeon Brothers, Inc.

Everell, P., T. McCabe, and R. de la Rosa, R. 1986. Cycle Test Evaluation of Various Polyester Types and a Mathematical Model for Projecting Flexura?. Fatigue Endurance. Presented at the International Conference on Marine Applications of Composite Materials, March 24-26, pp. D-1, D-5.

Faddoul, J. R. 1981. Test Evaluation of a Laminated Wood Wind Turbine Blade Concept. DOE Report DOE/NASA/20230-30, NASA TM-81719. U.S. Department of Energy, Washington, D. C.

Gougeon Brothers, Inc. 1985. Engineered Laminates, Technical Bulletin No. 1, Bay City, Michigan, April.

Miley, S. J. 1982. A Catalog of Low Reynolds Number Airfoil Data for wind Turbine Applications. Prepared by the Department of Aerospace Engineering, Texas A\&M University, for Rockwell International Corporation, Energy Systems Group under Subcontract No. PFY12781-W.

Musial, W. D., C. P. Butterfield, and D. Handman. 1985. ESI-80/EPRI Test Program.

Foore, R. Z., and M. Patterson. 1990. 7.5 Meter Blade Condition and Service bxperience. Presented at American Wind Energy Association Conference, Se:

stoddard, F. S. 1989. Field Problems with Wind Turbine Rotors. NAS presentation, before Committee on Assessment of Research Needs for Wind Turbine Rotor Materials Technology, November 7-8, Washington D.C.

Stoddard, F.S., and M. D. Zuteck. 1987. Blade Retention Fatigue: Symptoms, Causer, Cures. Presented at the windpower 87 seminar, October 5 .

Stroebel, T., C. Dechow, and M. D. Zuteck. 1984. Design of an Advanced Wood Composite Rotor and Development of Wood Composite Blade Technology. DOE Report DOE/NASA/0260-1, NASA CR-174713. U.S. Department of Energy. Washington D.C.:

Tangler, J. 1990. Advanced Airfoils/Blade Development at SERI. NAS presentation, January 22-23, Washington, D.C. 


\title{
MANUEACTURING PROCESSES FOR ROTOR BLADES
}

\author{
CURREMT MANUTACTURING PROCEsges
}

This chapter focuses on those parameters that pertain to the manufacturing procens for rotor blades. However, the design and the process are so interrelated that one can not be discussed without the other. Attention to local variations in resin content, fiber curvature, and very local matrix strains that result from the manufacturing process but that are inherent either in the design or the process are germane to undergtanding fatigue in composite structure.

Blade manufacturing methods have been discussed in depth in recent reports (Challis, 1987). Therefore, this discussion will only be sufficient to allow comparison with processes that are candidates for future blade manufacturing. Current processes will be discussed in two categories, manual and mechanized. The small and medium blades in the field now are largely made by manual processes, basically wet lay-up. Large blades have been made by filament and tape winding in glass-reinforced plastic, hand-laminated

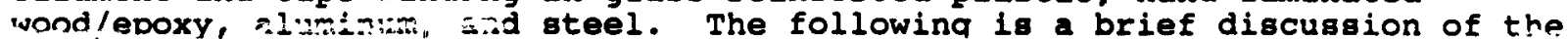
current methods for manufacturing composite blades in order that the relation of material choice, design, and manufacturing method to fatigue life may be presented.

Wet lay-up ia a process where fiber, in the form of fabric, mat or roving, is placed in the tool and impregnated with the resin by hand. This process is labor intensive but offers considerable flexibility in placement and orientation of material. With respect to cost this can be the least-cost process available. Quality can vary from poor to excellent depending on the skill and interest of the worker. Resin content is difficult to control, which results in a weight and balance problem. vacuum bag rub-out can improve laminate quality and aid in uniformity of resin distribution.

Prepreg lay-up, where the fiber form is impregnated by a supplier, is also a manual process but assures close control of resin content. Prepregs must have a reasonable shelf life even though the resin is already catalyzed, so cure is usually initiated by elevated temperature. Pressure is required for compaction, as air is easily trapped by the prepreg during lay-up. The cost of manufacturing is higher than for wet lay-up because of the need for heat and pressure in the curing process.

Blade skins made by manual processes are generally laid-up in one half shell and cured. Assembly bonding of the skins and spar, if required, is accomplished with paste adhesives. The two shells are sometimes cured as one piece in cavity-bonded tools using an internal bag to press the material out against the tool.

Filament and tape winding processes have been associated with a design approach utilizing a tubular spar for structural strength together with a lighter aerodynamic surface covering. The spar is wound first, leading and trailing edge mandrels are added, and winding is continued to completion. This process is relatively restricted in terms of fiber orientation and thickness in design, but it offers major rejuctions in labor with attendant uniformity in quality.

Tooling and facility requirements are minimal for the manual lay-up processes except where an autoclave is required for cure. Design options are maximized and costs are low. It is understandable then that manual processes 
were chosen for start-up or developmental phases by wind turbine blade producers. However, there is a practical size limit imposed by either the risk of human error in a lengthy lay-up operation or just the risk of dealing with thickness and warpage variations that increase with scale. The greater tooling and facility costs of the mechanized winding process are justified when the processing risk is sufficiently great.

Wood/epoxy blades are made by laminating 0.10 -inch thick wood veneers together using an epoxy resin system. Sheets of length $2.4 \mathrm{~m}$ ( 8 feet) are coated with resin and placed in mold halvej end on end from the root to tip. The outside plies are scarf jointed, out a'l inner plies are simply butt jointed in a staggered pattern. A fiberglias surface ply is used on both the inner and outer surfaces of the skin.

Once lay-up is completed, a vacuum bag system is installed and the laminates formed to the mold by vacuum pressure. Cure is completed at room temperature in 2 to 8 hours depending on the size of the component. The blade skin is made in two halves, which are trimmed at the mating plane after the skins are cured. A root to tip shear web is made from quality ply wood, and grooved blocks are bonded to both surfaces of the blade to receive the web on assembly. The two halves and the spar are bonded together with a filled epoxy.

The root end attachment is accomplished by bonding custom-designed studs into spanwise holes drilled in a thickened section of the spar. Bolts thread into these inserts for attachment of the blade to the hub. This process yields a lightweight, reliable quality blade at costs under $\$ 50 / 1 \mathrm{~b}$ (Stoddard, 1989 ).

\section{Blade Root End Concepts}

The various types of root ends that were reviewed in Chapter 4 will be

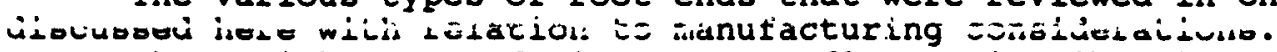

The Danish Hutter design turns a flange, in fiberglass, normal to the axis of the blade to allow attachment to a steel hub with tension bolts. The bolt holes are wrapped through $180^{\circ}$ with roving that is brought from the shank of the blade. This concept results in voids, resin pockets, and high resin stress. Metal collars trap this flange material as the attachment fasteners are tightened in an attempt to partially relieve the resin stresses, but field experience has shown this to be an unreliable concept.

U.S. designs utilize a metal flange on a tube that fits inside the fiberglass spar with bonding as the attachment method. The tube and opar are bonded together although fasteners may be added for their fail-safe benefits. The wall of the tube is tapered to better distribute load transfer in the bond. The tapered portion may also vary in diameter along the length to mechanically trap the blade should the bond fail. High matrix straing, which can limit blade life, are introduced at the outboard end of the metal taper because the metal cannot practically be tapered to a knife edge.

A third method employs bonded inserts for bolts that are aligned with the axis of the blade and attach directly to the mating flange. This latter method is used on the laminated wood and glass-reinforced plastic (GRP) blades and seems to be fabricable and reliable.

\section{Manufacturing Methods Influence Blade Life}

Manufacturing procedures can introduce conditions in the composite that greatly influence fatigue life. These are local resin content variations, local fiber curvature, and local residual stress. Such conditions are variables in all composite manufacturing processes and should be considered in design. A brief description of each of these potential problem areas follows. prior to cure, the viscosity of the resin is low enough that it can move around in the assembly due to the forces of gravity oi sight differentials in bag pressure or fiber tension. The result is large variations in resin content. An area of low resin content will be damage prone and subject to microcracking under compressive transverse or out-of-plane loadings. Areas of high resin content or resin pockets tend to be brittle and will crack under 
low applied strain or even cure shrinkage stress. These cracks can propagate as delaminations in fatigue (Rogers et al., 1990).

Movement of the laminate prior to cure, such as occurs during compaction of thick sections, can change the fiber length required by the final geometry. since the fiber will not stretch or compress elastically, because the actual fiber stress is low, the fiber will either bridge, causing a void, or buckle, yielding local fiber curvature. Either way, significant resin stresses are induced as the fiber tries to gtraighten out under tension loading or buckle under compression loading. The matrix will crack, and the frari-ure will propagate under fatigue loading as a delamination in tension or as fiber crimping in compression. The latter failure mode is catastrophi- (Morse and Piggon, 1990).

Heat is produced by the chemical reaction of cross-linking for all plastic matrix systems. This phenomenon is called exotherm. The matrix gells and becomen rigid at a given location as a function of time at temperature. The exotherm can ralse the internal temperature of a laminate well above the surface temperature, which causes gelling to occur at different locations and different times. The fiber and matrix generally have different thermal coefficients of expansion, which results in residual stresses on cool down after cure. Filament winding processes introduce residual fiber stresses in the fiber matrix assembly that are retained through cure. Each of these phenomena can result in local residual stresses of significance in the matrix. Procedures for computing these stresses were developed under U.S. government contract and reported by Rai and Brockman (1988); thus, the code is available on request.

The design phase is not complete until the effects of these conditions have been determined and their stress effects included in fatigue analysis.

macrix screst varbus ratsgue

Fatigue failure in GRP composite materials, especially carbon, is a matrix-dominated phenomenon (see, for example, Lagace, 1985). Matrix strength in the composite is low compared with the fiber gtrength. Matrix failure through the thickness of a ply is termed transverse cracking or splitting, depending on whether the primary laminate load is transverse to or aligned with the fiber direction of the ply. Matrix failure between plies is termed delamination. Delamination can induce unstable sublaminate buckling in compression (Chai et al., 1981). However, all of these matrix failure modes cause local points of strain concentration on the fiber (Rogers et al., 1990). The fiber can be described as brittle since its stress-strain response is linear to failure (Prandy and Hahn, 1990). Therefore, fiber failure will occur when these local strain concentrations, together with the global strain, exceed either the fiber tensile strength or compression instability strength (O'Brien, 1980). Fiber failure, once initiated, generally propagates catastrophically across the laminate (Reifsnider, 1980).

Transverse cracking in the matrix occurs in plies that are off the axis of the load-carrying plies due to their strain. But transverse cracking and delamination also occur as a result of loads that are out of the plane of the laminate (Chan et al., 1986; O'Brien, 1980). These failure modes both occur in areas of curved fibers. The fiber possesses linear strain response and excellent fatigue properties. The matrix is viscoelastic, thereby absorbing energy in each strain cycle and yielding very poor fatigue properties (Mandell, et al. 1985).

Any attempt to design long-life blades must consider minimization of matrix strain. Any design that contains curved fibers or any process that cannot maintain fiber alignment will result in fatigue-limited characteristics that are not represented by tne coupon-geizerated fatigue data unless the coupun containg the same defect in a controlled manner.

Examination of the failed blades presented to the committee revealed quality variations that exceed good practice. A portion of the disappointment in blade life must be attributed to lack of quality control. 


\section{HuICOPTER ROTOR EINDS DESIGN AN PROCESEINO}

A brief discussion of the design and manufacturing process for helicopter blades is included here to complete the background on current manufacturing processes. A helicopter blade is a tension-dominated structure for which mass balance is critical and cost is a secondary consideration. Thus, a good design for a helicopter blade may not be a good design for a wind turbine. HoweveF, since composite helicopter blades are considered to offer unlimited lif:, the knowledge gained in their development should have some value to the wind turbine designer.

Helicupter blades are made by semimechanized processes. Both Covington (1990) ant friedman (1988) describe the design and manufacturing process but with slightly different design concepts (Figure 5-1). Spar caps, which are unidirectional tape or tow, are wound by polar winding equipment around a root end pin fid and a tip pin. The tip end wrap is used to tension the cap material during cure to maintain fiber alignment. A compression-molded fiberglass filier called a fid is placed between the windings outboard of the root pin in order to lead the windings smoothly away from the pin. These unidirectional spar caps, generally four, are placed in a two-part cavity tool and wrapped with bias ply material. The caps react to bending and centrifugal loads and the bias plies react to shear. An internal rubber bag is placed inside the spar material. When it is inflated, the spar and torque wrap material is compacted against the insides of the cavity. The tool is then placed in an autoclave for cure.

The pin wrap at the root end of the blade is used for mechanical attachment of the blade to the hub. Although these fibers are curved, resin strains are low because the material is trapped between the flanges of a steel spool. Out-of-plane forces are minimum.

The trailing edge is honeycomb sandwich with very thin skins, and the

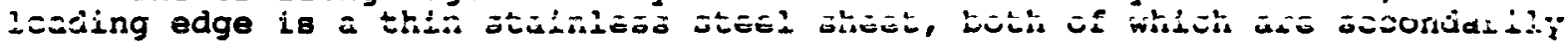
bonded to the spar. Balance and contour are maintained within 10 inch-pounds and \pm 0.010 on surface geometry, respectively.

Blade quality is excellent, but costs are high, greater than $\$ 100 / 1 b$, even though the bulk of the material is assembled by machine. The autoclave high-pressure cure entails an 8-hour cycle time, and both spar and assembly of the trailing and leading edges are separate autoclave cures. Current wind turbine blades are sold for under $\$ 10 / 1 \mathrm{~b}$.

\section{MANUFACIURING PROCESSES APPIICABLE TO WIND TURBINE BLADES}

Three processeg are being evaluated for blade production that offer advantages and disadvantages relative to those already discussed. They are resin transfer molding, pultrusion, and fiber placement. Each is discussed in turn below.

\section{Resin Transfer Molding (RMM)}

Resin transferred by vacuum and pressure into a dry preform of aligned fibers that are constrained by matched inner and outer surface tools is termed RTM. Special, low-viscosity, delayed-reactivity resins have been developed, making this process attractive. Of course, these resins have not been fully characterized in fatigue. Many ways have been utilized to make the preforms. Weaving, braiding, and manual assembly with local area stitching are methods used today. The key to low-cost, quality construction is mechanization of the preform fabrication and handling process. The low pressures involved allow low-cost tooling materials and concepts to be employed. The process lends itself to high-rate production, as the part residerce rime in a t.001 is as low as one-half hour (Monroe, 1230 ). 


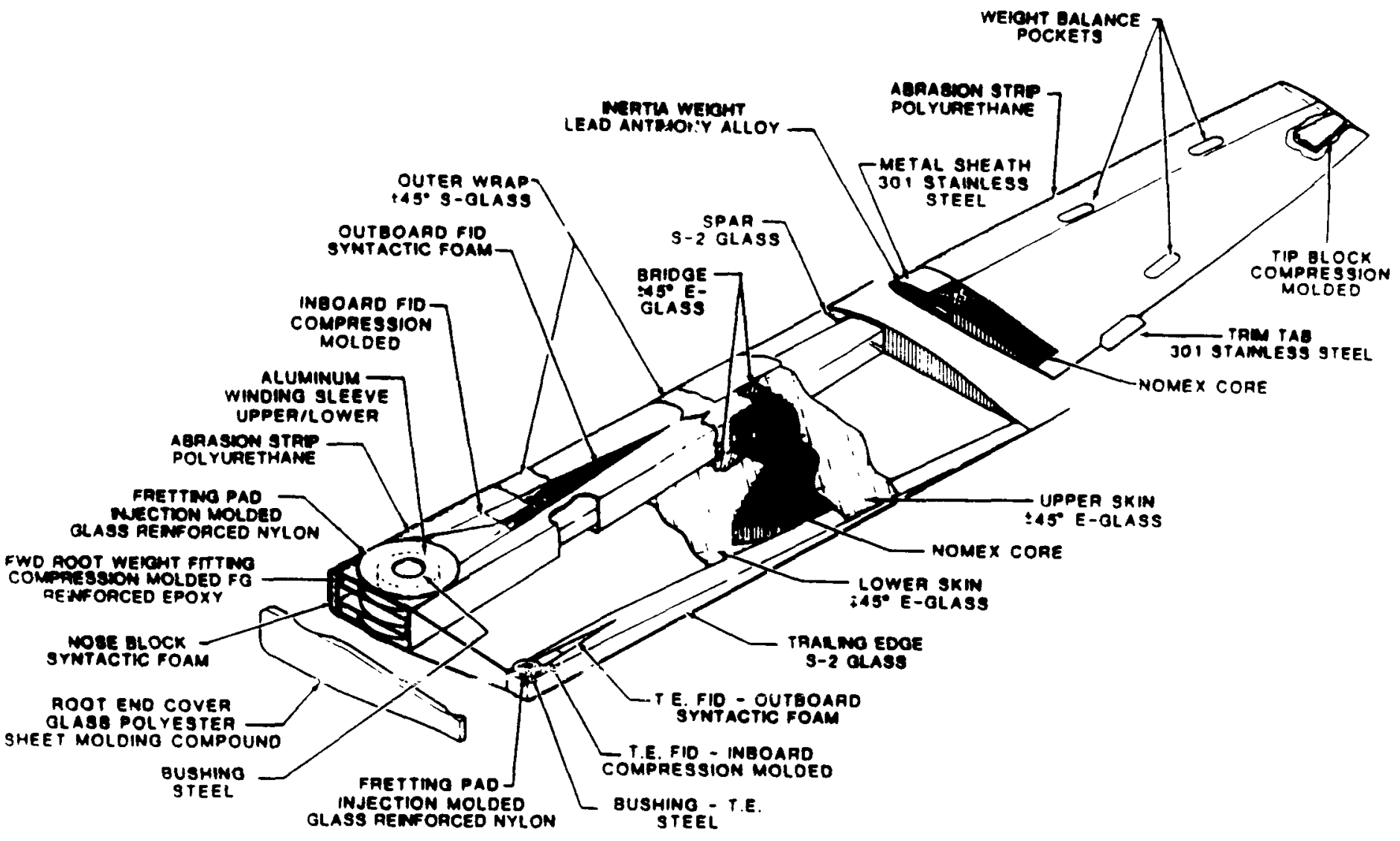

FIGURE 5-1 UH-1H composite main rotor blade. Source: Covington (1980).

The RTM process is utilized in the production of cooling tower fan blades up to $12.2 \mathrm{~m}(40$-feet) in diameter. These blades look quite different from current wind turbine blades because of constraints of the process (Figure 5-2). The rigid inner mandrel must be removed from the cured blade; therefore, the root end must be the largest section of the blade. To live with this constraint, tower blades are made in two parts, an outer section extending from quarter span out to the tip and an inner portion containing a root end joint. These sections are joined by bonding, and both sections are at their largase cross section at the splice joint. Local fiber curvatura can occur due to nonuniform flow of the resin throvgt. the preform. Cooling tower blades produced by this process gell for under $\$ 10$ a pound. (Monroe, 1990 ). 

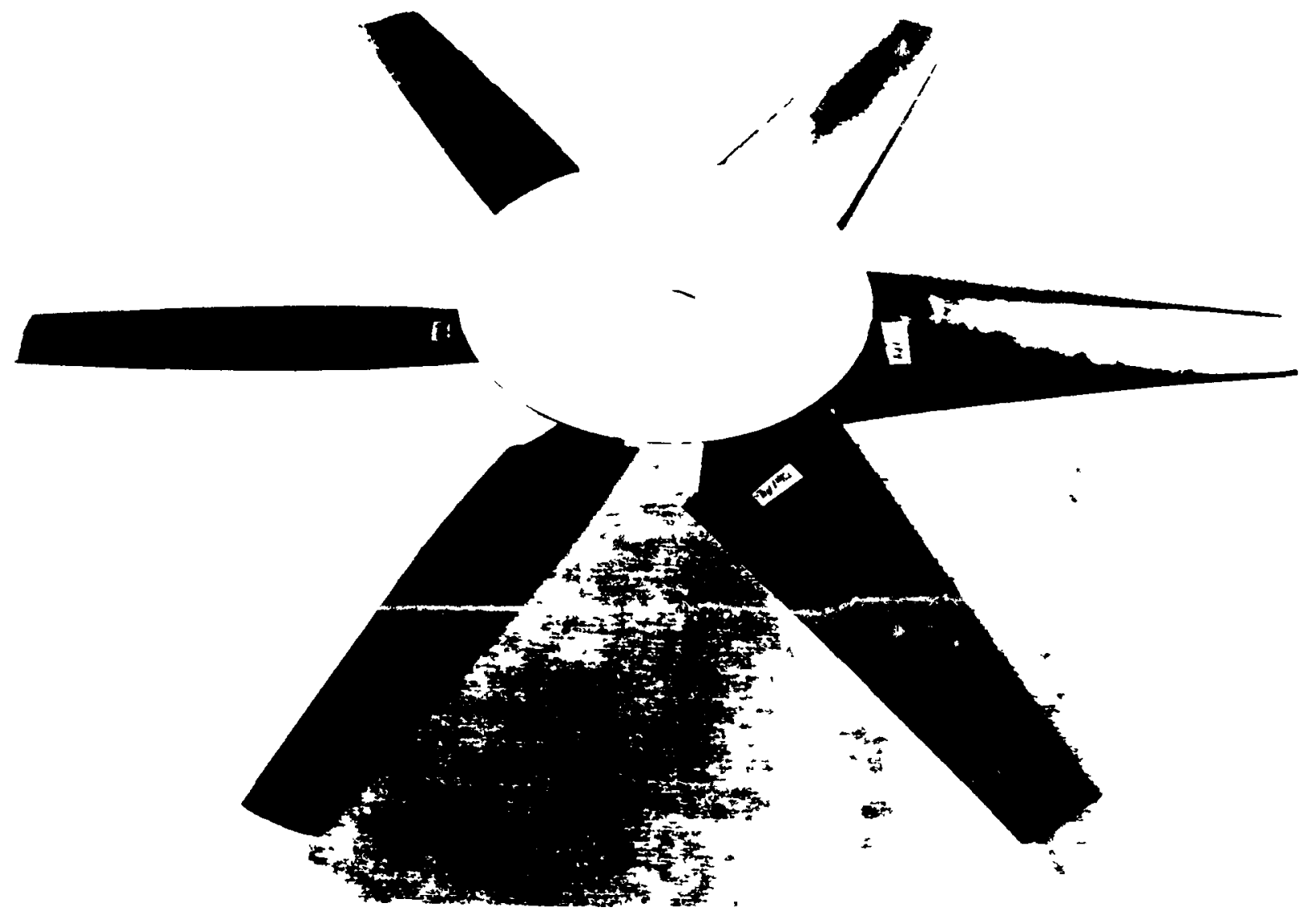

FIGURE 5-2 RTM cooling tower blade. (Courtesy, Hudson Products Corp.) 


\section{Pultrusion}

Pultrusion is a process in which a continuous dry preform is pulled through a matched die while resin is injected under high pressure. It is first heated for cure and then cooled in the die to a temperature where it possesses sufficient strength to support the pulling clamp pressure. Once in operation, the process is almost labor free, yielding a product at just above the material cost (Goldsworthy, 1990). Die cost is reasonable if any volume is refuired. The most obvious restriction is that the part must be constant in cross section and laminate design. The quality of the laminate is excal lent.

\section{Fiber Placenent}

Fiber placement is gimilar to filament winding in the sense that the raw material is tow rather than tape. It is also simllar to tape laying machinery, where a roller is used to stick the ply to the tool or prior ply. The merger of these two ideas yields a machine that can place fiber on any tool surface in any direction and produce a quality laminate. This process offers all the design freedom of manual lay-up together with the uniform quality of machine fabrication. Although quality is high and design freedom great, production costs are not comparable to either RTM or pultrusion processing. Lay-down rates of 10 pounds per man-hour have been quoted (Policelli, 1990).

Thermoplastics are touted as the low-cost composite material of the future largely because the requirement for cure is eliminated. Simply melt the resin while the preimpregnated plies are held together and then let it solidif;. Currently, high processing temperatures and pressures keep tooling costs high. If the raw form of the material is a precompacted sheet, design

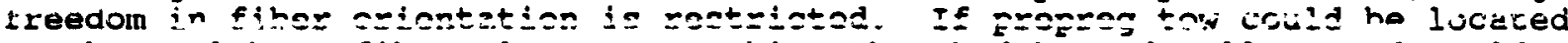
on the tool by a fiber placement machine that had heated rollers and could fuse and compact the added ply to the laminate already laid, perhaps thermoplastics could then replace thermosets. Efforts in this direction have not been successful to date.

\section{ROOT END DESIGN FOR PRODUCIBILITY}

The helicopter industry has come to appreciate composite materials for their inherent fatigue resistance, provided that the criticality of the resin matrix is understood. As a result, not only the blade but also the hub can be made of composite materials (Hause, 1989) (Eigure 5-3). The ability of composite material to flex and retain fatigue strength has allowed movement toward bearingless designs. These hubs tend to be thick laminates of essentially rectangular cross section. An understanding of free edge and residual stress coupled with the effects of fiber curvature is required (Chan et al., 1986).

A fundamental difference between the aerospace industry's approach to design of the blade to root attachment and that of the wind turbine industry is noted here. The aerospace industry uses a lap joint with bolts in shear while the wind turbine industry largely uses a flange with tension bolts. Aerospace emphasis is in keeping the load in the fiber and minimizing the load in the matrix and avoiding use of metal except for bolts and bushings. The helicopter indugtry is committed to composite blades and hubs because of their excellent fatigue life and benign failure modes. These reasons are just as applicable to the wind turbine industry.

\section{MAMTIACTURING RECONOENDATIONS}

To meet economic realities, the fatigue life and reliability of the blades must be improved. Fatigue life can be significantly improved by advancements in design. Reliability will be improved through carefully 


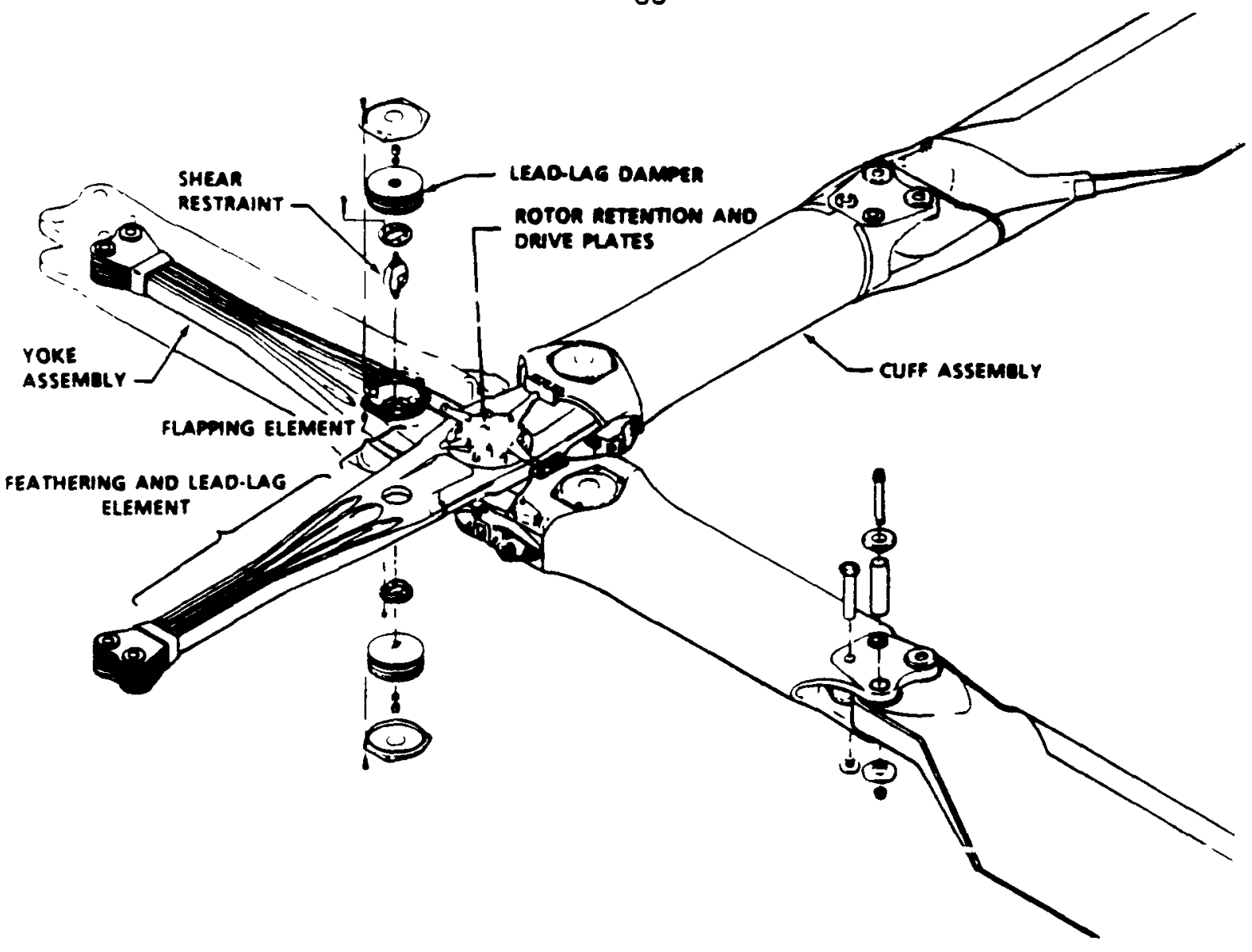

FIGURE 5-3 4BW hingeles bearingless rotor. Source: Friedman (1988).

controlled mechanized manufacturing processes. This all must be accomplished with lower labor content.

Pultrusion offers an immediate solution to the economic issues but at reduced aerodynamic and structural efficiencies. RTM offers glightly longerterm opportunities while retaining aerodynamic efficiency. Fiber placement offers optimum aerodynamic and structural efficiency but will require further development to meet the necessary cost objectives. Fiber placement may be the best match for the emerging family of thermoplastic matrices. It is not clear which of these processes is most suitable for wind turbine blade production in this decade, but it is clear that the next generation of blades can meet their performance goals, and it is likely that one or more of these procesees will achieve the cost objectives.

The technology to design and manufacture wind turbine blades with the desired 1 ife and reliability is emerging. Loads must be determined. Matrix strains must be computed and fatigue allowables not exceeded. guality in fiber alignment, resin content and weight, balance, and contour must be maintained and costs kept low. To achieve these requirements, the design must be developed with state-of-the-art and emerging anaiytical procedures. It is far more or znomical to examine design alternatives on the computer thas in tie field.

It is clear that aggressive use cf composites to reduce the weight of the rotor is of benefit to the entire wind turbine system. 


\section{REFERENCES AND BIBLIOGRAPHY}

Bragwell, J. L., and B. F. Robertson. 1985. New Wings for the Huey. American Helicopter Society National specialists' Meeting on Composites Manufacturing.

Chai, H., C. D. Babcock, and H. G. Rnauss. 1981. One Dimensional Modeling of Failure in Laminated Plates by Delamination Buckling. International Journal of Solids and structures, Vol. 17, Nov. 11 .

Challis, A. L. 1987. Use of Composite Materials Enx Wind Turbines. Proceedings of BWEA/DEN Workshop, Harwell.

Chan, W. S., C. W. Rogers, J. D., Cronkite, and J. Martin. 1986. Delamination Control of Composite Rotor Hubs. Journal of the American Helicopter Society, August.

Covington, C. E. 1990. Composite structural Applications in Helicopter Rotors. World Aerospace Technology 90, March.

Friedman, H. W. 1988. Design and Fabrication of an Advanced Light Rotor. 44th Annual Forum and Technology Display, AHS.

Goldsworthy, B. 1990. VA Wind Turbine Blades Made by the Pultrusion Process. NRC Workshop on Assessment of Research Needs for Wind Turbine Rotors, Washington, D.C., January 22-23.

Hause, J. H. 1989. The Four-Bladed Main Rotor System for the AH-1W Helicopter. 45th Annual Forum of the AHS.

Lagace, P. A. 1985. The Effect of Ply Thickness on Longitudinal splitting and Delamination in Graphite Epoxy Under Compressive Load. ASTM Fatigue and Fracture.

Mandell, J. F., F. J. MCGarry, A.J. Hsieh, and C. G. Li. 1985. Polymer Composites.

Monroe, R. C. 1990. Cooling Tower Fan Blades Made by the RTM Process. NRC Workshop on Assessment of Research Needs for Wind Turbine Rotorg, Washington, D.C., January 22-23.

Morse, A., and M. R. Piggon. 1990. Relation Between Fiber Divagation and Compressive Properties of Fiber Composites. 35th International SAMPE Symposium.

O'Brien, T. K. 1980. Characterization of Delamination Onset and Growth in a Composite Laminate. Damage in Composite Materials, ASTM STP 775.

O'Brien, T. K. 1988. Towards a Damage Tolerance Philosophy for Composite Materials and Structures. NASA TM 100548.

Policelli, F. 1990. Filament winding and Fiber Placement Techniques Applied to Wind Turbine Blades. NRC Workshop on Assessment of Research Needs for Wind Turbine Rotors, Washington, D.C., January 22-23.

Prandy, J. M. , and H. T. Hahn. 1990. Compressive Strength of Carbon Fibers. 35 th International SAMPE Symposium.

Rai, H. G., and R. A. Brockman. 1988. Cure Induced Micristaiklrig of Composite Materials. Proceedings of 4 th Japan-U.S. Conference on Composite Materials, pp. 732 .

Reifsnider, K. L., ed. 1980. Damage in Composite Materials, ASTM STP 775. 
Rogers, C. W., E. W. Lee, and D. A. Crane. 1990. The Effect of the Fracture Process on the Strength of Composite Laminates, 46th American Helicopter Society Forum, May 22.

Stoddard, F. S. 1989. Fleld Problems with Wind Turbine Rotors. Presented to: Committee on Assessment of Research Needs for Wind Turbine Rotor Materials 1.3chnology, Washington, D.C., November 7. 


\title{
ACTIVE CONTROL IN WIND TURBINES
}

\author{
THE CONIROL PROBLEY FOR WIND TURBINES
}

Active control, by complementing the primary technologies in wind turbines, can help significantly in attaining--perhaps even improving--the industry's objectives of safe and cost-efficient energy production. For example, although the need to understand and improve material properties will continue, active control can alleviate the requirements on materials at any stage of the technology. Discussed here are the control requirements for wind turbines, together with the control means and sensors typically employed in modern wind turbines. This will provide background and serve as a focal point for subsequent discussion of the applicability of modern control theory to wind turbines. requirements:

The wind turbine control problem has at least three important

1. Setting upper bounds on and limiting the torque and power

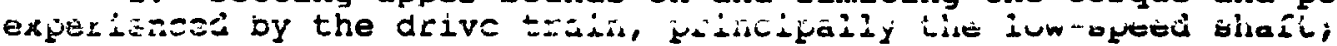

2. Minimizing the fatigue life extraction from the rotor drive train and other structural components due to changes in wind direction, speed (including gusts), and turbulence, as well as start-stop cycles of the wind turbine; and

3. Maximizing the energy production.

The control problem is the judicious balancing of these requirements.

The control theory discussion here will be cast in terms of a pitchcontrolled, variable-speed wind turbine. The discussion is general in the sense that the combination of sensors and control means is thought to span the space of current, practical control techniques. We recognize that gtallcontrolled and other wind turbines may not require all of the sensors and control means discussed. To the extent this is true, these architectures represent simpler cases. However, for all wind turbine architectures, research may reveal other analogous techniques for control that are functionally equivalent to the particular techniques listed here. In any case, there will remain the general requirementg for control of the torque and power in the drive train, the minimization of fatigue life extraction, and the maximization of energy production.

The control effectors (actuators) and commands, together with the sensors and the quantities they measure for a pitch-controlled, variablespeed wind turbine, are summarized in Table 6-1. By control effectors we mean the physical devices that implement angular or linear motion of a wind turbine control surface or component, examples of which are electric motors and hydraulic pistons. The control effectors (actuators) execute motion in response to commands from the control computer. The control computer executes the algorithms derived from the application of control theory. The algorithms, in turn, utilize information from the wind turbine sensors to generate the commands and assess their effects.

The control effectors $1: 3 t e \dot{\text { in }}$ Tabla $8 \mathrm{~min}$ include a contactor, nacelle yaw drive, and blade pitch actuator. These are listed along with typical command inputs. The contactor is an electrical relay that connects and disconnects the generator to the load. As shown in Figure 6-1, the generator 
TABLE 6-1 Control Effectors and Sensors for a Pitch-Controlled wind Turbine

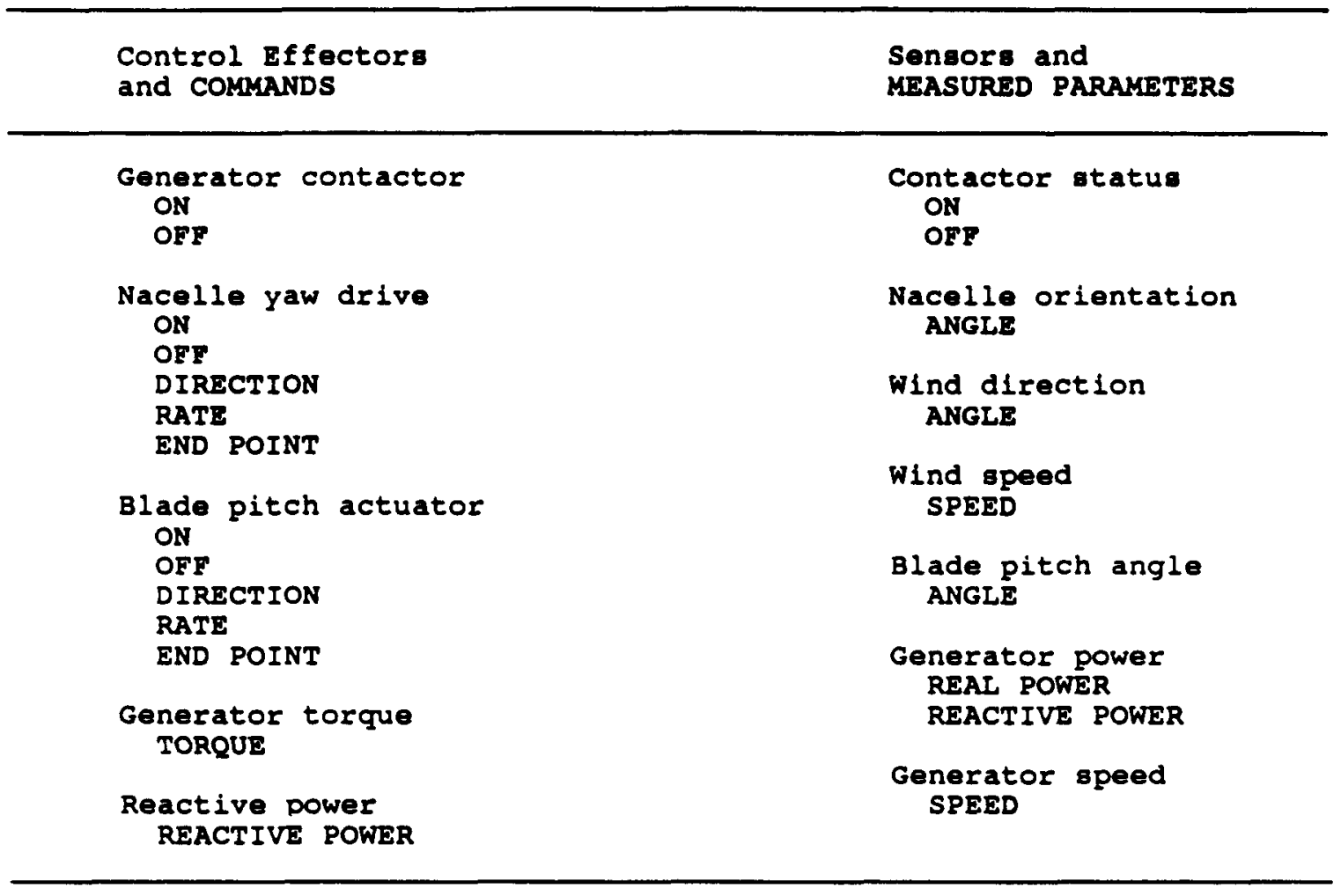

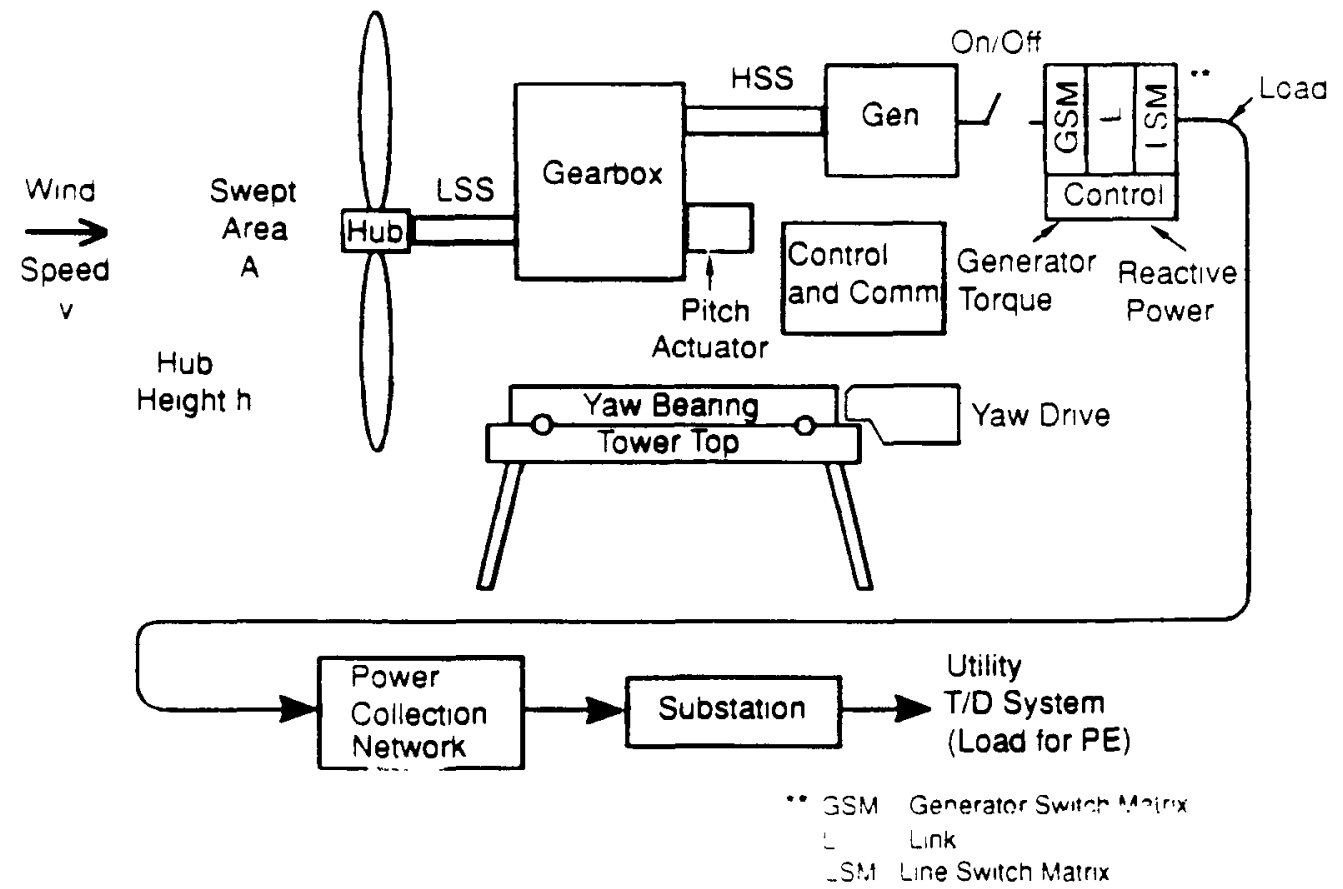

FIGURE 6-1 Wind turbine drive train. 
load is the input switch matrix of the power electronics. For a constantspeed wind turbine--one without power electronics--the generator load is the utility grid.

The nacelle yaw drive may be an electric or hydraulic motor acting through gearing to rotate the nacelle and rotor. The function of the yaw drive is to orient the wind turbine relative to the prevailing wind direction. The blade pitch actuator effects the rotation of the rotor blades about their pitch axis. With the blade pitch angle set at the full-power angle, maximum power is extracted from the incident wind flow fiely. As the blade pitch angle is rotated toward the full feather position, the bisies become less efficient at converting the power in the wind flow fieid tes ohaft power. Also listed in the first column of Table 6-1 are two controls that are effected by the power electronics. The generator torque may be controlled by the power electronics acting on the electrical characteristics of the generator. The power electronics, acting as the load for the generator, can electronically vary the load and thus the drive train torque. The reactive power delivered to or received from the utility grid may also be controlled by the power electronics. This is important for maintenance of one of the desired electrical characteristics (power factor) of the power delivered to the utility system.

The second column of Table 6-1 lists the typical sensor complement associated with a wind turbine. Given also is the physical information measured by these sensors. The contactor status sensor indicates whether the contactor is open or closed, that is, whether the generator is connected to the load. The nacelle orientation sensor measures the angular position of the nacelle, either relative to a fixed reference or to the wind direction. The wind direction sensor measures the angular direction from which the wind blows. The wind speed sensor measures the wind speed. This sensor may be shared by a number of wind turbines or may be ahsent altogethez. If absent, wind speed may be derived from knowledge of the blade airfcil characteristics, the power level, and the drive train rotational speed. The blade pitch angle sensor measures the pitch angle of the blades. The generator power sensor measures the real power flow into, or delivered by, the generator. Typically, the reactive power flow is also measured. The generator speed sensor measures the generator rotational speed and, through knowledge of the gearbox ratio, the speed of the low-speed shaft.

of importance to control are two quantities that may be estimated from the sensor measurements. These are the wind speed and the torque in the lowspeed shaft. Estimation of the wind speed value was discussed above. Estimation of the torque value proceeds from knowledge of the power, the rotational speed, and the gearbox ratio.

\section{RECENT TRENDS IN CONTROL SYSTEM THEORY}

The 1980s witnessed tremendous gtrides in the development of theory and algorithms applicable to the design of dynamic compensators for both singleinput single-output (SISO) and multiple-input multiple-output (MIMO) systems under different sets of assumptions about the process to be controlied and with a variety of performance/robustness criteria satisfied.

In the area of linear time invariant (LTI) systems with parameters assumed to be known, perhaps the greatest breakthrough in the early phase was the unification of frequency and time domains so as to allow for the design of compensators that satisfy frequency domain specifications and robustness constraints using time domain synthesis tools (i.e., solutions to Riccati equations).

Clearly, the advantage of uging time domain mathematics, which is finite dimensiona: and numerically robust, has greatly facilitated control system designs for arbitrary plant dimensions both for SISO and MIMO systems. In the $\mathrm{H}_{2}$ framework, a two-norm formulation was adopted, admitting the interpretation that root mean square (rms) tracking errors are to be minimized in a fixed spectrum, flat power spectral density (PSD), disturbance environment. Other measures of performance may be desirable, such as minimizing the worst possible error (in the frequency domain), captured by an infinity norm 
minimization, which may be important for some systems/operating conditions. Certainly, in the wind turbine environment, a reasonable designer's objective would be to minimize the cogt of energy. Furthermore, if performance specifications are expressed in the time domain (as, for example, in terms of an upper bound on the system impulse response), the absolute integral norm is the appropriate measure (Dahleh and Pearson, 1987). Each design method is geared toward a particular aspect of system performance as expressed by the corresponding no:m, and it is conceivable that simultaneous suboptimization of all thrfe nc-ins could be achleved, by appropriately modifying/combining the solutior: to each individual norm optimization. Results along these lines are presentiy bocening available (Bernetein and Haddad, 1989; Doyle et al.. 1989). HCirever, in processes where parametric variation drastically affects their nominal characteristics, serious performance degradation or even instability can occur. The need for design under parametric uncertainty/ (slow) time variation gave rise to the area of adaptive control, which allows for real-time, on-line "learning" and subsequent compensator parameter adjustment for performance, while maintaining overall system stability. This class of algorithms is very distinct from "gain-scheduled" control algorithms, which are quite often perceived and referred to as adaptive. Gain-scheduled controllers change the compensator characteristics as the operating conditions change, in an open-loop fashion, from table look-ups, based on the scheduling parameter $(s)$. On the other hand, truly adaptive algorithms are real-time learning to update compensator parameters in a feedback fashion. Impressive theoretical advances were achieved, by the late 1970s, for adaptive algorithms designed to operate with the assumption of no modeling (unstructured) errors. However, in the early 19808 such algorithms were shown to be nonrobuat in the presence of unmodeled dynamics and persistent disturbances (Fohrs et al., 1985). Subsequently, various methods were developed for robustification, with a newly evolved notion for robust adaptive control. which encompasses rodust laentirication witn robust control

(Middleton et al., 1988). A systematic study of the former has resulted in algorithms that identify the processes with guaranteed frequency domain error bounds but at the expense of excessive--but not prohibitive, nowadays-computational burden that requires real-time spectral monitoring of pertinent signals in the feedback loop (LaMaire et al., 1991). The combination of robust idestification with a robust controller structure as discussed above, with only infrequent compensator parameter update, as indicated by the quality of the identification process information, has resulted in the study of performance/stability robustness of time-varying systems, in particular as they arise in this context. A number of results only recently became available (Dahleh et al., 1990; and Meyer, 1988).

At the same time, analysis and design methods have been developed for nonlinear systems via the use of appropriate transformations for "nonlinear inversion" and feedback (input-output) linearization.

In conclusion, the current state of the art in control theory provides the designer with a rich environment of design modules/algorithms that can be ingeniously combined to meet large classes of design challenges. The wind turbine rotor certainly belongs to the class of problems that can be readily addressed by the existing state of the art, without the need for new theoretical developments. What is needed in the present problem is a good modeling effort of the wind turbine/tower combination as well as the environment within which it operates and by which it is affected.

\section{EXISTINE CONTROI TECENOLOGY FOR WIND TURBINES}

As discussed earlier in this report, wind turbines are classified into two major categories: vertiral axis and horizontal axis machines. There are two general modes or operation: constant speed (HAWT) and variable speed; the latter is under active investigation in the United states and Europe. The existing machines have been operating in either of the two modes with an industry-projected life-cycle cost of energy (LCCOE) of approximately 5c/kwh. At the present time, however, the cost remains in the range of 7 to $94 / \mathrm{kwh}$. 
But with the cost of power electronics decreasing, the variable-speed mode may be an attractive mode of operation for such machines in the future.

In order for the LCCOE to be kept sufficiently low for wind power to be a competitive energy alternative, the lifetime of a machine would extend over a period of up to 30 years and should be operating at a maximum of "economic" performance. This presupposes that fatigue during "normal" operation is minimized while appropriate measures are taken to avoid accidents (e.g., blade breakage, tower hits) during abrupt, environmental changes. Assuming that the structural, material, mechanical, nd manufacturing aspects of the process are sufficient, additional benefits car be gained by appropriately controlling the blade for minimization of wind-coading effects and gust alleviation as well as maximizing efficiency of power production under variable wind speed profiles. Aerodynamic and mechanical solutions in the form of stall-controlled blades that limit $C_{\text {max }}$, teetered hub versus rigid hub, and optimum choices of materials have been successful as one method of addressing problems cited above. In addition, other less cumplex, potentially less costly control schemes are under development, including passive control schemes. However, the full achievable potential of fered by active control for improvement in the overall performance of wind turbines has not yet been fully exploited.

The existing active (feedback) control strategies known to the committee have for the most part addressed the issue of energy production (McNerney, 1981; Vachon, 1987; Ralph, 1989), although Vachon (1987) also addresses fatigue issues primarily for vertical axis machines. Others are deemed proprietary and were not available to the committee. The designed controllers referred to above are of the proportional integral (P-I) type and are rather ad hoc. Typically, P-I action is taken on the basis of wind speed information--averaged over sampling windows of various lengths--in conjunction with the turbine power curve. The latter provides the equivalent of a

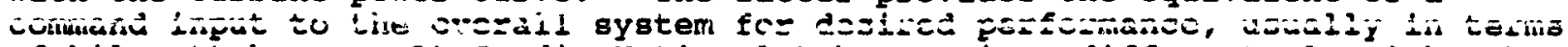
of kilowatt-hours. At Sandia National Laboratories, different algorithms have been tested for evaluation in a controlled simulation environment. These are discrete wind speed; moving wind speed; moving power; and discrete, double-power. These four algorithms have two adjustable parameters for optimum operation: cut-in/cut-off threshold (of wind speed) and test window (for averaging). As they stand, no real safeguards for robustness are built in to the algorithms, particularly in response to severe wind gusts. This is so because the system is set to respond to averaged time information of wind speed profiles, in which high-frequency information is suppressed; certainly this is true for the fast wind gust characteristic times. Thus, although statistical predictive capability exists, application of a modern control design can further help anticipate or, at a minimum, initiate a fast system response on an individual system basis so as to alleviate a severe wind profile that may be building up. Thus, alleviating wind-loading effects under nominal operation can be more systematically addressed in real time for each specific wind turbine.

\section{ROLE OF CONTROL TECENOLOCY IN THE WIND POWER INDUSTRY}

A systematic control approach to the overall system operation can favorably impact the economics of wind power systems while assuring safe operation with a minimal number of system failures. Within the wind industry, there is no general consensus as to whether active versus passive control is preferable. Both are employed at various levels of sophistication; however, the committee is not aware of any systematic study that has quantified the benefits of either.

All avillable advances in structural tailoring, advanced airfoil design, and advanced machine configurations need to be apsiled for passive load alleviation. Simultaneously, active control techniques should be employed to assess the performance capabilities of an existing structure while also establishing achievable limits and indicating modifications necessary to realize further benefits. Thus, a parallel development of both strategies 18 advisable in the design stage, with a number of iterations before a final overall system design is arrived at. Such a process will reduce the 
performance requirements for control and have, as a by-product, a system operational fault tolerance resulting from simpler control functions and implementation; moreover, it will be cost-effective in the long run.

Consequently, active and passive control strategies are not mutually exclusive, but, when both are synergistically employed, they are capable of enhancing the overall system capabilities by alleviating the requirements on either or both component strategies. Thus, actuator loads 1.2 an active setting could be greatly alleviated if operating in a posively tailored structure. Suffice it to say that neither approach alone is capable of delivering performance equivalent to that obtainable by the synergy of both.

A passive approach, on the one hand, is effects $u$ through a judicious hardware/material design and thus may not be adaptable to changing requirements or dramatically changing operating conditions; "passive tailoring" of the system cannot be done on-line, if the tinresholds of a passive design have been exceeded. Moreover, passively designed structures are not easily modifiable to changing requirements/forcing functions with any reliable guarantees for consistent performance. Furthermore, the design margins of a passive control structure in response to dynamic exogenous inputs can be severely limited in comparison with an active control computerimplemented strategy that is easily modifiable as needed. On the other hand, an active controller may be considerably limited by state-of-the-art actuator/sensor bandwidths, which may constitute an "unbreakable barrier" to system performance. Certainly, weight, cost, and compatibility with an existing system also factor in but to a more manageable extent (i.e., provided the system setup/architecture is modifiable for tolerance of such factors) once satisfactory performance can be assured by the components in question. Ultimately, this is an area where trade-offs have to be sysiematically worked out and weighed.

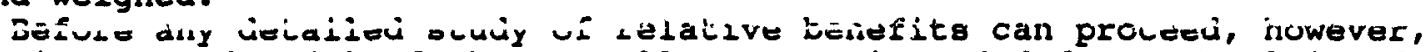
developing a good model of the overall process intended for control is of utmost importance. This seems to be the crux of a successful engineering endeavor, particularly in the wind turbine environment, which involves interaction of fluids (possibly unsteady aerodynamics) with electromechanical structures. For the purposes of alleviating wind gust effects and/or undesirable vibrations due to the interaction of the blade and unsteady aerodynamics (turbulence increases with deeper location in the wind farm), mass flow or pressure sensors need to be placed at judiciously chosen locations (perhaps even in the blade), in order to measure (precursors to) turbulent upcoming events (i.e., wind gusts). Such sensor bandwidth should be extremely high given the nature of the latter. The sensor signal can be used to generate an appropriate actuator command, via a microprocessor-implemented control algorithm. Actuation can be effected through incorporation of aileron-like surfaces on the main blade structure. Thus, fast response can be achieved locally, with very limited control actions, which will be effective in modifying the boundary layer of the unsteady fluid process, thus alleviating excessive loading on the blade. On a more global actuation scale, control of variable-speed machines through their power electronics effected via the rotor does appear to have the potential of tailoring the blade structure to operating in close to optimal configuration in adverse wind profiles.

Based on experience with higher harmonic control (HHC) for helicopter vibrations (Goldenthal et al., 1987) and, more recently, on active control of rotating stall and surge in compressors (Paduano et al., 1990), such models of the fluid processes are readily obtainable. Sensor data of mass flow perturbations (velocity, pressure) can be used while the perturbations are small (i.e., the nonlinear [unsteady] process is still at its inception and it evolves in a close to linear fashicin tor a short period of time). Control designs based on models thusly obtained have proven successful fo: ure and for active surge and rotating stall control. Experience gained there can be brought to bear in the wind turbine environment, given the basic similarities of the processes involved.

In fact, the dynamic models obtained for the fluid processes in the areas mentioned above are as simple as low-order, linear, time-invariant (even scalar) systems that admit to the simplest control algorithm synthesis: fixed 
parameter compensation that can be derived via the simplest theory, even classical approaches. Certainly, an ingeniously designed lead/lag network will work effectively, whether derived via classical considerations or, more formally, via a modern methodology such as the linear quadratic Gaussian with loop Transfer recovery.

Computational and implementation/hardware requirements are within existing state-of-the-art capabilities, and, as already stated, no new control theorv is necessary for a successful outcome. The emphasis here 18 primarily in a good modeling effort. However, the literature is severely lacking 1. cimplate methodologies for syatematic modeling of the effect on the machine $c f$ unch tilid procesese. Given its importance, this is an area that needs to he mathematically formulated and formalized.

The foregoing suggestions are immediately implementable as a technology transfer from other related industries (Paduano et al., 1990; Goldenthal et al., 1987). To be precise, the proof of concept in a realistic engine (laboratory) setting was so recent that industrial production can only be in the very near future and is certainly not in existence at the present time. However, implementation details in an industrial setting need to be worked out specifically within the particular application industry at hand.

Further down the line, for future development, smart materials (e.g., piezoelectric sensors and actuators embedded in them) may result in similar performance/operation improvements for wind turbines (Spangler and Hall, 1990). In such a case, an essential continuum (or distributed network) of sensors and actuators results in appropriate blade twisting so as to alleviate the effect of the aforementioned undesirable wind disturbances. This technology is under development, actively being researched at this time in large snace structures groups and materials science laboratories. Preliminary results are encouraging (deluis et al., 1989), although the problem of forcing aith i jistributed structure into a desirable coordinated confi auxatinn iia local sensor feedback entails complexities and performance robustness ris':s. This is an area that requires further investigation. One should also note that the existing preliminary results in large space structures rely on the overall passivity of a flexible structure. However, the wind turbine environment is considerably more severe.

In conclusion, a systematic application of readily available control technology can offer substantial advantages in enabling the wind power industry to realize its long-term objectives and become a competitive energy alternative. More specifically, the following are recommended control technology areas for research and development in the immediate (near) term:

1. Continue investigating viable models for the fluid structure interaction, together with signal-processing algorithms for valid signal extraction.

2. Develop other active control techniques and incorporate the beat response means (e.g., aileron surfaces and boundary layer control).

3. Design control algorithms for wind loading/gust alleviation.

4. Develop models and algorithms for control of variable-speed machines to optimize energy production versus fatigue life. 


\section{REFEREYCES AND BIBLIOGRAPEY}

Bernstein, D. S. and W. M. Haddad. 1989. LQG Control with an Hoo Performance Bound. IEEE Trans A-C, Vol. 34, No. 3, February, pp. 293-305.

Dahleh, M. A. and J. B. Pearsc. 1987. 1 $1^{1}$ Optimal Feedback Controllers for MIMO Discrete-Time Systems. IEEE Trans A-C, Vol. AC-32, April.

Dahleh, M. A., P. Voulgarie, and L. Valavani. 1990. Optlmal Rejection of Bounded Persistent Disticibances in Periodic systems. Proceedings of the Decision and Control Conference, Honolulu, Hawail, December.

deluis, J., E. F. Crawley, end S. R. Hall. 1989. Design and Implementation of Optimal Controllers for Intelligent Structures Using Infinite order Structural Models. SSL \$3-89, MIT Space Systems Laboratory, Cambridge, Massachusetts, January.

Doyle, J. C. 1985. Structured Uncertainty in Control Design. Proceedings of the 24th Conference on Decision and Control, Ft. Lauderdale, Florida, December, pp. 260-265.

Doyle, J. C., K. Glover, P. Khargonekar P., and B. Francis. 1988. State Space Solutions to Standard $\mathrm{H}_{2}$ and Hoo Control Problems. Proceedings of American Control Conference, Atlanta, Georgia, June, pp. 1691-1896.

Doyle, J. C., K. Zhou, B. Bodenheimer. 1989. Optimal Control with Mixed $\mathrm{H}_{2}$ and Hoo Performance Objectives. Proceedings of the American Control

Conterence, Pittoburgh, Penngylvania, June, pp. 2065-2070.

Goldenthal, W., V. Valavani, P. Motyka, S. R. Hall, and B. Eberman. 1987. Development and Evaluation of a Dynamic Model Active Vibration Control Concept. C.S. Draper Laboratory Technical Report, March.

LaMaire, R. O., V. Valavani, M. Athans, and G. Stein. 1991. Robust Time and Frequency Domain Estimation Methods in Adaptive Control. Automatica, January, pp. 23-39.

McNerney, G. M. 1981. Vertical Axis Wind Turbine Control strategy. SAND81-1156, SANDIA National Laboratories Report, August.

Meyer, D. G. 1988. Shift-Invariant Equivalents for a New Class of Shift-Varying Operators with Applications to Multi-Rate Digital Control. Proceedings of the 27th Conference on Decision and Control, Austin, Texas, December, pp. 1697-1701.

Middleton, R., G. C. Goodwin, and D. Mayne. 1988. Adaptive Robust Control. IEEE Transaction on Automatic Control, Vol. AC-33.

Paduano, J., L. Valavani, A. H. Epstein, E. M. Greitzer, and J. Guennette. 1990. Modeling for Control of Rotating Stall. Invited Paper, IEEE Conference on Decision and Control, December. Submitted to Automatica.

Ralph, M. E. 1989. Control of the Variable speed Generator on the SANDIA 34-Metre Vertical Axis Wind Turbine. Presented at Windpower 189, San Francisco, California, September.

Rohrs, C. E., L. Valavani, M. Athang and G. Stein. 1985. Robustness of Adaptive Control Algorithms in the Presence of Unmodeled Dynamics. IEEE Transaction on Automatic Control, Vol. AC-30, No. 9, September, pp. 881-889.

Spangler R. L. and S. R. Hall. 1990. Piezoelectric Actuators for Helicopter Rotor Control. 31st Structures, Structural Dynamics and Materials Conference, Long Beach, California, April 2-4. 
Stein, G. 1985. Beyond Singular Values and Loop Shapes. Proceedings of the American Control Conference, Boston, Massachusetts, June.

Stein G., and M. Athans. 1987. The LQG/LTR Procedure for Multivariable Feedback Control Design. IEEE Transaction on Automatic Control, Vol. AC-32, No. 2, February, pp. 105-114.

Vachon, W. A. 1987. The Effects of Control A:yorithms on Fatigue Life and Energy Production of Vertical Axis Wind Turbirss. Vachon Associates Report. 


\section{7 \\ CONCLUSIONS AND RECOMMENDATIONS}

\section{CONCLUSIONS}

wind turbine technology has demonstrated the potential for contributing to the energy needs of the United States. If the sites with acceptable wind characteristics were fully utilized, they could contribute up to about 10 percent of the nation's electrical energy needs. The limitation is based on utility system stability issues rather than available site locations. As in all energy investment decisions, the ultimate penetration level will be driven by the cost of energy that is produced. In turn, this is decided by the initial cost of the wind energy plant and the annual cost for maintenance and operation.

Since a number of U.S. electric power utilities are continuing to add capacity, there will be an opportunity to introduce a new, longer-lasting design for a wind turbine system. Moreover, renewed interest by the public in environmental issues associated with power generation gives a special alvantage to wind power. A new wind turbine gyotem probably will take suantage of advances in semiconductor power electronina to improva distiy production as well as provide reactive power control, which will make windgenerated electric power more amenable for use by the electric utilities. New speed control schemes will be introduced, but the major advance must come through the design of less expensive, longer-lived, and higher-efficiency rotors. A guiding principle in creating this design should be that knowledge of aerodynamic forces must be carefully integrated with the structural response of the material, all balanced by the practicalities of field experience and tempered by the need to manufacture a consistently high quality product at reasonable cost.

This committee has examined the experience base accumulated by wind turbines, and the accompanying R\&D programs sponsored by the Department of Energy and has concluded that a wind energy system such as described above is within the capability of engineering practice. However, certain gaps in knowledge exist. The achievement of this goal without costly and inefficient trial and error requires certain critical research and development. Because of the fragile nature of the wind power equipment producers in the United States, this will require an R\&D invegtment by the Department of Energy. The committee cannot conclude without commenting on the status of the wind power equipment industry. Because of the decrease in the number of machines installed in the past 5 years, since the tax incentives expired, there currently is only one major integrated manufacturer in the United states. In addition, only a few companies are actively producing blades. Moreover, in recent years, a major Japanese manufacturer has entered the world market to join the European manufacturers who have been participants for some time. As a result, the U.S. industry is not in a financial position to engage in the R\&D necessary to gain worldwide technological leadership for what the committee sees as a future growing worldwide market for wind power. The committee believes that the United States is facing a future major reduction in fossil fuel sources of energy. When this is coupled with a resurgence of public concern for environmental issues in energy production, the need to develop wind power energy to the fullest extent possible seems compelling. 
In the recommendations below, specific research tagks are listed that need to be carried out. Within each category of research--materials, manufacturing, structural response, etc.--these research tasks are listed in approximate order of priority. However, we wishes to emphasize that the overall goal of an RED program should be to develop a system to produce longer-lived, less expensive, and more efficient wind turbine rotors. Increased knowledge of the fatigue properties and fatigue failure mechanisms of blades should take precedence, but this cannot be separated from the search for better manuiaturing procesese or from design innovations that will either minimize the likeithood of failure or ease the aerodynamic constraints of blade shape that irapedu process innovation. The committee wish to emphasize that the four factors of fatigue, manufacturing, advanced materials, and design are closely interrelated in the quest to produce a more cost-effective blade.

\section{RESEARCA RECONGMDATIONS}

Recommendations are classified with respect to four goals. More detailed recommendations will be found at the ends of Chapters $2,3,4$, 5, and 6 .

Goal 1: To improve the material properties and design
capability so that the structure will withstand
higher stresses, or the same level of stress for a
much longer period of time.

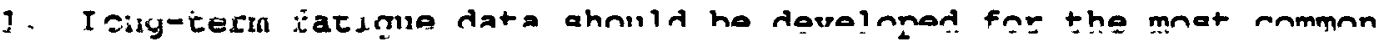
glass-reinforcej plastics (GRP) laminates and critical elements under appropriate environmental conditions. The data should be carried to $10^{\circ}$ to $10^{5}$ cycles if possible, at strese ratios of $R=0.1$ (tension and compression) and $R=-1$ (fully reversed). An extensive search of all fatigue data on GRP composites should be conducted and published in a source convenient to blade designers. This should evolve into a databank of wind turbine blade materials.

2. The extensive compendium of mechanical data, including fatigue data, on wood/epoxy laminates should be published and made available to domestic blade designers. Very high cycle $\left(10^{8}\right.$ to $\left.10^{9}\right)$ fatigue tests should be conducted on this material to compare its fatigue response with that of GRP materials.

3. The potential benefits for significant weight reduction in blades (about 50 to 70 percent) while maintaining required stiffness through the use of hybrid composites (in which carbon or aramid fibers are placed in critical blade locations) should be explored through design studies and limited blade testing. Critical use of cost models must be a requirement in this work because of the strong industry reluctance to utilize materials that are more expensive than E-glass/vinyl ester or wood/epoxy.

Goal 2: To lower the operating stress levels by altering the structural/configuration design.

1. Simple cross-sectional analyses and computer codes need to be developed for determination of sectional elastic constants in composite blades with elastic couplings. These design tools should consider blade parameters such as curvature, twist, taper, and, above all, completely general iiaterial/geometry.

2. An aeroelastic design cnie shoula oe developed for wind turbine blades. This would permit the investigation of aeroelastic tailoring as a passive control mechanism.

3. An invertigation of new active control techniques for wind turbine blades should be initiated. This should be aimed at a new generation design in which gust loads are essentially reduced, thereby minimizing over-design of blades. 
1. The resin transfer molding process has demonstrated the capability of producing quality fan blades up to 40 feet in diameter. Prototype studies to make GRP blades by this process should be undertaken. The study must include trade-off studies of manufacturing cost and quality versus losses in aerodynamic efficiency to enhance producibility.

2. The pultrusion process has a demonetrated capability to produce lowcost GRP blades but with a relatively inefficient constant cross section. Aeroelastic tailoring may partially cumpensate for the lack of twist and tapered planform compared to usual wind tu:-bine blade geometries. A feasibility study should be conducted.

3. The introduction of new manufacturing processes must be accompanied by fatigue testing of full-size blades. Only in this way can the design details and the material quality be validated for the manufacturing process. Baseline studies on blades produced by current practice are needed.

Goal 4: ro reduce the cost of blades enough so that periodic replacement becomes cost-effective.

1. Because fatigue crack propagation is slow in GRP composites, and is believed to be readily visible on annual tower-top inspections, the atrategy described by goal 4 may be feasible. This would eliminate the need for extensive and expensive high-cycle fatigue testing. Eliminating the uncertainties in accounting for long-life service in design calculations would result in considerable weight savings. A detailed feasibility study with a realistic cost model should be undertaken if the manufacturing studies show promise of significant reduction in blade life-cycle cost. 


\title{
APPENDIX A STATEMENT OF TASK
}

\author{
OBJECIIVES
}

The final technical report shall provide state-of-the-art information via a current survey of wind turbine materials, fabrication, operation, and life performance. Research areas shall be identified and given priority. Also, through an evaluation of research related to strese/deformation response, direction shall be given to Department of Energy (DOE) for the development of models that will aid in the understanding of the stress problem. By considering research related to failure of joints, fasteners, and critical sections, applied research in material sciences shall be brought to the attention of the DOE program manager.

\section{TASKS TO BE PERFORUDD}

The committee will asgess:

a. The adequacy of existing models to predict dynamic stress patterns.

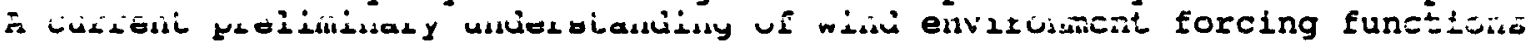
shall be obtained from DOE.

b. The understanding of the structural stress/deformation response of various wind turbine materials subject to representative forcing functions, with particular reference to dynamic and fatigue failure.

c. The understanding of the performance of joints, fasteners, and critical sections in relation to failure modes and fractures and how they originate and propagate.

d. The effects of environmental degradation, including such factors as wear and erosion, corrosion, and ultraviolet degradation over time in wind turbine materials.

e. The research tools needed to study these phenomena, such as sensors, computer hardware, software, and databases.

f. The opportunities for new materials and coatings to improve wind turbine life performance.

g. The need for special laboratory facilities, models, and prototypes to improve the design and operation of wind energy systems.

h. The prospects for improving the ability to predict wind turbine life and improved economics as a function of material choice, design fabrication, and life-cycle maintenance factors.

\section{ASSESSMENT OUYCOME}

This work will influence and improve DOE's plan for wind energy research described in the latest version of "Federal Wind Energy Program: Five-Year Research Plan." Policymakers will be provided with an improved understanding of the role of wind technology research in relation to national policies on energy science and technology. 


\title{
APPENDIX B COMMITTEE MEETINGS AND ACTIVITIES
}

\author{
1. Firet Committee Meeting, November 7-8, 1989, Washington D.C. \\ The following presentations were made to the committee: \\ Overview of DOE Wind Energy Technology Program \\ Leonard J. Rogers, Director, Wind/Ocean Technologies Division, \\ U.S. Department of Energy \\ Expectations of the study \\ Jeffrey H. Rumbaugh, Rrogram Manager, wind/Ocean Technologies \\ Division, U.S. Department of Energy \\ Field Problems with Wind Turbine Rotorg \\ Forrest $s$. Stoddard, Alternative Energy Institute, West Texas \\ strece University \\ Load Cyrclew \\ Robert Thresher, Program Manager, Solar Energy Regearch \\ Institute (SERI) \\ Fatigue Problems \\ Herbert Sutherland, Distinguished Member of the scientific staff, \\ Sandia National Laboratories \\ Wind Turbine Blade Material Experiences \\ Daniel F. Ancona III, Program Manager, Wind/Ocean Technologies \\ Division, U.S. Department of Energy \\ Evolution and Operational Experience of the Wind Industry \\ Jamie Chapman, Committee Member \\ After-Dinner Speakers: \\ Richard H. Hilt, Strategic Planning and Analysis Division \\ Gas Research Institute \\ Edwin T. C. Ing, Past President of the American Wind Energy \\ Association \\ 2. Workshop and Second Committee Meeting, January 22-23, 1990,
} Washington D.C. 


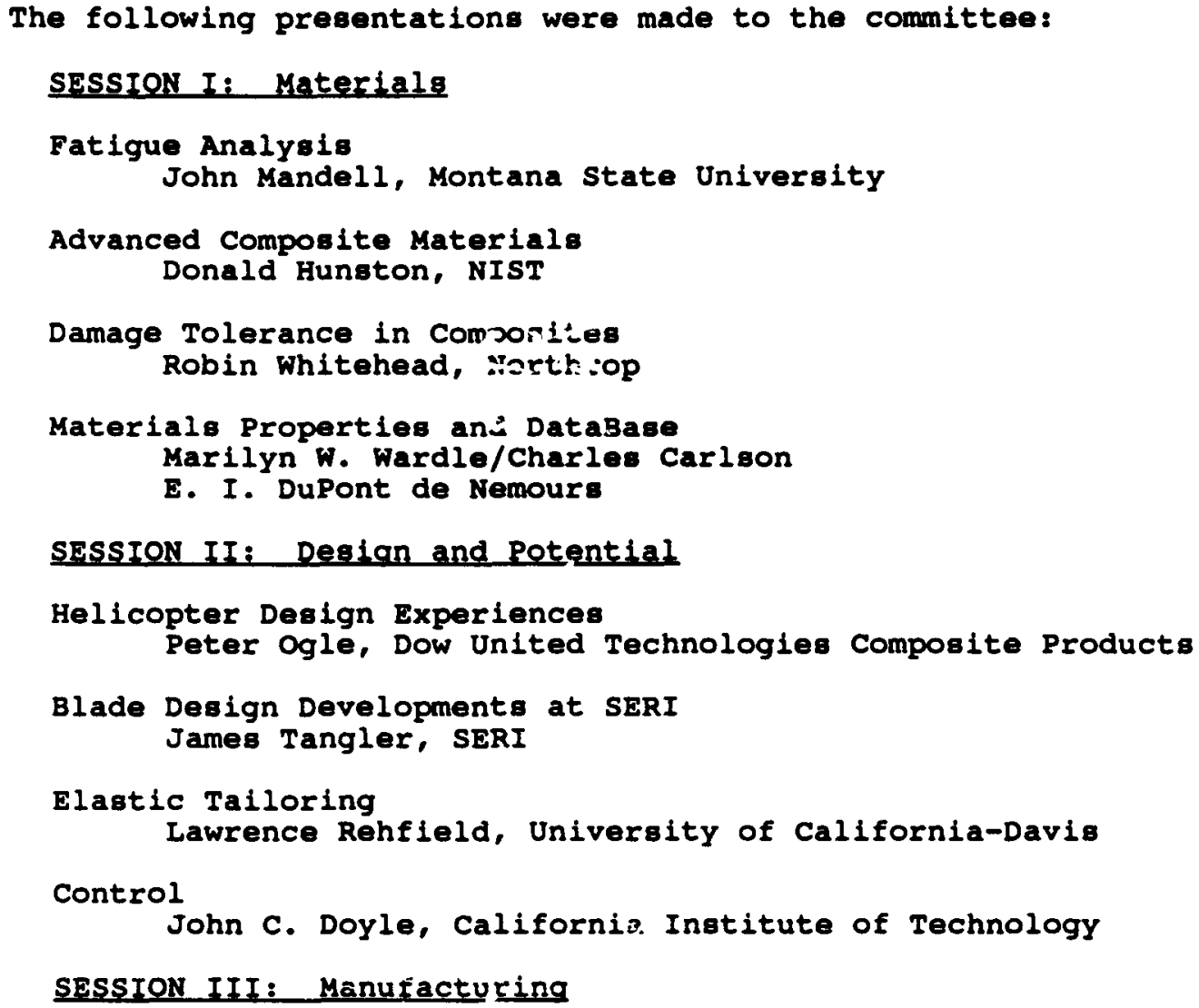

3. Third and Final Committee Meeting, June 1-2, 1990, Washington D.C. 


\section{Executive Summary}

The commiticee's charge was to define a research and development agenda for the Department of Energy' wind energy program focusing on materials aspects of the wind turbine rotor technology. In particular, the comnittee interpreted its mandate to include an assessment of the potential for new design methods, better manufacturing processes, and advanced control methods in addition to advanced materials for improvement in turblne rotor performance and lifetime.

In addition, the committee took as its responsibility the development, in broad outline, of a research and development program that would place U.S. technology in rotors for wind power in a preeminent world position.

In carrying out its charge the committee examined an extensive literature on wind machines and wind turbine rotor materials and was briefed by many experts on these subjects, both in the wind industry and in related industries.

Wind-driven power systems represent a renewable energy technology that is still in the early stages of development. Arrays of interconnected wind turbines convert the power carried by the wind into electricity for users of the utility power grid. Major concentrations of this technology exist in Caiformia, Denmark, and hawail. At the end of 1989 , the wind power plants in California comprised a power-generating capacity of $1335 \mathrm{MW}$, equivalent to a medium-sized utility power plant. Not only do these wind power plants produce no gaseous emiseions, particulates, or radioactive by-producte, but they can be installed rather quickly as modular units, each providing capacity from a few tens of kilowatts to hundreds of megawatts. They can be readily integrated into existing utility generation-transmission-distribution systems. While economic utilization of wind energy depends critically on location and siting, many available sites exist in the United states. While land intensive, wind power plants can coexist with other uses of the land on which they are situated.

Wind power plants installed in the early 1980 s suffered structural failures chiefly because of incomplete understanding of the wind forces (especially the turbulence component) acting on these large structures and in some cases because of poor quality in manufacture. Failure of the rotor blades was one of the principal and most serious gtructural failures. Failures from these causes are now somewhat better understood. An associated additional limitation to achievement of the full economic potential of wind energy is uncertainty about the long-term response of wind turbine rotor materials to the turbulent stochastic loadings to which they are subjected. over their profected operational lifetimes (typically 20 to 30 years), these structures are subjected to as many as a biliion stress cycles.

Since a number of U.S. electric power utilities are continuing to add capacity, there will be an opportunity to introduce new, longer-lasting designs. Moreover, renewed public interest in environmental issues associated with power generation gives a renewed impetus to wind power. A new wind turbine syatem will probably take advantage of advances in semiconductor power electronice to produce changes in the syetem configuration that will make wind-generated electric power more amenable for use by eiectric utilities. New speed control schemes will be introduced, but a major advance must come 
through the design of less expensive, longer-lived, and higher-efficiency rotor blades. A guiding principle in creating this design ahould be that knowledge of aerodynamic forces muet be carefuliy integrated with the structural response of the material, all balanced by the practlcalities of field experience and tempered by the need to manufacture a consistently highquality product at reasonable cost.

This committee has examined the experience base accumulated by wind turbines, and the accompanying RED programs sponsored by the Department of Energy. We have concluded that a wind energy syetem such as described above is within the capability of engineering practice. But certain gape in knowledge exist, so achieving the goal without coetly and inefficient trial and error requires certain critical research and development. Because of the fraglie nature of the wind power equipwent producers in the United states this will require an RED investment from the Department of Energy.

The committe cannot conclude without commenting on the status of the wind power equipment industry. Because of the decrease in the rate of ingtaliation of machines in the last 5 years (since the tax incentives expired), there currently ia only one major integrated manufacturer in the United states; only a few companies are actively producing blades. In recent years a major Japanese manufacturer has entered the world market, joining the European manufacturers who have been participants for some time. As a result, the U.S. industry is not in a financial position to engage in the RED necessary to gain worldwide technological leadership for what the committee sees as a future growing worldwide market for wind power. The committee believes that the United states is facing a future reduction in most fossil fuel sources of energy. When this is coupled with a resurgence of public concern over environmental iseues in energy production, the need to develop wind power energy to the fullest extent posilble seems compeliing.

\section{RGSERRCE RECOMGADATIOAS}

The comittee has identified four goals to gulde the research needs in wind turbine rotor technology:

Goal 1: To improve the material properties and design capability so that the structure will either withstand higher stresses or the same level of stress for a much longer period of time.

Goal 2: To lower the operating stress levels by altering the structural/configuration design. minimized.

Goal 3: To improve the blade manufacturing process so that quality variations and cost are

Goal 4: To reduce the cost of blades enough so that periodic replacement becomes cost-effective.

The details of epecific research recommendations are given in Chapter 7 (Conclusions and Recommendations) and, in greater depth, at the ends of Chapters $2,3,4,5$, and 6 . The main research tasks are aumarized below.

\section{MATERIAIS}

Initiate a program to generate long-term (10-year-equivalent), highcycle fatigue $\left(10^{8}-10^{5}\right)$ data for candidate structural materials: glassreinforced plastic, wood/epoxy, and advanced high-modulus composite materials under appropriate environmental conditions. The program would contribute an element in a needed databank for wind turbine blade materials.

\section{DESIOA}

The wind turbine industry needs design tools that are beyond the capability for development by the private gector. For example, it is necessary to be able to compute laminate stresses in three dimensions and to 


\section{Executive Summary}

The committee's charge was to define a reeearch and development agenda for the Department of Energy's wind energy program focuaing on materials aspects of the wind turbine rotor technology. In particular, the committee interpreted its mandate to include an aseessment of the potential for new design methods, better manufacturing procesese, and advanced control methods in addition to advanced materials for improvement in turbine rotor performance and lifetime.

In addition, the committee took as its responsibility the development, in broad outline, of a research and development program that would place U.S. technology in rotors for wind power in a preeminent world position.

In carrying out its charge the committee examined an extensive

literature on wind machines and wind turbine rotor materials and was briefed by many experts on these aubjects, both in the wind industry and in related industries.

Wind-driven power systems represent a renewable energy technology that is atill in the early atages of development. Arrays of interconnected wind turbines convert the power carried by the wind into electricity for users of the utility power grid. Major concentrations of this technology exist in Caifiornia, Denmark, and hawail. At the end of 1989 , the wind power plants in California comprised a power-generating capacity of $1335 \mathrm{MH}$, equivalent to a medium-rized utility power plant. Not only do these wind power plants produce no gaseous emissions, particulates, or radioactive by-products, but they can be installed rather quickly as modular units, each providing capacity from a few tens of kilowatta to hundreds of megawatts. They can be readily integrated into existing utility generation-transmission-distribution systems. While economic utilization of wind energy depends critically on location and siting, many available gites exist in the United states. While land intensive, wind power planta can coexist with other uses of the land on which they are situated.

Wind power plants installed in the early $1980 \mathrm{~s}$ suffered structural failures chiefly because of incomplete understanding of the wind forces (especially the turbulence component) acting on these large structures and in some cases because of poor quality in manufacture. Failure of the rotor blades was one of the principal and most serious structural failures. Failures from these causes are now somewhat better understood. An associated additional limitation to achievement of the full economic potential of wind energy is uncertainty about the long-term response of wind turbine rotor materials to the turbulent stochastic loadings to which they are subjected. Over their projected operational lifetimes (typically 20 to 30 years), these structures are subjected to as many as a biliion stress cycles.

since a number of U.S. electric power utilities are continuing to add capacity, there will be an opportunity to introduce new, longer-lasting designs. Moreover, renewed public interest in environmental issues associated with power generation gives a renewed impetus to wind power. A new wind turbine system will probably take advantage of advances in semiconductor power electronics to produce changes in the system configuration that will make wind-generated electric power more amenable for use by eiectric utilities. New epeed control schemes w11l be introduced, but a major advance must come 
through the design of less expensive, longer-lived, and higher-efficiency rotor blades. A guiding principle in creating this design should be that knowledge of aerodynamic forces must be carefully integrated with the structural response of the material, all balanced by the practicalities of field experience and tempered by the need to manufacture a consistently highquallty product at reasonable cost.

This committee has examined the experisnce base accumulated by wind turbines, and the accompanying RED programs sponsored by the Department of Energy. We have concluded that a wind energy system such as described above is within the capability of engineering practice. But certain gaps in knowledge exist, 80 achieving the goal without costly and inefficient trial and error requires certain critical research and development. Because of the fragile nature of the wind power equipment producers in the United States this will require an RED investment from the Department of Energy.

The committee cannot conclude without commenting on the status of the wind power equipment industry. Because of the decrease in the rate of installation of machines in the last 5 yeare (eince the tax incentives expired), there currently is only one major integrated manufacturer in the United States; only a few companies are actively producing blades. In recent years a major Japanese manufacturer has entered the world market, joining the European manufacturers who have been participants for some time. As a result, the U.S. Industry is not in a financial position to engage in the ReD necessary to gain worldwide technological leadership for what the committee sees as a future growing worldwide market for wind power. The committee belleves that the United States is facing a future reduction in most fossil fuel sources of energy. When this is coupled with a resurgence of public concern over environmental iseues in energy production, the need to develop wind power energy to the fullest extent possible seems compeling.

\section{RESEARCA RECONGADATIONS}

The committee has identified four goals to guide the research needs in wind turbine rotor technology:

Goal 1: To improve the material properties and design capability so that the structure will either withstand higher stresses or the same level of stress for a much longer period of time.

Goal 2: To lower the operating stress levels by altering the structural/configuration design.

Goal 3: To improve the blade manufacturing process so that quality variations and cost are minimized.

Goal 4: To reduce the cost of blades enough so that periodic replacement becomes cost-effective.

The details of epecific research recommendations are given in Chapter 7 (Conclusions and Recommendations) and, in greater depth, at the ends of Chapters 2, 3, 4, 5, and 6. The main research tasks are aummarized below.

\section{MATERIALS}

Initiate a proqram to generate long-term (10-year-equivalent), highcycle fatigue $\left(10^{8}-10^{\circ}\right)$ data for candidate structural materials: glassreinforced plastic, wood/epoxy, and advanced high-modulus composite materials under appropriate environmental conditions. The program would contribute an element in a needed databank for wind turbine blade materials.

\section{DEsIGX}

The wind turbine industry needs design tools that are beyond the capability for development by the private sector. For example, it is necessary to be able to compute laminate stresses in three dimensions and to 